\title{
Supramolecular Architectures in Some 4-Halophenylboronic Acids
}

\author{
Nanappan SeethaLekshmi and Venkateswara Rao Pedireddi* \\ Solid State \& Supramolecular Structural Chemistry Unit, Division of Organic Chemistry, \\ National Chemical Laboratory, Dr. Homi Bhabha Road, Pune 411 008, India. \\ Email: vr.pedireddi@ncl.res.in
}

\section{Supporting information:}

Refcodes obtained from CSD Search for boronic acids done using CSD version 5.28 update (January 2007) are arranged in a year wise manner to show the recent interest in these compounds since the first structure is known in 1958. 


\begin{tabular}{|c|c|c|c|c|c|c|}
\hline Refcode & Year & Refcode & Year & Refcode & Year & \\
\hline BPHBAC & 1958 & AQUYAM & 2003 & FECSEM & 2005 & \\
\hline BZTALR & 1970 & BAJTEM02 & 2003 & FEJGIL & 2005 & \\
\hline PHBORA & 1977 & BATDEG & 2003 & FEJGOR & 2005 & \\
\hline KAJPIU & 1989 & BATDOQ & 2003 & FEJGUX & 2005 & \\
\hline VEXFUZ & 1990 & BATDUW & 2003 & FEJHAE & 2005 & \\
\hline VEXFUZ01 & 1990 & BATFEI & 2003 & FEJHEI & 2005 & \\
\hline LABCUM & 1993 & BATFEI01 & 2003 & FETDAK & 2005 & \\
\hline YICHIB & 1994 & BATFUY & 2003 & FETDEO & 2005 & \\
\hline YICHOH & 1994 & BAVJIS & 2003 & FETDIS & 2005 & \\
\hline YIWKOE & 1994 & HUYRAU & 2003 & FETZUA & 2005 & \\
\hline PAYYAP & 1995 & IKIFAJ & 2003 & CAQZAW & 2005 & \\
\hline ZAPDAV & 1995 & OLIDOC & 2003 & TASCEW & 2005 & \\
\hline ZIGPAG & 1995 & QADKIQ & 2003 & WAPDIB & 2005 & \\
\hline ZILBEB & 1995 & UMUHOZ & 2003 & XARNAG & 2005 & \\
\hline TUNGAK & 1996 & WADQIC & 2003 & DECROT & 2005 & \\
\hline NITFOL & 1997 & XUVBAR & 2003 & XECHOD & 2005 & \\
\hline ROGMEF & 1997 & XUVBEV & 2003 & XECHUJ & 2005 & \\
\hline RONLIP & 1997 & XUVBIZ & 2003 & BEWYAE01 & 2006 & \\
\hline CEZHUK & 1999 & ACEPAA & 2004 & GENTOJ & 2006 & \\
\hline ZIGPAG01 & 1999 & ASUDOH & 2004 & KECJIM & 2006 & \\
\hline ZIGPAG02 & 1999 & AVOTIO & 2004 & KECJOS & 2006 & \\
\hline DOBKUA & 2000 & BEWYAE & 2004 & KEGNAM & 2006 & \\
\hline AFOLUC & 2001 & ETOLAA & 2004 & KEGNEQ & 2006 & \\
\hline QIXTIA & 2001 & FAKTER & 2004 & KEGNIU & 2006 & \\
\hline QIXVAU & 2001 & ITEPUS & 2004 & LEFXUQ & 2006 & \\
\hline QIXVAU01 & 2001 & ITEQAZ & 2004 & LEFYAX & 2006 & \\
\hline VEXFUZ02 & 2001 & ITIQIL & 2004 & LEFYEB & 2006 & \\
\hline BAJTEM & 2002 & ITIQOR & 2004 & LEFYIF & 2006 & \\
\hline BAJTEM01 & 2002 & ITIQUX & 2004 & PEPNUU & 2006 & \\
\hline \multirow[t]{15}{*}{ BAJTIQ } & 2002 & ITIRAE & 2004 & PEQLED & 2006 & \\
\hline & & IYAXAH & 2004 & PEQLIH & 2006 & \\
\hline & & OCAJUY & 2004 & PEQLON & 2006 & \\
\hline & & WAJXEL & 2004 & PEQLUT & 2006 & \\
\hline & & PAXSUD & 2004 & PEQMAA & 2006 & \\
\hline & & PAXTAK & 2004 & PEQMEE & 2006 & \\
\hline & & PAXTEO & 2004 & PEQMII & 2006 & \\
\hline & & PAXTIS & 2004 & PESVAL & 2006 & \\
\hline & & & & WENZUL & 2006 & \\
\hline & & & & REHDOY & 2006 & \\
\hline & & & & UCETUS & 2006 & \\
\hline & & & & VEFCIT & 2006 & \\
\hline & & & & VEFCOZ & 2006 & \\
\hline & & & & VEFCUF & 2006 & \\
\hline & & & & WEJCIY & 2006 & \\
\hline
\end{tabular}


Tabulation of Refcodes based on the conformations observed in the boronic acids

\begin{tabular}{|c|c|c|c|c|c|}
\hline 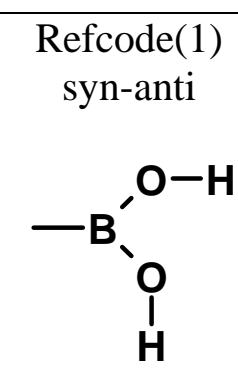 & Year & $\begin{array}{l}\text { Refcode(2) } \\
\text { syn-syn } \\
\text { - B }\end{array}$ & Year & 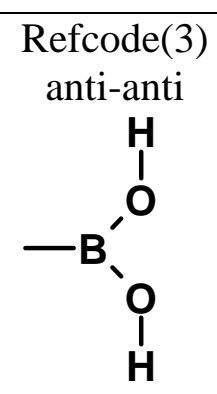 & Year \\
\hline PHBORA & 1977 & YIWKOE & 1994 & VEXFUZ01 & 1990 \\
\hline LABCUM & 1993 & BATFUY & 2003 & & \\
\hline PAYYAP & 1995 & ITEQAZ & 2004 & & \\
\hline ZAPDAV & 1995 & ITIQIL & 2004 & & \\
\hline ZILBEB & 1995 & ITIQOR & 2004 & & \\
\hline TUNGAK & 1996 & PAXTAK & 2004 & & \\
\hline NITFOL & 1997 & FEJGOR & 2005 & & \\
\hline RONLIP & 1997 & FEJHAE & 2005 & & \\
\hline CEZHUK & 1999 & FETDAK & 2005 & & \\
\hline ZIGPAG01 & 1999 & FETDEO & 2005 & & \\
\hline ZIGPAG02 & 1999 & FETDIS & 2005 & & \\
\hline DOBKUA & 2000 & FETZUA & 2005 & & \\
\hline QIXTIA & 2001 & CAQZAW & 2005 & & \\
\hline QIXVAU & 2001 & GENTOJ & 2006 & & \\
\hline QIXVAU01 & 2001 & KECJIM & 2006 & & \\
\hline VEXFUZ02 & 2001 & KECJOS & 2006 & & \\
\hline BAJTEM & 2002 & LEFXUQ & 2006 & & \\
\hline BAJTEM01 & 2002 & LEFYAX & 2006 & & \\
\hline BAJTIQ & 2002 & LEFYEB & 2006 & & \\
\hline AQUYAM & 2003 & LEFYIF & 2006 & & \\
\hline BAJTEM02 & 2003 & PEQLUT & 2006 & & \\
\hline BATDOQ & 2003 & PEQMAA & 2006 & & \\
\hline BATDUW & 2003 & PEQMEE & 2006 & & \\
\hline BATFEI & 2003 & PEQMII & 2006 & & \\
\hline IKIFAJ & 2003 & PESVAL & 2006 & & \\
\hline OLIDOC & 2003 & & & & \\
\hline QADKIQ & 2003 & & & & \\
\hline UMUHOZ & 2003 & & & & \\
\hline WADQIC & 2003 & & & & \\
\hline XUVBAR & 2003 & & & & \\
\hline XUVBEV & 2003 & & & & \\
\hline ACEPAA & 2004 & & & & \\
\hline ASUDOH & 2004 & & & & \\
\hline AVOTIO & 2004 & & & & \\
\hline
\end{tabular}




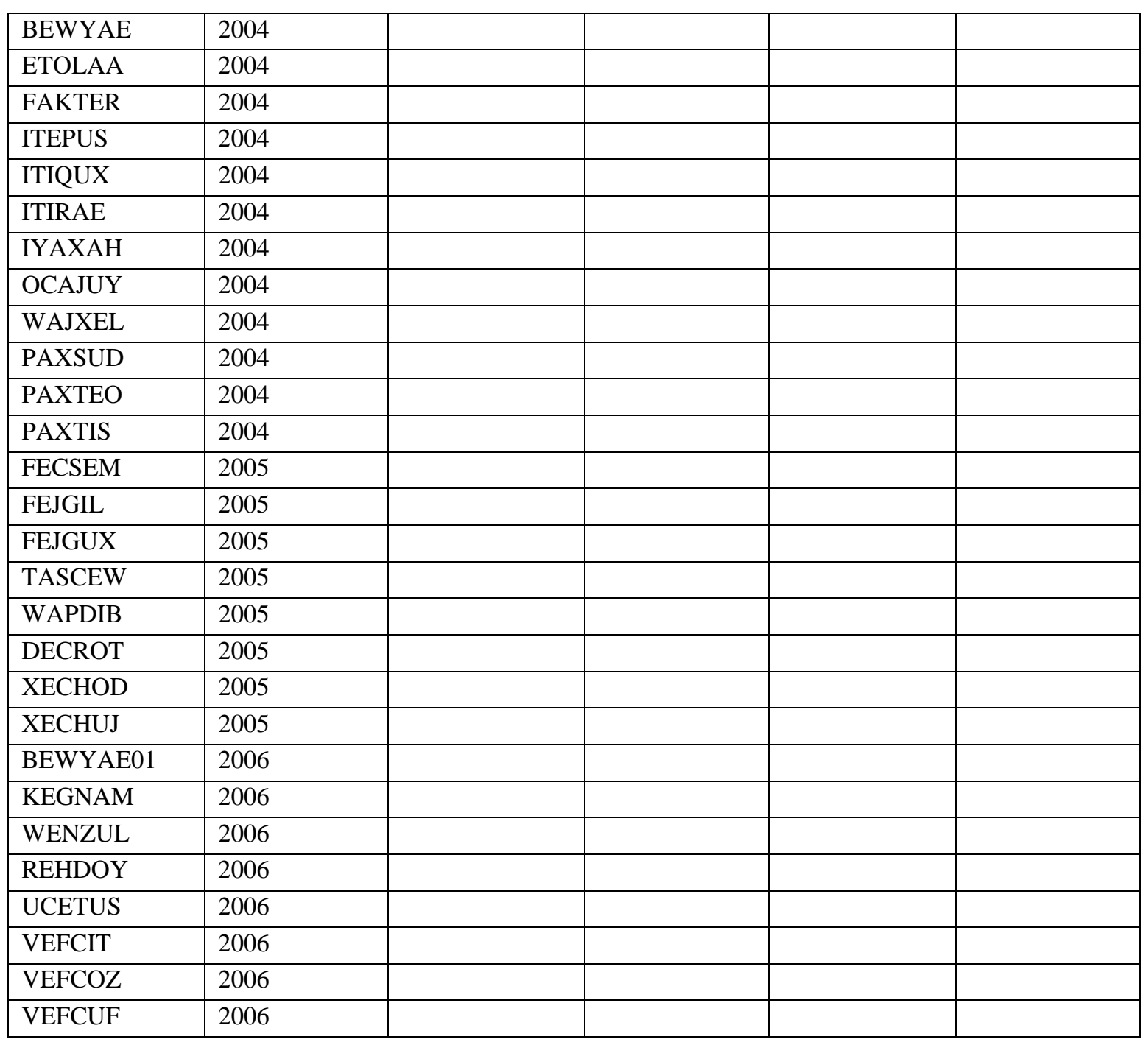




\section{Search Overview}

Search:

Date/Time done:

Database(s):

Restriction Info:

Filters:

Percentage Completed:

Number of Hits: search2

Thu Apr 05 09:21:46 2007

CSD version 5.28 (November 2006)

CSD version 5.28 updates (Jan 2007)

No refcode restrictions applied

None

$100 \%$

111

Single query used. Search found structures that:

match

\section{Query 1}

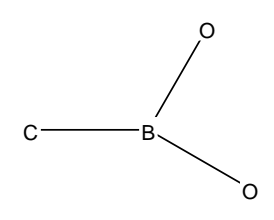




\section{Search: search2 (Thu Apr 05 09:21:46 2007): Hits 1-4}

ACEPAA

Reference:

B.Zarychta, K.Ejsmont, M.Bujak, J.Zaleski, A.Sporzynski, B.Zarycha, K.EJs Nrut, M.Bujak, J.Zalowk, A.Sporzyn A.Miskiewicz, A.Strutynska, J.Serwatowski (2004)

Formula: $\mathrm{C}_{5} \mathrm{H}_{5} \mathrm{~B}_{1} \mathrm{O}_{4}$

Compound Name: 3-Formyl-2-furanboronic acid

Space Group: $\quad$ P21/c Cell: $\quad$ a $3.660(1) \quad b \quad 14.252(2) \quad$ c $11.447(1)$

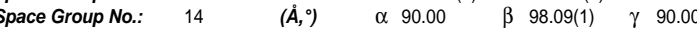
R-Factor (\%): $\quad 4.29 \quad$ Temperature(K): $100 \quad$ Density $\left(\mathbf{g} / \mathrm{cm}^{3}\right)$ : 1.572

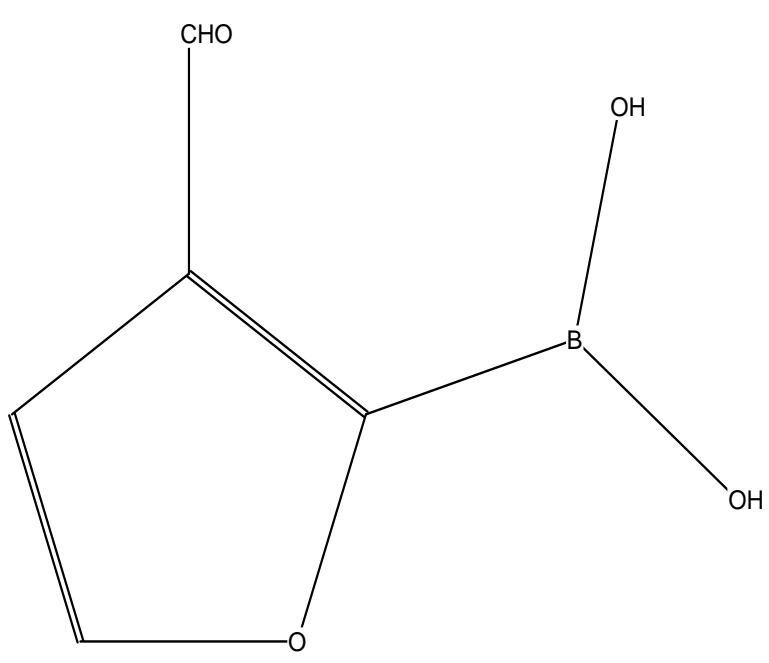

AQUYAM

\begin{tabular}{|c|c|c|c|c|c|c|}
\hline Reference: & \multicolumn{6}{|c|}{$\begin{array}{l}\text { Hong Yan, A.M.Beatty, T.P.Fehlner (2003) } \\
\text { J.Am.Chem.Soc. , 125,16367 }\end{array}$} \\
\hline Formula: & \multicolumn{6}{|c|}{$\mathrm{C}_{24} \mathrm{H}_{41} \mathrm{~B}_{3} \mathrm{O}_{4} \mathrm{Ru}_{2}$} \\
\hline Compound Name: & \multicolumn{6}{|c|}{$\begin{array}{l}\text { 1,5-bis( } \eta^{5} \text {-Pentamethylcyclopentadienyl)-2-(methoxycarbonyl)-3- } \\
\text { (dihydroxyboryl)-1,4,5:1,5,6:4,5:5,6-tetra- } \mu \mathrm{H}-1,5 \text {-diruthena-2,3-dicarba- } \\
\text { nido-hexaborane(6) }\end{array}$} \\
\hline Space Group: & $P-1$ & Cell: & a $10.926(0)$ & b $16.046(1)$ & & 16.096(1) \\
\hline Space Group No.: & 2 & $\left(\dot{A},{ }^{\circ}\right)$ & $\alpha 89.78(0)$ & $\beta 88.89(0)$ & & $74.15(0)$ \\
\hline -Factor (\%): & 4.27 & Temp & $\operatorname{re}(K): 100$ & Density $(\mathrm{g} / \mathrm{cm}$ & 3): & 1.537 \\
\hline
\end{tabular}

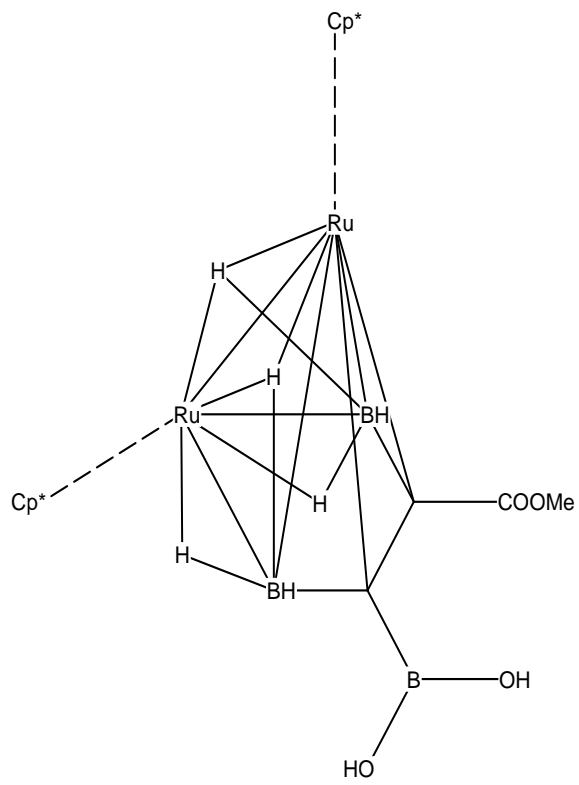

AFOLUC

Reference:

C.Zheng, B.F.Spielvogel, R.Y.Smith, N.S.Hosmane (2001) Z Kristallogr.-New Cryst.Struct. 216,341

Formula:

$\mathrm{C}_{7} \mathrm{H}_{9} \mathrm{~B}_{1} \mathrm{O}_{2}$

Compound Name: 4-Methylphenylboronic acid

\begin{tabular}{|c|c|c|c|c|c|}
\hline $\begin{array}{l}\text { ace Group: } \\
\text { ace Group No.: }\end{array}$ & $\begin{array}{l}\text { Iba2 } \\
45\end{array}$ & $\begin{array}{l}\text { Cell: } \\
(\dot{A}, \circ)\end{array}$ & $\begin{array}{ll}\text { a } & 17.016(5) \\
\alpha & 90.00\end{array}$ & $\begin{array}{ll}\boldsymbol{b} & 19.164(5) \\
\beta & 90.00\end{array}$ & $\begin{array}{ll}c & 9.722(5) \\
\gamma & 90.00\end{array}$ \\
\hline Factor & 6.42 & lemp & K): 293 & ensity & 1.139 \\
\hline
\end{tabular}

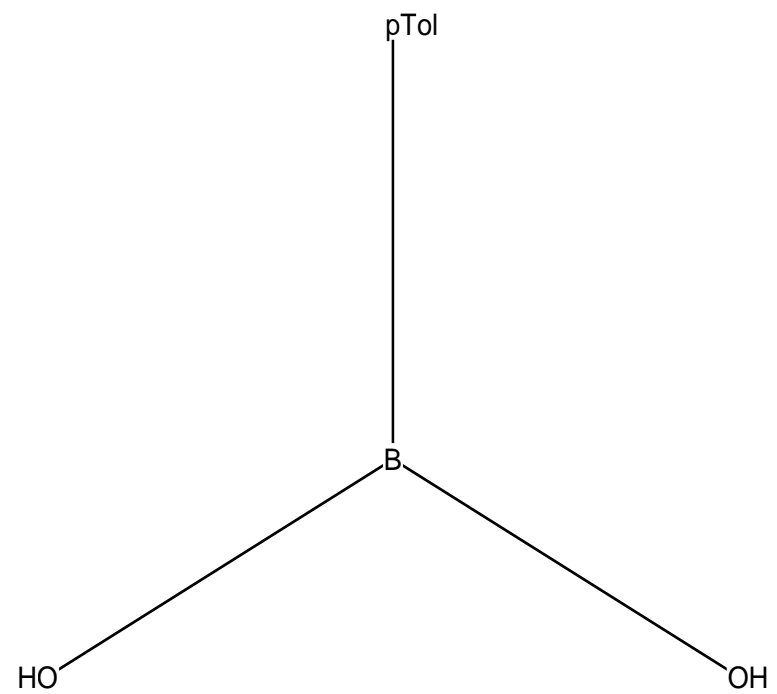

ASUDOH

\begin{tabular}{|c|c|c|c|c|c|c|}
\hline Reference: & \multicolumn{6}{|c|}{$\begin{array}{l}\text { C.Bresner, S.Aldridge, I.A.Fallis, Li-Ling Ooi (2004) } \\
\text { Acta Crystallogr.,Sect.E:Struct.Rep.Online ,60,m441 }\end{array}$} \\
\hline Formula: & \multicolumn{6}{|c|}{$\mathrm{C}_{10} \mathrm{H}_{11} \mathrm{~B}_{1} \mathrm{Fe}_{1} \mathrm{O}_{2}$} \\
\hline Compound Name: & \multicolumn{6}{|c|}{ ferroceneboronic acid } \\
\hline $\begin{array}{l}\text { Space Group: } \\
\text { Space Group No.: }\end{array}$ & $\begin{array}{l}\mathrm{P} 21 / \mathrm{a} \\
14\end{array}$ & $\begin{array}{l}\text { Cell: } \\
\left(\dot{A},{ }^{\circ}\right)\end{array}$ & $\begin{array}{ll}a & 10.068(0) \\
\alpha & 90.00\end{array}$ & $\begin{array}{l}\boldsymbol{b} \quad 7.008(0) \\
\beta 106.32(0)\end{array}$ & & $\begin{array}{l}14.030(1) \\
90.00\end{array}$ \\
\hline R-Factor (\%): & 5.45 & Temr & ure(K): 180 & Density $(\mathrm{g} / \mathrm{cm}$ & & 1.607 \\
\hline
\end{tabular}

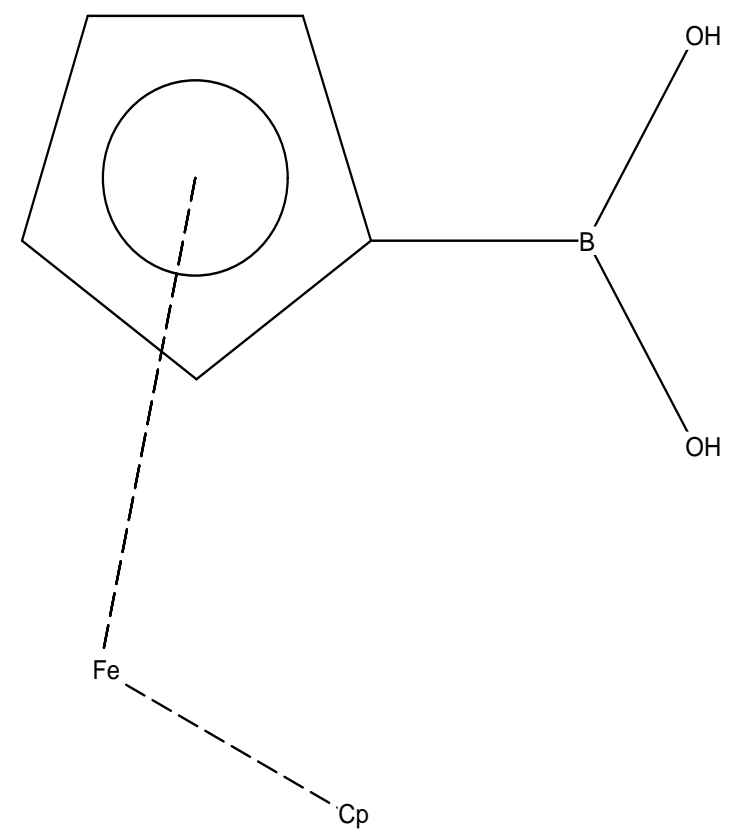




\section{Search: search2 (Thu Apr 05 09:21:46 2007): Hits 5-8}

AVOTIO

Reference:

N.Saygili, A.S.Batsanov, M.R.Bryce (2004) Org.Biomol.Chem. 2,852

Formula:

$\mathrm{C}_{4} \mathrm{H}_{5} \mathrm{~B}_{1} \mathrm{~N}_{2} \mathrm{O}_{2}, 0.5\left(\mathrm{H}_{2} \mathrm{O}_{1}\right)$

Compound Name:

5-Pyrimidylboronic acid hemihydrate

Space Group: Space Group No:

R-Factor (\%):

\begin{tabular}{|c|c|c|c|c|}
\hline $\begin{array}{l}\text { P21212 } \\
18\end{array}$ & $\begin{array}{l}\text { Cell: } \\
(\dot{A}, \circ)\end{array}$ & $\begin{array}{ll}a & 7.647(0) \\
\alpha & 90.00\end{array}$ & $\begin{array}{ll}\boldsymbol{b} & 21.062(5) \\
\beta & 90.00\end{array}$ & $\begin{array}{ll}c & 3.635(0) \\
\gamma & 90.00\end{array}$ \\
\hline 3.18 & Ten & 120 & sity) & 1.508 \\
\hline
\end{tabular}

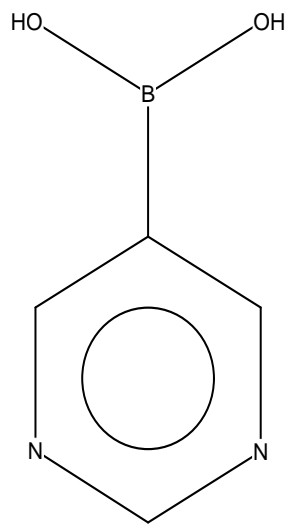

$\mathrm{H}_{2} \mathrm{O}$

BAJTEM01

Reference:

P.R.Parry, Changsheng Wang, A.S.Batsanov, M.R.Bryce, B.Tarbit (2002) J.Org.Chem. 67,754

Formula:

$\mathrm{C}_{5} \mathrm{H}_{5} \mathrm{~B}_{1} \mathrm{Br}_{1} \mathrm{~N}_{1} \mathrm{O}_{2}$

Compound Name:

2-bromo-5-pyridylboronic acid $\begin{array}{lllllllll}\text { Space Group: } & \text { P21/c } & \text { Cell: } & \boldsymbol{a} & 7.346(1) & \boldsymbol{b} & 6.938(1) & \boldsymbol{c} & 13.727(1) \\ \text { Space Group No.: } & 14 & \left(\dot{A},{ }^{\circ}\right) & \alpha & 90.00 & \beta & 96.62(1) & \gamma & 90.00\end{array}$

R-Factor (\%): $\quad 1.89 \quad$ Temperature(K): $120 \quad$ Density $\left(g / \mathrm{cm}^{3}\right): 1.929$
BAJTEM

Reference: $\quad$ P.R.Parry, Changsheng Wang, A.S.Batsanov, M.R.Bryce, B.Tarbit (2002) J.Org.Chem. ,67,7541

Formula: $\quad \mathrm{C}_{5} \mathrm{H}_{5} \mathrm{~B}_{1} \mathrm{Br}_{1} \mathrm{~N}_{1} \mathrm{O}_{2}$

Compound Name: 2-bromo-5-pyridylboronic acid

Space Group: $\quad$ P21/c $\quad$ Cell: $\quad$ a $7.535(2) \quad b \quad 6.941(1) \quad c \quad 13.877(3)$

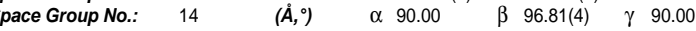

R-Factor (\%): $\quad 3.59 \quad$ Temperature(K): $295 \quad$ Density(g/cm3): 1.860

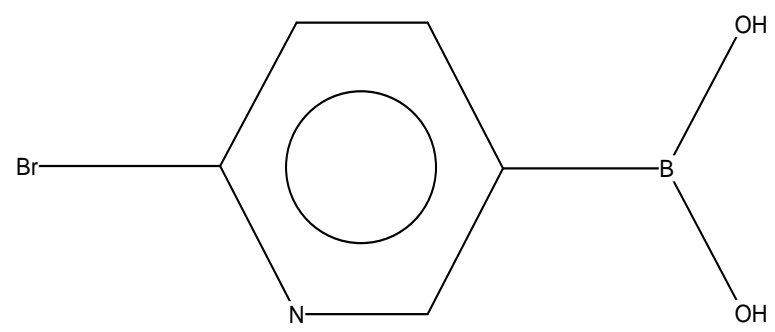

BAJTEM02

Reference: J.Sopkova-de Oliveira Santos, J.-C.Lancelot, A.Bouillon,

S.Rault (2003) Acta Crystallogr.,Sect.C.Cryst.Struct.Commun. ,59,0111

Formula: $\quad \mathrm{C}_{5} \mathrm{H}_{5} \mathrm{~B}_{1} \mathrm{Br}_{1} \mathrm{~N}_{1} \mathrm{O}_{2}$

Compound Name: (6-Bromopyridin-3-yl)boronic acid

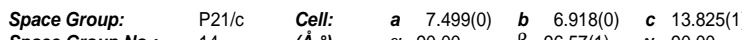

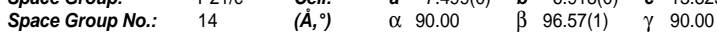

R-Factor (\%): $\quad 4.90 \quad$ Temperature(K): $293 \quad \operatorname{Density(g/\mathrm {cm}^{3}):} 1.881$
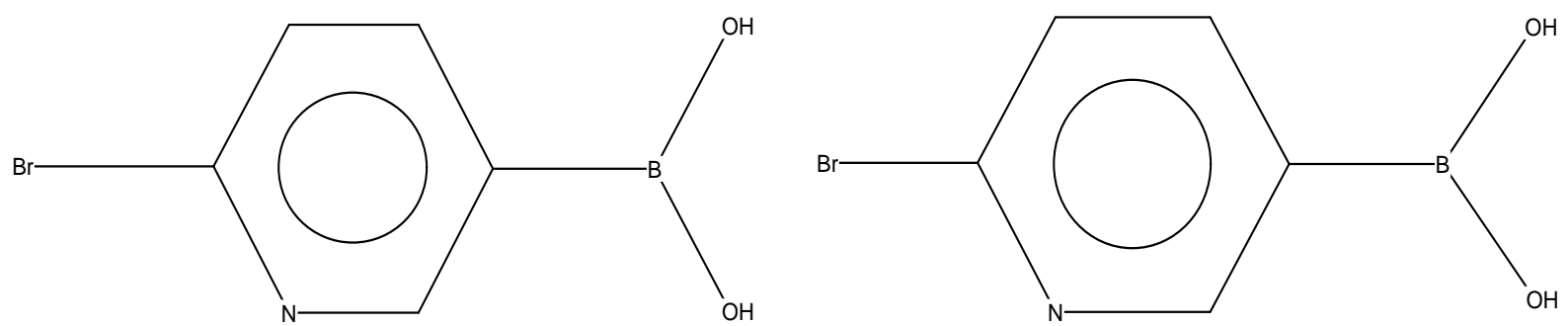


\section{Search: search2 (Thu Apr 05 09:21:46 2007): Hits 9-12}

BAJTIQ

Reference:

P.R.Parry, Changsheng Wang, A.S.Batsanov, M.R.Bryce, B.Tarbit (2002) J.Org.Chem. ,67,7541

Formula:

$\mathrm{C}_{5} \mathrm{H}_{5} \mathrm{~B}_{1} \mathrm{Cl}_{1} \mathrm{~N}_{1} \mathrm{O}_{2}$

Compound Name: 2-chloro-5-pyridylboronic acid

\begin{tabular}{|c|c|c|c|c|c|}
\hline $\begin{array}{l}\text { ace Group: } \\
\text { ace Group No.: }\end{array}$ & $\begin{array}{l}\mathrm{P} 21 / \mathrm{n} \\
14\end{array}$ & $\begin{array}{l}\text { Cell: } \\
(\dot{A}, \circ)\end{array}$ & $\begin{array}{ll}a & 8.906(1) \\
\alpha & 90.00\end{array}$ & $\begin{array}{lc}\boldsymbol{b} & 7.277(1) \\
\beta & 96.55(1)\end{array}$ & $\begin{array}{ll}c & 10.389(1) \\
\gamma & 90.00\end{array}$ \\
\hline$a c t$ & 2.94 & $m i$ & 120 & ensity & 1.563 \\
\hline
\end{tabular}

R-Factor (\%):

rature(K): 120

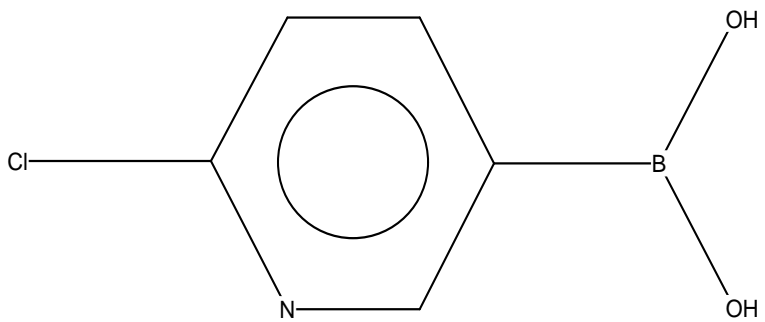

BATDOQ

$\begin{array}{ll}\text { Reference: } & \text { D.Braga, M.Polito, M.Bracaccini, D.D'Addario, } \\ & \text { E.Tagliavini, L.Sturba, F.Grepioni (2003) Organometallics , 22,2142 } \\ \text { Formula: } & \mathrm{C}_{15} \mathrm{H}_{14} \mathrm{~B}_{1} \mathrm{Fe}_{1} \mathrm{~N}_{1} \mathrm{O}_{2}, 0.5\left(\mathrm{H}_{2} \mathrm{O}_{1}\right)\end{array}$

Compound Name: $\quad 1$-(4-Pyridy)ferrocene-1-boronic acid hemihydrate

$\begin{array}{llllllll}\text { Space Group: } & \text { C2/c } & \text { Cell: } & \text { a } 17.330(3) & \boldsymbol{b} ~ 13.121(3) & \boldsymbol{c} & 15.996(3) \\ \text { Space Group No.: } & 15 & (\dot{\boldsymbol{A}}, \%) & \alpha-90.00 & \beta 131.08(2) & \gamma & 90.00\end{array}$

R-Factor (\%): $\quad 3.78 \quad$ Temperature(K): $293 \quad$ Density $\left(\mathrm{g} / \mathrm{cm}^{3}\right): 1.531$

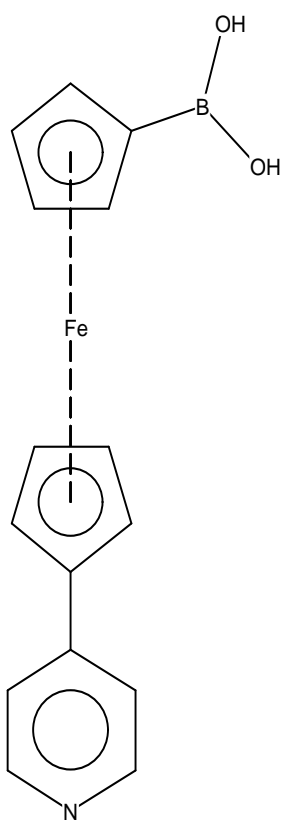

BATDEG

Reference: $\quad$ D.Braga, M.Polito, M.Bracaccini, D.D'Addario, E.Tagliavini, L.Sturba, F.Grepioni (2003) Organometallics ,22,2142

Formula: $\mathrm{C}_{10} \mathrm{H}_{12} \mathrm{~B}_{2} \mathrm{Fe}_{1} \mathrm{O}_{4}$

Compound Name: Ferrocene-1,1'-diboronic acid

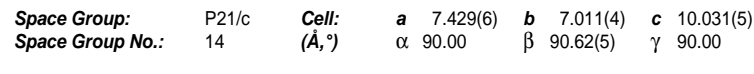

R-Factor (\%): $\quad 9.13 \quad$ Temperature(K): $293 \quad$ Density $\left(\mathrm{g} / \mathrm{cm}^{3}\right): 1.740$

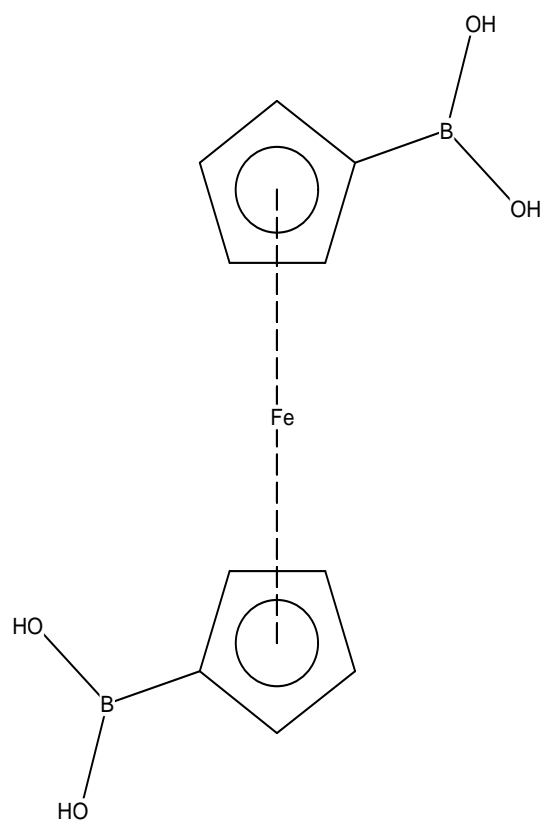

BATDUW

Reference: $\quad$ D.Braga, M.Polito, M.Bracaccini, D.D'Addario,

Formula: $\quad \mathrm{C}_{15} \mathrm{H}_{15} \mathrm{~B}_{1} \mathrm{Fe}_{1} \mathrm{~N}_{1} \mathrm{O}_{2}{ }^{1+}, \mathrm{N}_{1} \mathrm{O}_{3}{ }^{1}$

Compound Name: $\quad$ 1'-(4-Pyridinium)ferrocene-1-boronic acid nitrate

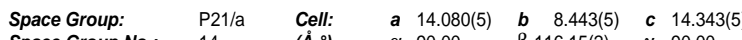

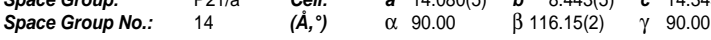
R-Factor (\%): $\quad 5.98 \quad$ Temperature(K): $293 \quad$ Density $\left(\mathrm{g} / \mathrm{cm}^{3}\right): 1.606$

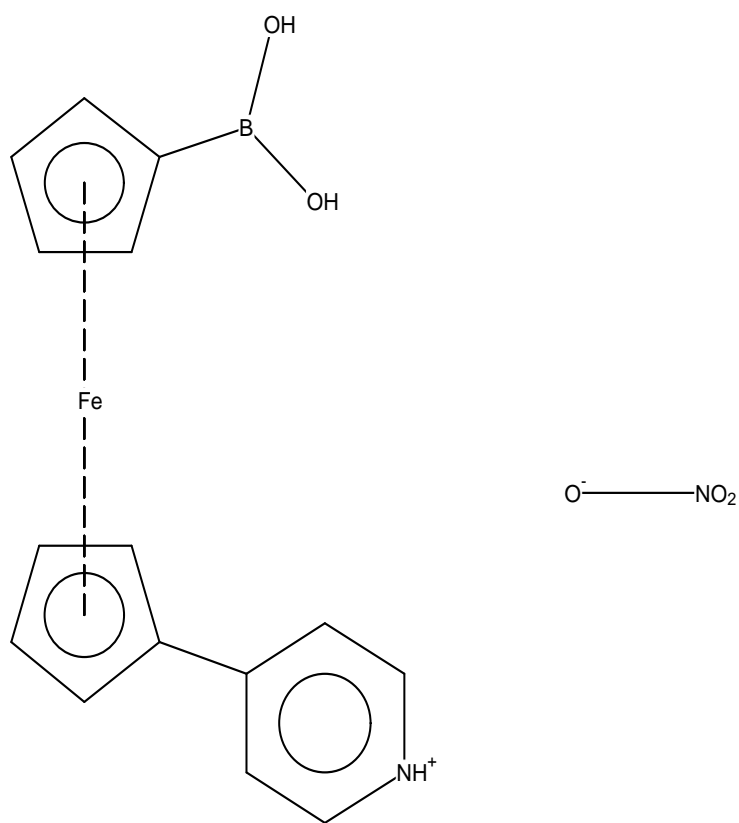




\section{Search: search2 (Thu Apr 05 09:21:46 2007): Hits 13-16}

BATFEI

Reference:

D.Braga, M.Polito, M.Bracaccini, D.D'Addario, E.Tagliavini, L.Sturba, F.Grepioni (2003) Organometallics ,22,2142

Formula: $\mathrm{C}_{15} \mathrm{H}_{14} \mathrm{~B}_{1} \mathrm{Fe}_{1} \mathrm{~N}_{1} \mathrm{O}_{2}$

Compound Name:

1'-(4-Pyridyl)ferrocene-1-boronic acid

BATFEI01

Reference:

D.Braga, M.Polito, M.Bracaccini, D.D'Addario, E.Tagliavini, L.Sturba, F.Grepioni (2003) Organometallics ,22,2142

Formula: $\mathrm{C}_{15} \mathrm{H}_{14} \mathrm{~B}_{1} \mathrm{Fe}_{1} \mathrm{~N}_{1} \mathrm{O}_{2}$

Compound Name:

1'-(4-Pyridyl)ferrocene-1-boronic acid

\begin{tabular}{|c|c|c|c|c|c|}
\hline $\begin{array}{l}\text { oace Group: } \\
\text { pace Group No.: }\end{array}$ & $\begin{array}{l}\text { P21/a } \\
14\end{array}$ & $\begin{array}{l}\text { Cell: } \\
\left(\dot{A},{ }^{\circ}\right)\end{array}$ & $\begin{array}{ll}a & 8.838(2) \\
\alpha & 90.00\end{array}$ & $\begin{array}{lc}\boldsymbol{b} & 9.385(4) \\
\beta & 96.40(1)\end{array}$ & $\begin{array}{ll}c & 15.937(3) \\
\gamma & 90.00\end{array}$ \\
\hline & 6.82 & n & 293 & sity & 1.552 \\
\hline
\end{tabular}

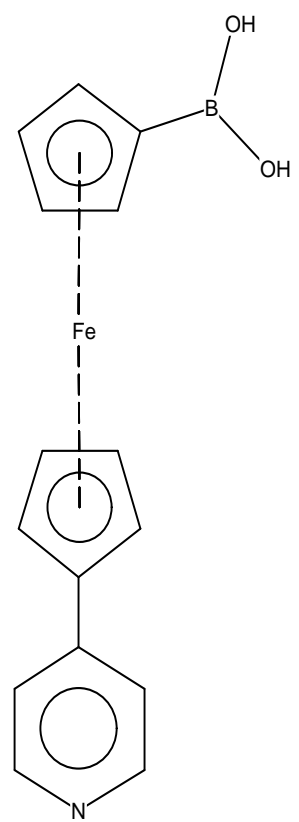

BATFUY

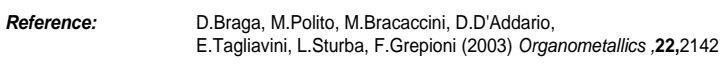

Formula: $2\left(\mathrm{C}_{15} \mathrm{H}_{15} \mathrm{~B}_{1} \mathrm{Fe}_{1} \mathrm{~N}_{1} \mathrm{O}_{2}{ }^{1+}\right), \mathrm{O}_{4} \mathrm{~S}_{1}{ }^{2-3}, 3\left(\mathrm{H}_{2} \mathrm{O}_{1}\right)$

Compound Name: $\quad$ bis(1'-(4-Pyridinium)ferrocene-1-boronic acid) sulfate trihydrate \begin{tabular}{llllllll} 
Space Group: & P21/c & Cell: & a 21.954(4) & b $7.362(1)$ & \multicolumn{1}{c}{$20.871(4)$} \\
Space Group No.: & 14 & $(\dot{A}, \circ)$ & $\alpha$ & 90.00 & $\beta 111.35(3)$ & $\gamma$ & 90.00
\end{tabular} R-Factor (\%): $\quad 3.96 \quad$ Temperature(K): $293 \quad$ Density $\left(\mathbf{g} / \mathrm{cm}^{3}\right): 1.619$
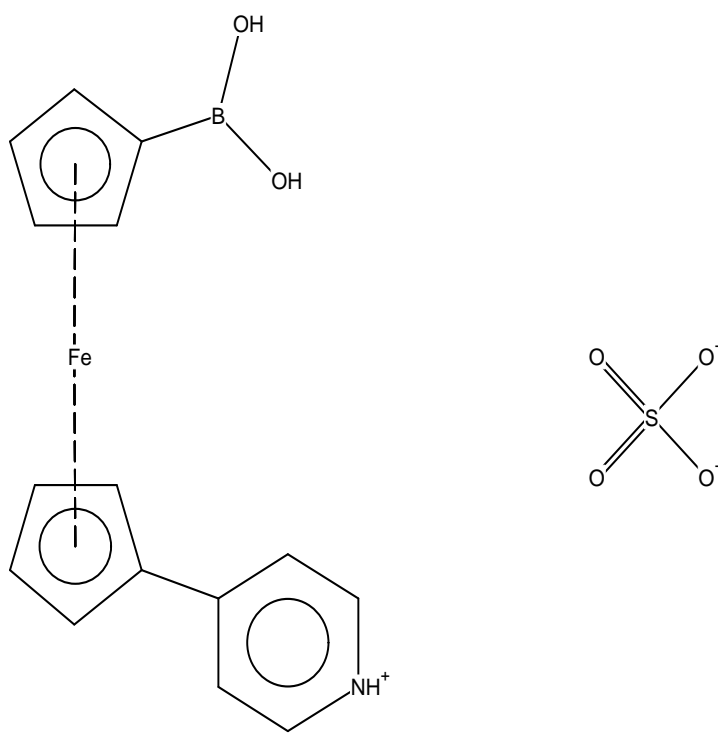

BAVJIS

Reference:

Formula:

Compound Name:

Synonym:

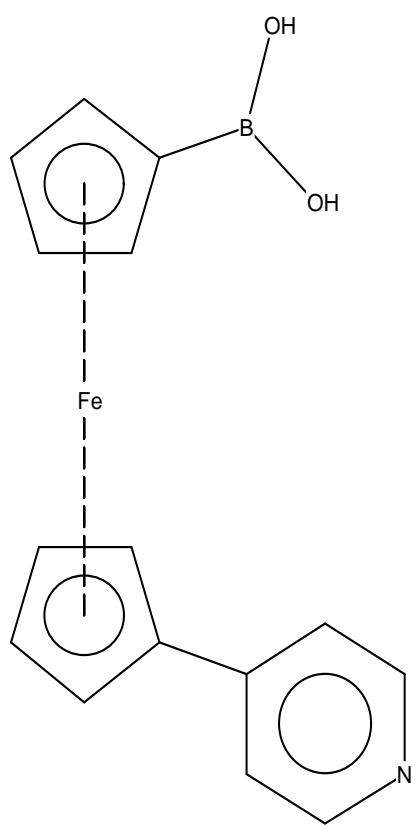

Space Group: Space Group No.:

R-Factor (\%):

T.Beringhelli, G.D'Alfonso, D.Donghi, D.Maggioni, P.Mercandelli, A.Sironi (2003) Organometallics ,22,1588 $\mathrm{C}_{36} \mathrm{H}_{3} \mathrm{~B}_{3} \mathrm{~F}_{30} \mathrm{O}_{3}$

$\operatorname{tris}\left(\left(\mu_{2}\right.\right.$-Hydroxo)-bis(pentafluorophenyl)-boron)

Cyclo-tris(bis(pentafluorophenyl)borinic acid)
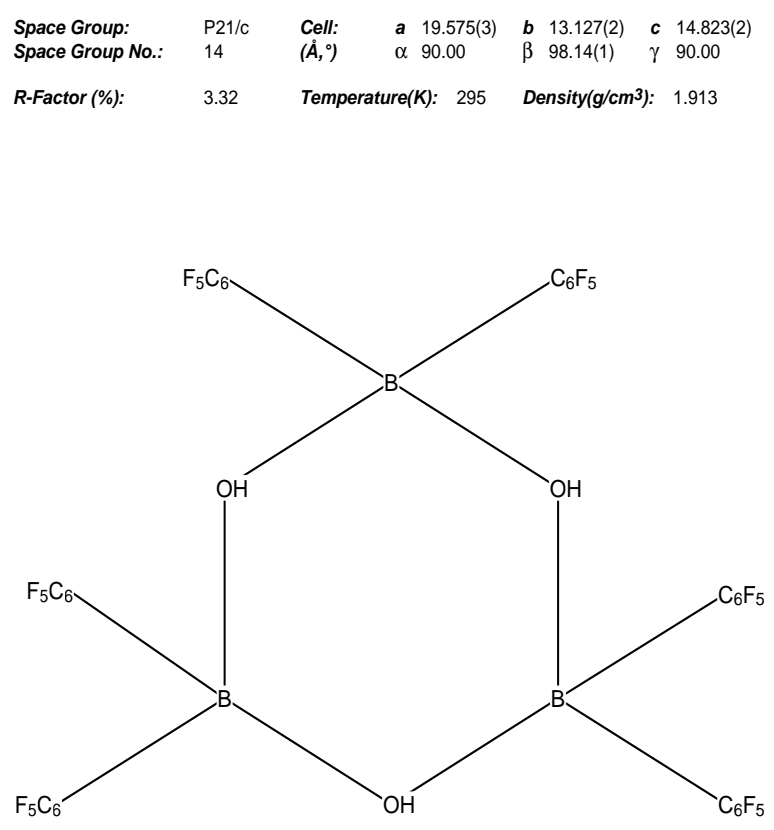


\section{Search: search2 (Thu Apr 05 09:21:46 2007): Hits 17-20}

BEWYAE

\begin{tabular}{|c|c|c|c|c|c|}
\hline Reference: & \multicolumn{5}{|c|}{$\begin{array}{l}\text { P.Rodriguez-Cuamatzi, G.Vargas-Daz, H.Hopfl (2004) } \\
\text { Angew.Chem.,Int.Ed. , } 43,3041\end{array}$} \\
\hline Formula: & \multicolumn{5}{|c|}{$\mathrm{C}_{6} \mathrm{H}_{8} \mathrm{~B}_{2} \mathrm{O}_{4}, 4\left(\mathrm{H}_{2} \mathrm{O}_{1}\right)$} \\
\hline Compound Name: & \multicolumn{5}{|c|}{ 1,4-Phenylenediboronic acid tetrahydrate } \\
\hline $\begin{array}{l}\text { Space Group: } \\
\text { Space Group No.: }\end{array}$ & $\begin{array}{l}\mathrm{P}-1 \\
2\end{array}$ & $\begin{array}{l}\text { Cell: } \\
\left(\dot{A},{ }^{\circ}\right)\end{array}$ & $\begin{array}{lc}a & 4.940(2) \\
\alpha & 95.03(0)\end{array}$ & $\begin{array}{lc}\boldsymbol{b} & 8.727(4) \\
\beta & 91.79(0)\end{array}$ & 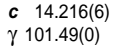 \\
\hline -Factor (\%): & 4.40 & Temp & $r e(K): 293$ & Density $(\mathrm{g} / \mathrm{cm}$ & ): 1.322 \\
\hline
\end{tabular}

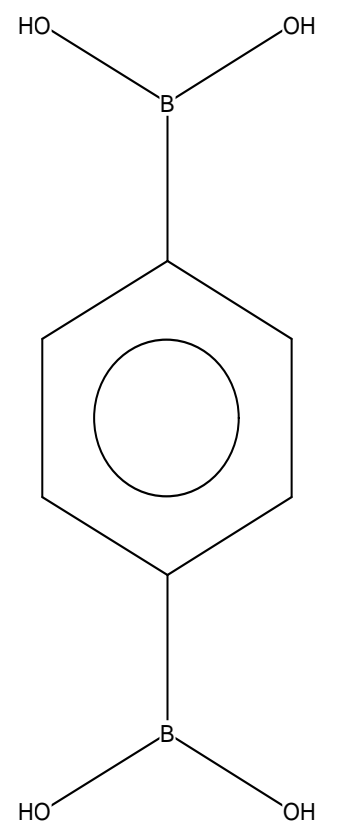

$\mathrm{H}_{2} \mathrm{O}$

BPHBAC

$\begin{array}{ll}\text { Reference: } & \begin{array}{l}\text { Z.V.Zvonkova, V.P.Gluskova (1958) } \\ \text { Kristallografiya(Russ.)(Crystallogr.Rep.) ,3,559 }\end{array} \\ \text { Formula: } & \mathrm{C}_{6} \mathrm{H}_{6} \mathrm{~B}_{1} \mathrm{Br}_{1} \mathrm{O}_{2} \\ \text { Compound Name: } & \text { p-Bromophenylboronic acid }\end{array}$

Compound Name: p-Bromophenylboronic acid

Space Group: $\quad \mathrm{P} 6 / \mathrm{mcc} \quad$ Cell: $\quad$ a $28.730 \quad$ b $28.730 \quad$ c 9.740

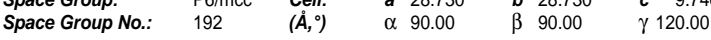
R-Factor (\%): $\quad 24.00 \quad$ Temperature(K): $295 \quad$ Density $\left(\mathrm{g} / \mathrm{cm}^{3}\right): \quad 1.724$

\section{BEWYAE01}

T.Morawitz, H.-W.Lerner, M.Bolte (2006) Private Communication,

Formula: $\mathrm{C}_{6} \mathrm{H}_{8} \mathrm{~B}_{2} \mathrm{O}_{4}, 4\left(\mathrm{H}_{2} \mathrm{O}_{1}\right)$

Compound Name: 1,4-Phenylenediboronic acid tetrahydrate

$\begin{array}{lllllllll}\text { Space Group: } & \text { P-1 } & \text { Cell: } & \boldsymbol{a} & 4.942(0) & \boldsymbol{b} & 8.744(1) & \boldsymbol{c} & 14.259(2) \\ \text { Space Group No.: } & 2 & (\hat{A}, 0) & \alpha & 95.38(1) & \beta & 91.14(1) & \gamma & 101.26(1)\end{array}$

R-Factor (\%): $\quad 4.79 \quad$ Temperature(K): $173 \quad$ Density(g/cm3): 1.314

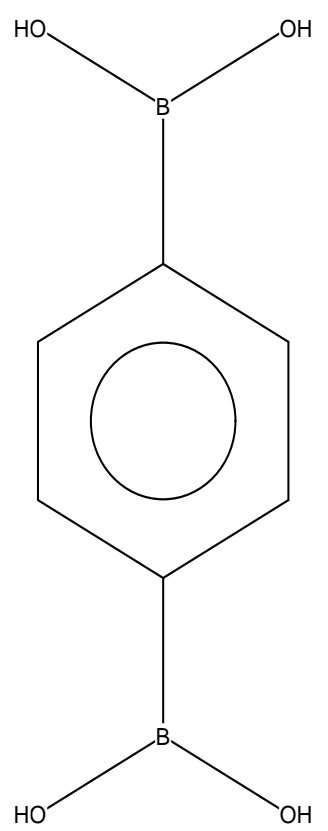

\section{BZTALR}

Reference: $\quad$ E.B.Fleischer, R.Dewar (1970) Tetrahedron Lett. ,363

Formula: $\mathrm{C}_{24} \mathrm{H}_{33} \mathrm{~B}_{3} \mathrm{~N}_{3} \mathrm{O}_{3}$

Compound Name:

Tribenzotaralene

Space Group: $\quad$ P212121 Cell: $\quad$ a $26.970 \quad$ b $8.070 \quad$ c 10.020

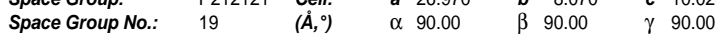
R-Factor (\%): $\quad 6.40 \quad$ Temperature(K): $295 \quad$ Density $\left(\mathrm{g} / \mathrm{cm}^{3}\right): 1.352$
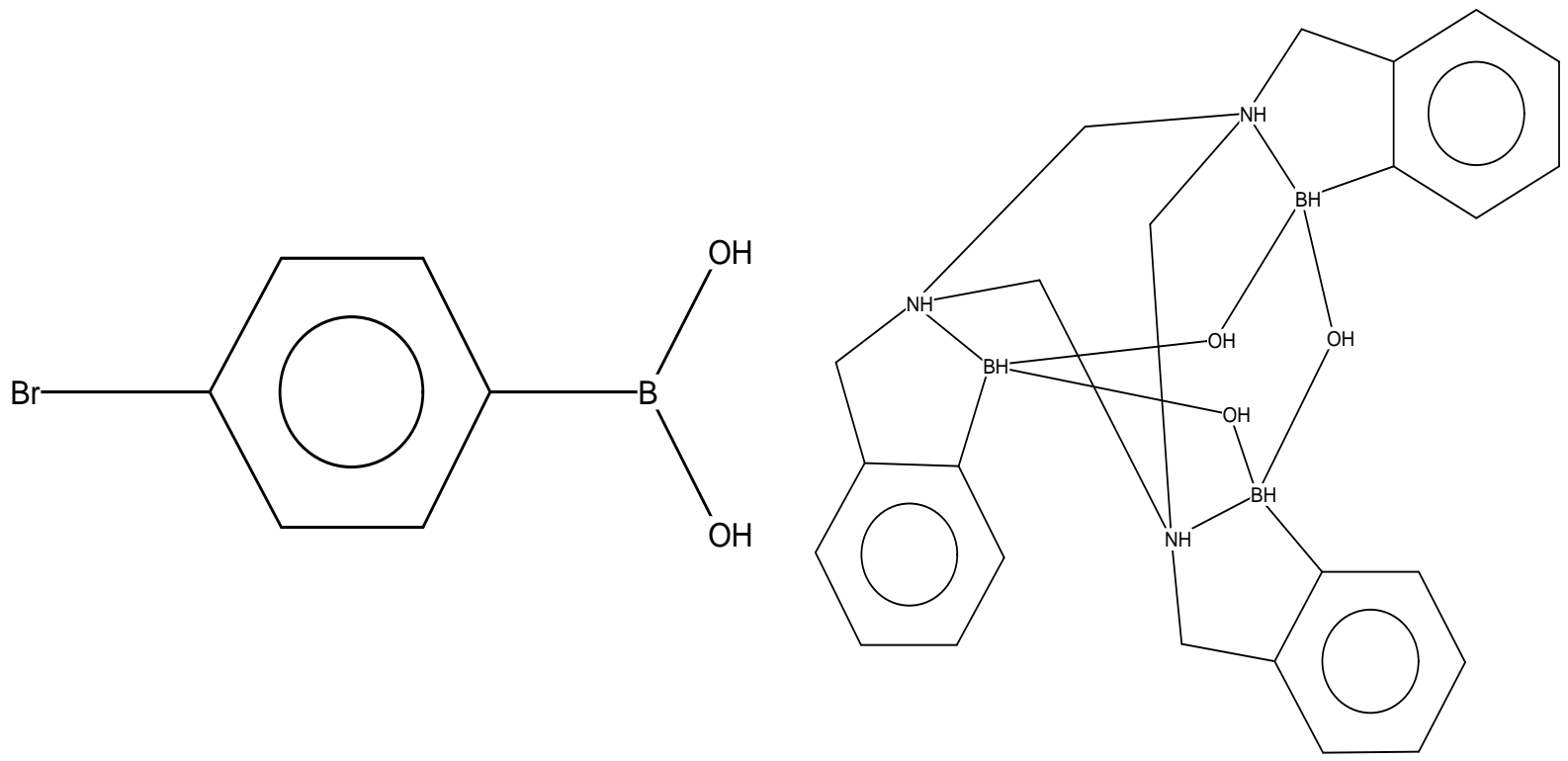


\section{Search: search2 (Thu Apr 05 09:21:46 2007): Hits 21-24}

CAQZAW

\begin{tabular}{|c|c|c|c|c|c|}
\hline Reference: & \multicolumn{5}{|c|}{$\begin{array}{l}\text { G.Vargas, N.Farfan, R.Santillan, A.Gutierrez, E.Gomez, } \\
\text { V.Barba (2005) Inorg.Chim.Acta } 358,2996\end{array}$} \\
\hline Formula: & \multicolumn{5}{|c|}{$\mathrm{C}_{39} \mathrm{H}_{32} \mathrm{~B}_{1} \mathrm{~N}_{1} \mathrm{O}_{2}, \mathrm{C}_{6} \mathrm{H}_{7} \mathrm{~B}_{1} \mathrm{O}_{2}, 0.5\left(\mathrm{C}_{1} \mathrm{H}_{2} \mathrm{Cl}_{2}\right)$} \\
\hline Compound Name: & \multicolumn{5}{|c|}{$\begin{array}{l}\text { (2,6-bis(2,2-Diphenyl-2-oxyethyl)pyridyl)phenylboron phenylboronic acid } \\
\text { dichloromethane solvate }\end{array}$} \\
\hline $\begin{array}{l}\text { Space Group: } \\
\text { Space Group No.: }\end{array}$ & $\begin{array}{l}\mathrm{P} 1 \\
1\end{array}$ & $\begin{array}{l}\text { Cell: } \\
(\dot{A}, \circ)\end{array}$ & $\begin{array}{l}a \quad 10.403(2) \\
\alpha 102.74(3)\end{array}$ & $\begin{array}{ll}\boldsymbol{b} & 12.451(2) \\
\beta & 95.43(3)\end{array}$ & $\begin{array}{l}c \quad 16.425(3) \\
\gamma 110.12(3)\end{array}$ \\
\hline R-Factor (\%): & 4.23 & Tem & ure(K): 293 & Density $(\mathrm{g} / \mathrm{cm}$ & 3): 1.252 \\
\hline
\end{tabular}<smiles></smiles><smiles>OB(O)P</smiles>

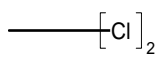

DECROT

\begin{tabular}{|c|c|c|c|c|c|}
\hline Reference: & \multicolumn{5}{|c|}{$\begin{array}{l}\text { S.W.Coghlan, R.L.Giles, J.A.K.Howard, L.G.F.Patrick, } \\
\text { M.R.Probert, G.E.Smith, A.Whiting (2005) J.Organomet.Chem. ,690, } \\
4784\end{array}$} \\
\hline Formula: & \multicolumn{5}{|c|}{$\mathrm{C}_{13} \mathrm{H}_{22} \mathrm{~B}_{1} \mathrm{~N}_{1} \mathrm{O}_{2}$} \\
\hline Compound Name: & \multicolumn{5}{|c|}{ (2-(Diisopropylaminomethyl)phenyl)boronic acid } \\
\hline $\begin{array}{l}\text { Space Group: } \\
\text { Space Group No.: }\end{array}$ & $\begin{array}{l}\mathrm{P} 21 / \mathrm{c} \\
14\end{array}$ & $\begin{array}{l}\text { Cell: } \\
\left(\dot{A},{ }^{\circ}\right)\end{array}$ & $\begin{array}{ll}a & 13.620(0) \\
\alpha & 90.00\end{array}$ & $\begin{array}{l}\boldsymbol{b} \quad 7.658(0) \\
\beta 109.61(0)\end{array}$ & $\begin{array}{ll}c & 13.486(0 \\
\gamma & 90.00\end{array}$ \\
\hline 3-Factor (\%): & 4.09 & Tempe & $\operatorname{re}(K): \quad 120$ & Density $(\mathrm{g} / \mathrm{cm}$ & ): 1.179 \\
\hline
\end{tabular}

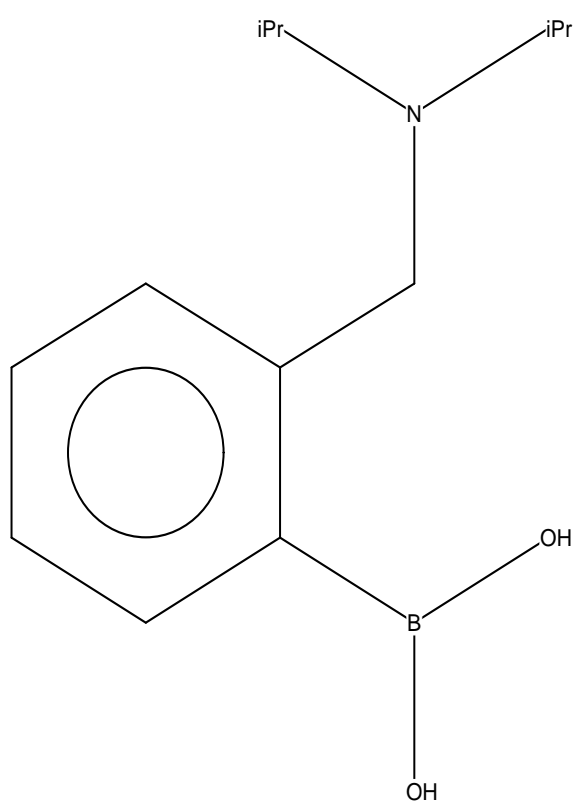

CEZHUK

Reference: M.A.Beckett, D.S.Brassington, P.Owen, M.B.Hursthouse, M.E.Light, K.M.A.Malik, K.S.Varma (1999) J.Organomet.Chem. ,585,7

Formula: $\mathrm{C}_{7} \mathrm{H}_{20} \mathrm{~B}_{3} \mathrm{~N}_{1} \mathrm{O}_{3}, \mathrm{C}_{1} \mathrm{H}_{5} \mathrm{~B}_{1} \mathrm{O}_{2}$

Compound Name: Isobutylamine trimethylboroxine dihydroxy(methyl)borane

$\begin{array}{lllllllll}\text { Space Group: } & \text { P21/c } & \text { Cell: } & \boldsymbol{a} & 9.342(2) & \boldsymbol{b} 22.300(4) & \boldsymbol{c} & 15.935(3) \\ \text { Space Group No.: } & 14 & (\dot{A}, \circ) & \alpha & 90.00 & \beta & 106.49(3) & \gamma & 90.00\end{array}$

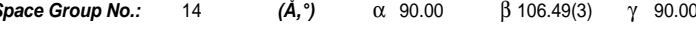

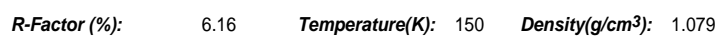
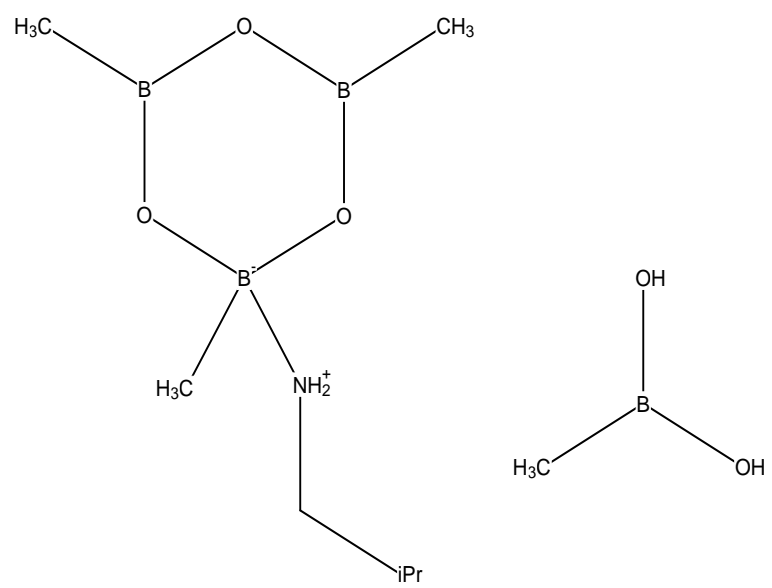

DOBKUA

Reference: $\quad$ B.K.Shull, D.E.Spielvogel, R.Gopalaswamy, S.Sankar,

P.D.Boyle, G. Head, K.Devito (2000) J.Chem.Soc.,Perkin Trans. 2,557
P.

Formula:

$\mathrm{C}_{9} \mathrm{H}_{12} \mathrm{~B}_{1} \mathrm{~N}_{1} \mathrm{O}_{4}$

Compound Name: L-p-Boronophenylalanine

Space Group: $\quad$ P21 $\quad$ Cell: $\quad \begin{array}{llllll}\text { a } & 5.347(0) & \boldsymbol{b} & 7.323(0) & \boldsymbol{c} & 12.171(0)\end{array}$

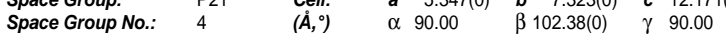
R-Factor (\%): $\quad 3.10 \quad$ Temperature(K): $295 \quad$ Density $\left(\mathbf{g} / \mathrm{cm}^{3}\right): 1.491$ 


\section{Search: search2 (Thu Apr 05 09:21:46 2007): Hits 25-28}

ETOLAA

Reference:

B.Zarychta, J.Zaleski, A.Sporzynski, M.Dabrowski,

J.Serwatowski (2004) Acta Crystallogr.,Sect.C:Cryst.Struct.Commun 60,0344

Formula: $\mathrm{C}_{7} \mathrm{H}_{7} \mathrm{~B}_{1} \mathrm{O}_{3}$

Compound Name: (3-Formylphenyl)boronic acid

\begin{tabular}{|c|c|c|c|c|c|}
\hline ace Group: & $\begin{array}{l}\mathrm{C} 2 / \mathrm{c} \\
15\end{array}$ & $\begin{array}{l}\text { Cell: } \\
\left(\dot{A},{ }^{\circ}\right)\end{array}$ & $\begin{array}{ll}\text { a } & 22.635(2) \\
\alpha & 90.00\end{array}$ & $\begin{array}{lr}\boldsymbol{b} & 3.733(0) \\
\beta & 102.05(0)\end{array}$ & $\begin{array}{ll}c & 17.126 \\
\gamma & 90.00\end{array}$ \\
\hline & 3.63 & & 100 & Density(g & 1.407 \\
\hline
\end{tabular}

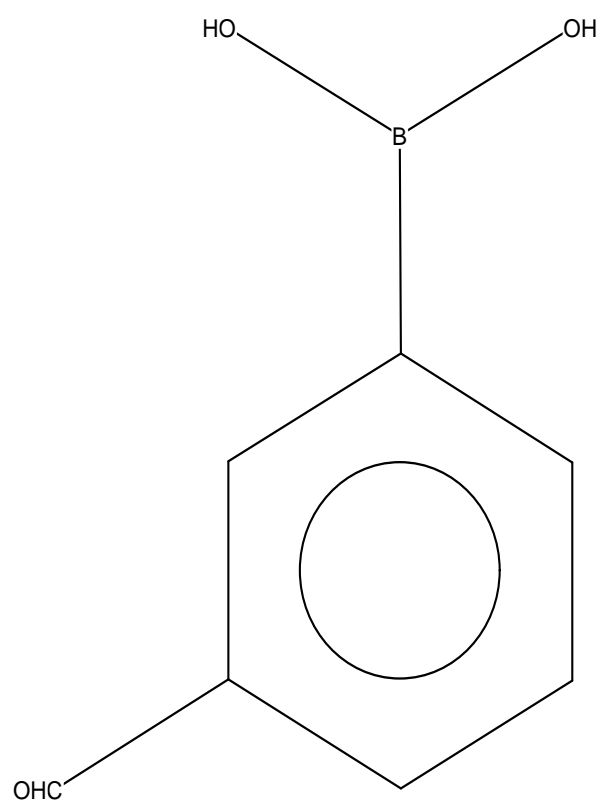

FECSEM

$\begin{array}{ll}\text { Reference: } & \text { A.E.Thompson, G.Hughes, A.S.Batsanov, M.R.Bryce, } \\ & \text { P.R.Parry, B.Tarbit (2005) J.Org.Chem. ,70,388 } \\ \text { Formula: } & \mathrm{C}_{6} \mathrm{H}_{8} \mathrm{~B}_{1} \mathrm{~N}_{1} \mathrm{O}_{3} \\ \text { Compound Name: } & \text { 2-Methoxy-5-pyridylboronic acid }\end{array}$

$\begin{array}{lllllllll}\text { Space Group: } & \text { P-1 } & \text { Cell: } & \text { a } & 7.071(1) & \boldsymbol{b} & 9.898(2) & \boldsymbol{c} & 10.636(2)\end{array}$ $\begin{array}{llllllll}\text { Space Group No.: } \quad 2 & \left(\dot{A},{ }^{\circ}\right) & \alpha & 85.74(1) & \beta & 89.27(1) & \gamma & 74.64(1)\end{array}$ R-Factor (\%): 4.29

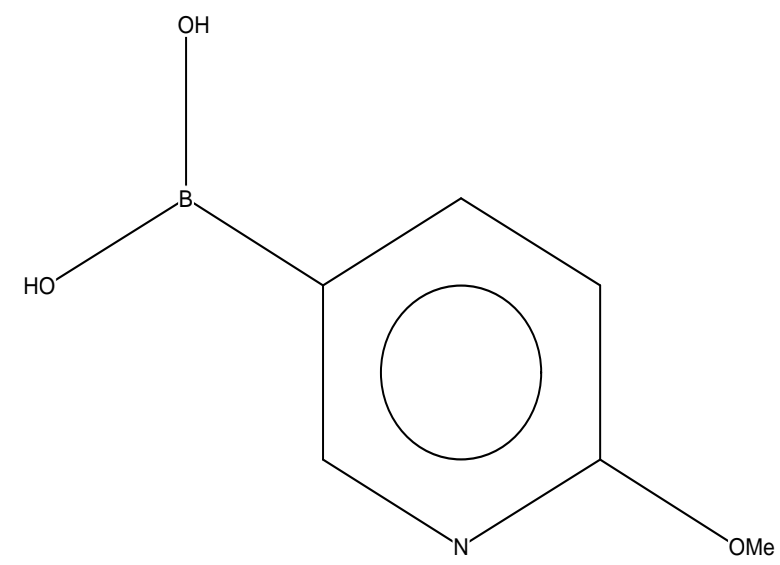

FAKTER

Reference: Jianzhang Zhao, M.G.Davidson, M.F.Mahon,

G.Kociok-Kohn, T.D.James (2004) J.Am.Chem.Soc. ,126,16179

Formula: $\quad \mathrm{C}_{46} \mathrm{H}_{46} \mathrm{~B}_{2} \mathrm{~N}_{2} \mathrm{O}_{4}, 0.25\left(\mathrm{C}_{1} \mathrm{H}_{2} \mathrm{Cl}_{2}\right)$

Compound Name: $\quad(\mathrm{R}, \mathrm{R})-(-)-9,10-\mathrm{bis}(\mathrm{N}-((2-($ Dihydroxyboryl) phenyl)methyl)-N-(1phenylethyl)aminomethyl)anthracene dichloromethane solvate

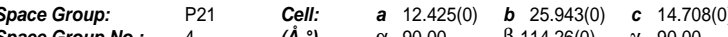
$\quad(A)=\quad \beta 114.26(0) \quad \gamma 90.00$

R-Factor (\%): $\quad 6.27 \quad$ Temperature(K): $150 \quad$ Density $\left(\mathrm{g} / \mathrm{cm}^{3}\right): 1.128$
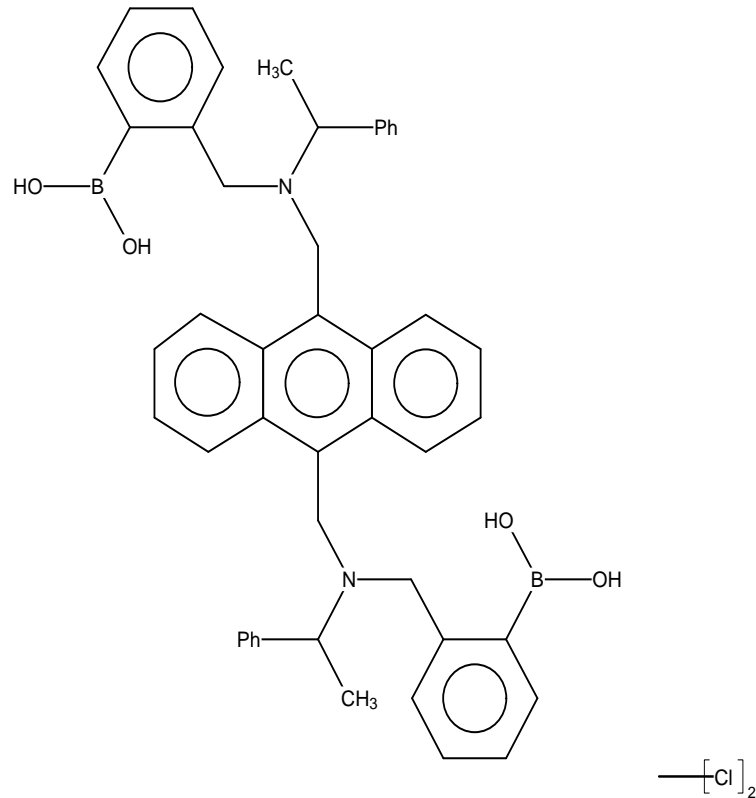

FEJGIL

\begin{tabular}{|c|c|c|c|c|c|c|}
\hline Reference: & \multicolumn{6}{|c|}{$\begin{array}{l}\text { P.Rodriguez-Cuamatzi, O.I.Arillo-Flores, } \\
\text { M.I.Bernal-Uruchurtu, H.Hopfl (2005) Cryst.Growth Des. ,5,167 }\end{array}$} \\
\hline Formula: & \multicolumn{6}{|c|}{$\mathrm{C}_{8} \mathrm{H}_{5} \mathrm{~N}_{1} \mathrm{O}_{6}, \mathrm{C}_{6} \mathrm{H}_{7} \mathrm{~B}_{1} \mathrm{O}_{2}, 2\left(\mathrm{H}_{2} \mathrm{O}_{1}\right)$} \\
\hline Compound Name: & \multicolumn{6}{|c|}{ 5-nitroisophthalic acid phenyl boronic acid dihydrate } \\
\hline $\begin{array}{l}\text { Space Group: } \\
\text { Space Group No.: }\end{array}$ & $\begin{array}{l}P-1 \\
2\end{array}$ & $\begin{array}{l}\text { Cell: } \\
(\dot{A}, \circ)\end{array}$ & $\begin{array}{ll}a & 8.498(1) \\
\alpha & 68.79(0)\end{array}$ & $\begin{array}{ll}\boldsymbol{b} & 9.810(1) \\
\beta & 69.65(0)\end{array}$ & & $\begin{array}{l}11.594(1) \\
83.61(0)\end{array}$ \\
\hline 8-Factor (\%): & 7.04 & Temp & ure(K): 293 & Density $(\mathrm{g} / \mathrm{cm}$ & 3): & 1.451 \\
\hline
\end{tabular}

HOOC

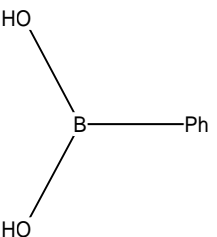

$\mathrm{H}_{2} \mathrm{O}$ 


\section{Search: search2 (Thu Apr 05 09:21:46 2007): Hits 29-32}

FEJGOR

Reference:

P.Rodriguez-Cuamatzi, O.।Arillo-Flores,

M.I.Bernal-Uruchurtu, H.Hopfl (2005) Cryst.Growth Des. 5,167

Formula:

$\mathrm{C}_{16} \mathrm{H}_{36} \mathrm{~N}_{1}{ }^{1+}, \mathrm{C}_{8} \mathrm{H}_{4} \mathrm{~N}_{1} \mathrm{O}_{6}{ }^{1-}, 0.5\left(\mathrm{C}_{6} \mathrm{H}_{8} \mathrm{~B}_{2} \mathrm{O}_{4}\right)$

Compound Name: tetrabutylammonium 5-nitrohydrogenisophthalate 1,4phenylenediboronic acid

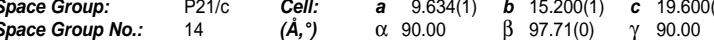

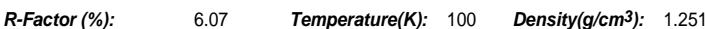
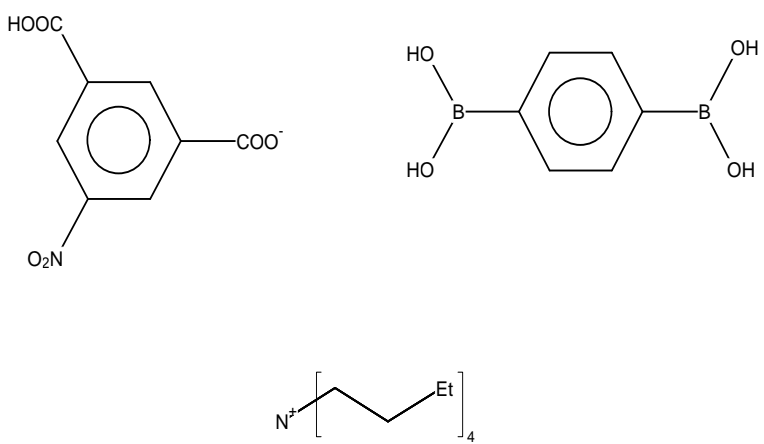

FEJHAE

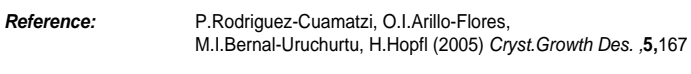

Formula: $\mathrm{C}_{7} \mathrm{H}_{5} \mathrm{O}_{2}{ }^{1-}, \mathrm{C}_{6} \mathrm{H}_{7} \mathrm{~B}_{1} \mathrm{O}_{2}, \mathrm{C}_{16} \mathrm{H}_{36} \mathrm{~N}_{1}{ }^{1+}$

Compound Name: phenylboronic acid tetra-n-butylammonium benzoate

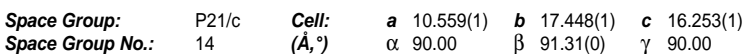

R-Factor (\%): $\quad 9.13 \quad$ Temperature(K): $293 \quad$ Density $\left(\mathrm{g} / \mathrm{cm}^{3}\right): \quad 1.077$

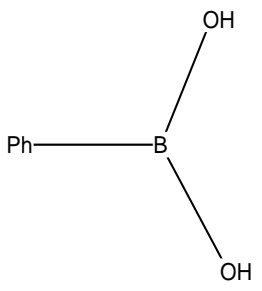

$\mathrm{OOC}$

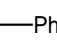

FEJGUX

Reference: P.Rodriguez-Cuamatzi, O.I.Arillo-Flores,

M.I.Bernal-Uruchurtu, H.Hopfl (2005) Cryst.Growth Des. ,5,167

Formula:

$\mathrm{C}_{8} \mathrm{H}_{5} \mathrm{~N}_{1} \mathrm{O}_{6}, \mathrm{C}_{6} \mathrm{H}_{7} \mathrm{~B}_{1} \mathrm{O}_{2}, \mathrm{H}_{2} \mathrm{O}_{1}$

Compound Name: 5-nitrohydrogenisophthalate phenyl boronic acid monohydrate

Space Group: $\quad$ P21/n Cell: $\quad \begin{array}{llllll}\text { a } & 8.640(1) & \boldsymbol{b} & 21.251(3) & \text { c } & 9.681(1)\end{array}$

$\begin{array}{lllllll}\text { Space Group No.: } \quad 14 & \left(\dot{A},{ }^{\circ}\right) & \alpha & 90.00 & \beta 112.11(0) & \gamma & 90.00\end{array}$

R-Factor (\%): $\quad 6.66 \quad$ Temperature(K): $293 \quad$ Density $\left(\mathrm{g} / \mathrm{cm}^{3}\right): 1.416$
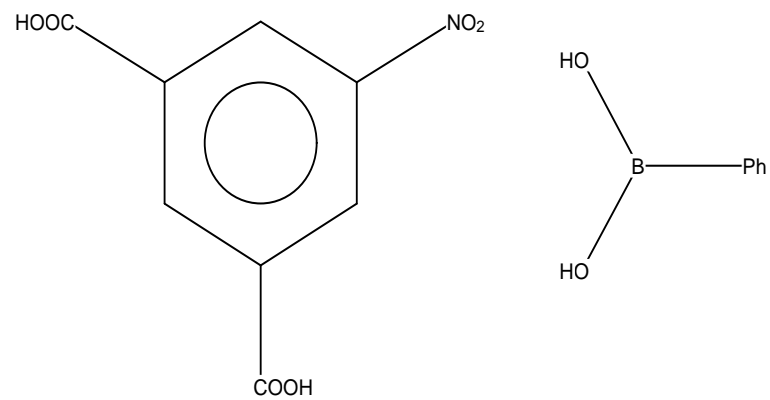

$\mathrm{H}_{2} \mathrm{O}$

\section{FEJHEI}

$\begin{array}{ll}\text { Reference: } & \text { P.Rodriguez-Cuamatzi, O.I.Arillo-Flores, } \\ \text { M.I.Bernal-Uruchurtu, H.Hopfl (2005) Cryst.Growth Des. ,5,167 }\end{array}$

Formula: $\quad 2\left(\mathrm{C}_{16} \mathrm{H}_{36} \mathrm{~N}_{1}{ }^{1+}\right), \mathrm{C}_{6} \mathrm{H}_{8} \mathrm{~B}_{2} \mathrm{O}_{4}, \mathrm{C}_{8} \mathrm{H}_{4} \mathrm{O}_{4}{ }^{2-}$

Compound Name: bis(tetra-n-butylammonium) 1,4-phenylenediboronic acid terephthalate

Space Group: $\quad$ P21/c $\quad$ Cell: $\quad$ a $9.753(1) \quad$ b $15.912(0) \quad c \quad 16.814(2)$

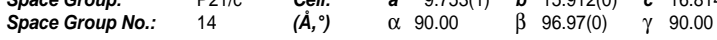

R-Factor (\%): $\quad 12.70 \quad$ Temperature(K): $293 \quad$ Density $\left(\mathrm{g} / \mathrm{cm}^{3}\right): 1.045$
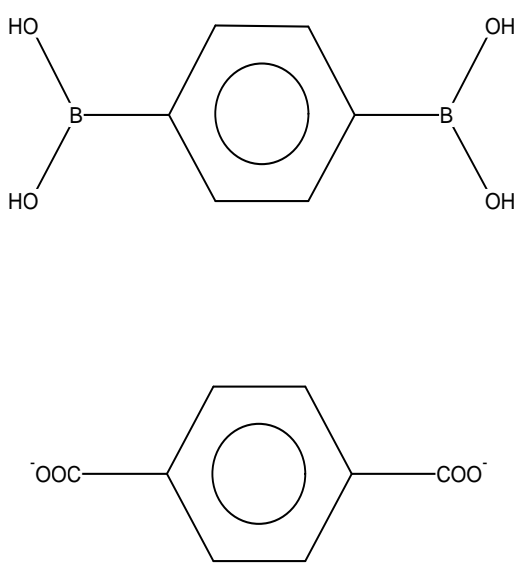
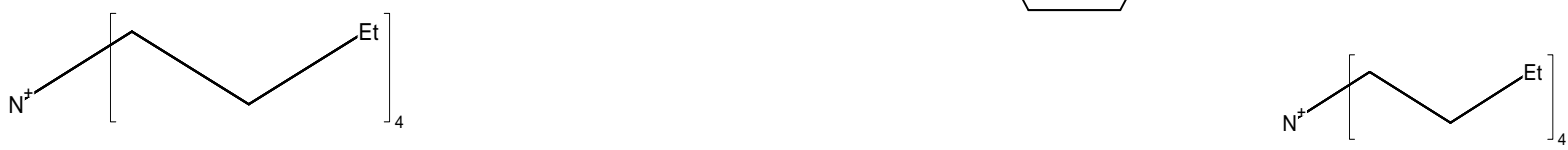


\section{Search: search2 (Thu Apr 05 09:21:46 2007): Hits 33-36}

FETDAK

Reference:

C.B.Aakeroy, J.Desper, B.Levin (2005) CrystEngComm ,7, 102

Formula:

$\mathrm{C}_{4} \mathrm{H}_{7} \mathrm{~N}_{2}{ }^{1+}, \mathrm{C}_{11} \mathrm{H}_{12} \mathrm{~B}_{1} \mathrm{~N}_{2} \mathrm{O}_{4}{ }^{1-}, \mathrm{H}_{2} \mathrm{O}$

Compound Name: 2-Methylimidazolium (4-carboxybenzene)(2-methylimidazolyl)boronate monohydrate

Space Group: $\quad$ P-1

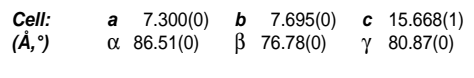

R-Factor (\%): $\quad 4.45$

Temperature(K): $203 \quad$ Density $\left(\mathrm{g} / \mathrm{cm}^{3}\right): 1.367$
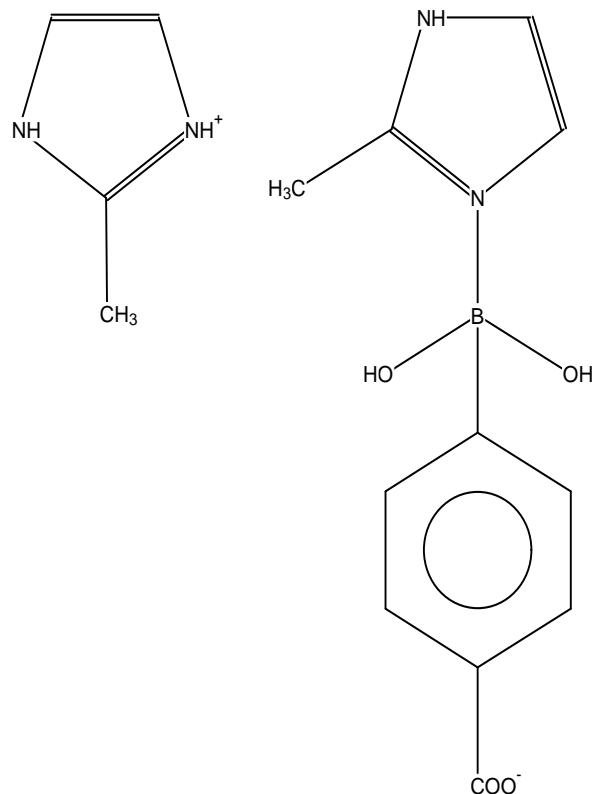

Space Group: Space Group No.:

R-Factor (\%):

FETDEO

Reference:

C.B.Aakeroy, J.Desper, B.Levin (2005) CrystEngComm ,7,

Formula:

$3\left(\mathrm{C}_{7} \mathrm{H}_{11} \mathrm{~N}_{2}{ }^{1+}\right), 2\left(\mathrm{C}_{7} \mathrm{H}_{10} \mathrm{~N}_{2}\right), 3\left(\mathrm{C}_{7} \mathrm{H}_{6} \mathrm{~B}_{1} \mathrm{O}_{4}{ }^{1-}\right), 3\left(\mathrm{H}_{2} \mathrm{O}_{1}\right)$

Compound Name:

ris(4-(Dimethylamino)pyridinium) bis(4-(dimethylamino)pyridine) tris(4carboxybenzeneboronate) trihydrate

\begin{tabular}{llllllll} 
P21/c & Cell: & $\boldsymbol{a}$ & $17.866(3)$ & $\boldsymbol{b}$ & $17.879(3)$ & $\boldsymbol{c}$ & $19.370(3)$ \\
14 & $(\dot{\boldsymbol{A}}, \circ)$ & $\alpha$ & 90.00 & $\beta$ & $107.96(0)$ & $\gamma$ & 90.00 \\
6.41 & \multicolumn{1}{l}{ Temperature(K): 203} & Density $\left(\mathbf{g} / \mathrm{cm}^{3}\right):$ & 1.312
\end{tabular}

FETDIS

Reference: $\quad$ C.B.Aakeroy, J.Desper, B.Levin (2005) CrystEngComm ,7,

Formula:

$\mathrm{C}_{7} \mathrm{H}_{9} \mathrm{~N}_{2} \mathrm{O}_{1}{ }^{1+}, \mathrm{C}_{7} \mathrm{H}_{6} \mathrm{~B}_{1} \mathrm{O}_{4}{ }^{1-}, 2\left(\mathrm{H}_{2} \mathrm{O}_{1}\right)$

Compound Name: 4-Acetylpyridine oxime 4-carboxybenzeneboronate dihydrate

$\begin{array}{lllllllll}\text { Space Group: } & \mathrm{P} 1 & \text { Cell: } & \boldsymbol{a} & 5.855(0) & \boldsymbol{b} & 8.572(0) & \boldsymbol{c} & 8.688(0) \\ \text { Space Group No.: } & 1 & \left(\boldsymbol{A},{ }^{\circ}\right) & \alpha & 69.04(0) & \beta & 89.41(0) & \gamma & 77.33(0)\end{array}$

R-Factor (\%): $\quad 4.55 \quad$ Temperature(K): $203 \quad$ Density $\left(\mathrm{g} / \mathrm{cm}^{3}\right): 1.417$
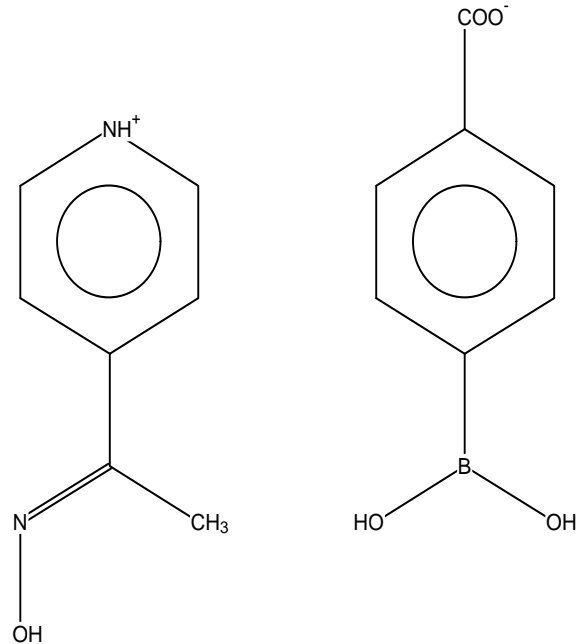

$\mathrm{H}_{2} \mathrm{O}$

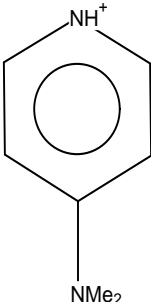

$\mathrm{H}_{2} \mathrm{O}$

FETZUA

Reference:

N. P Bhuvanesh, JH Reibenspies (2005)
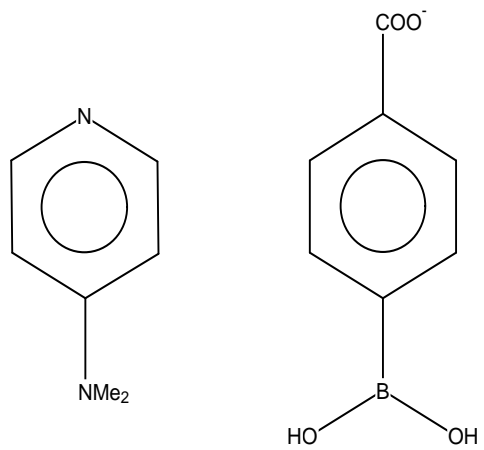

Formula: $\mathrm{C}_{6} \mathrm{H}_{6} \mathrm{~B}_{1} \mathrm{Br}_{1} \mathrm{O}_{2}, 0.04\left(\mathrm{C}_{2} \mathrm{H}_{6} \mathrm{O}_{1}\right)$

Compound Name: 4-Bromophenylboronic acid ethanol solvate

Space Group: $\quad$ C2/m Cell: $\quad$ a $29.186(1) \quad b \quad 9.825(0) \quad$ c $12.029(0)$ Space Group No.: $\quad 12 \quad\left(\dot{A},{ }^{\circ}\right) \quad \alpha \quad 90.00 \quad \beta 101.90(0) \quad \gamma \quad 90.00$ R-Factor (\%): $\quad 4.95 \quad$ Temperature(K): $110 \quad$ Density $\left(\mathrm{g} / \mathrm{cm}^{3}\right): 1.595$

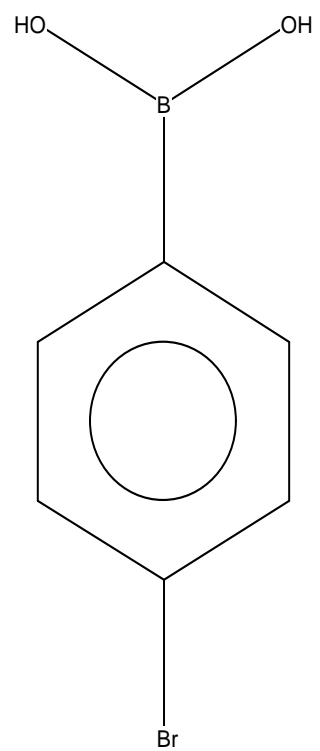




\section{Search: search2 (Thu Apr 05 09:21:46 2007): Hits 37-40}

HUYRAU

Reference:

J.M.Stoddard, K.J.Shea (2003) Organometallics ,22,1124

Formula:

$\mathrm{C}_{1} \mathrm{H}_{5} \mathrm{~B}_{1} \mathrm{O}_{2}$

Compound Name: Methylboronic acid

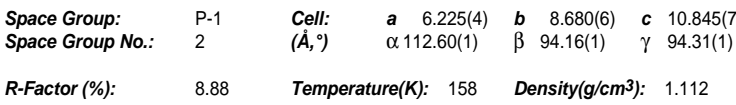

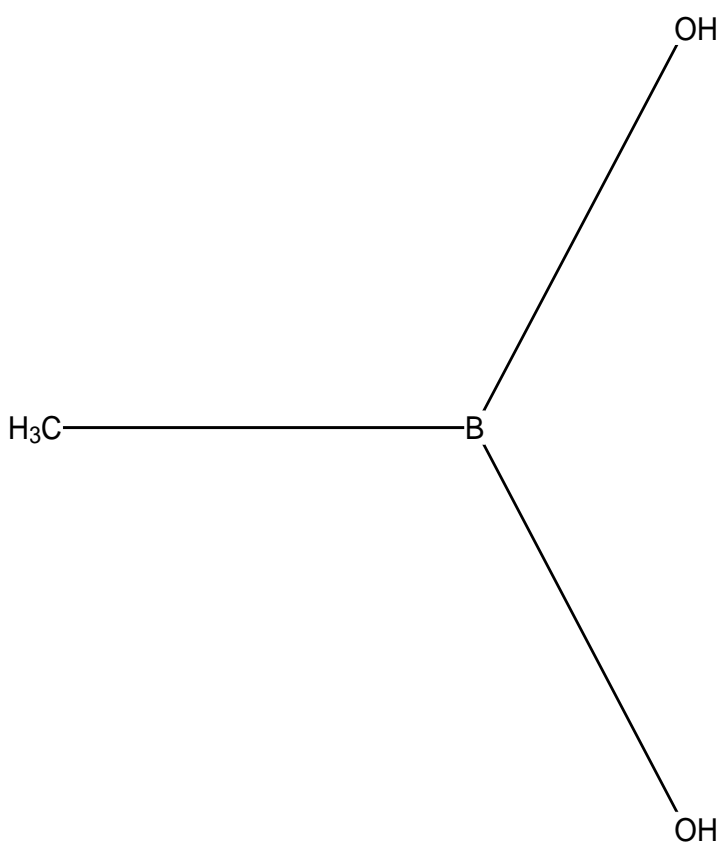

ITEPUS

\begin{tabular}{|c|c|c|c|c|c|c|}
\hline Reference: & \multicolumn{6}{|c|}{$\begin{array}{l}\text { C.Elschenbroich, M.Wolf, J.Pebler, K.Harms (2004) } \\
\text { Organometallics ,23,454 }\end{array}$} \\
\hline Formula: & \multicolumn{6}{|c|}{$\mathrm{C}_{12} \mathrm{H}_{13} \mathrm{~B}_{1} \mathrm{O}_{2} \mathrm{~V}_{1}, \mathrm{C}_{4} \mathrm{H}_{10} \mathrm{O}_{1}$} \\
\hline Compound Name: & \multicolumn{6}{|c|}{$\begin{array}{l}\text { ( } \eta^{7} \text {-Cycloheptatrienyl)-( } \eta^{5} \text {-cyclopentadienyl boronic acid)-vanadium } \\
\text { diethyl ether solvate }\end{array}$} \\
\hline Synonym: & \multicolumn{6}{|c|}{ (5)Trovacenyl boronic acid diethyl ether solvate } \\
\hline $\begin{array}{l}\text { Space Group: } \\
\text { Space Group No.: }\end{array}$ & $\begin{array}{l}\text { Pca21 } \\
29\end{array}$ & $\begin{array}{l}\text { Cell: } \\
\left(\dot{A},{ }^{\circ}\right)\end{array}$ & $\begin{array}{ll}\text { a } & 11.996(1) \\
\alpha & 90.00\end{array}$ & $\begin{array}{ll}\boldsymbol{b} & 13.333(1) \\
\beta & 90.00\end{array}$ & $\begin{array}{l}c \\
\gamma\end{array}$ & $\begin{array}{l}10.096(0) \\
90.00\end{array}$ \\
\hline R-Factor (\%): & 3.68 & Tempe & Jre(K): 193 & Density $(\mathrm{g} / \mathrm{cm}$ & 3): & 1.337 \\
\hline
\end{tabular}

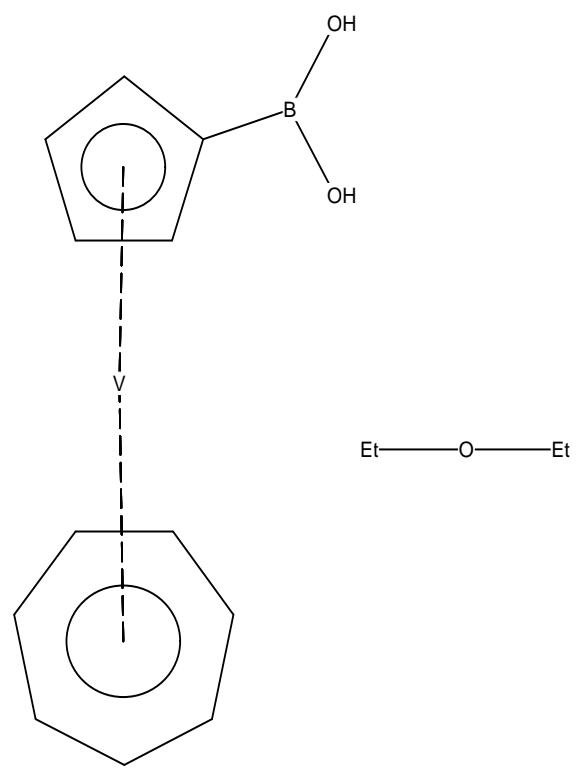

IKIFAJ

Reference: $\quad$ K.Ejsmont, J.Zaleski, A.Sporzynski, M.Lewandowski (2003) Acta Crystallogr.,Sect.E:Struct.Rep.Online ,59,01324

Formula: $\mathrm{C}_{5} \mathrm{H}_{5} \mathrm{~B}_{1} \mathrm{O}_{4}$

Compound Name:

5-Formyl-2-furanboronic acid

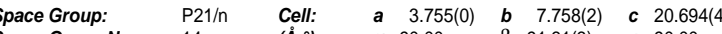

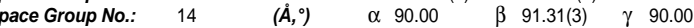
R-Factor (\%): $\quad 4.74 \quad$ Temperature(K): $100 \quad$ Density(g/cm 3 ): 1.542

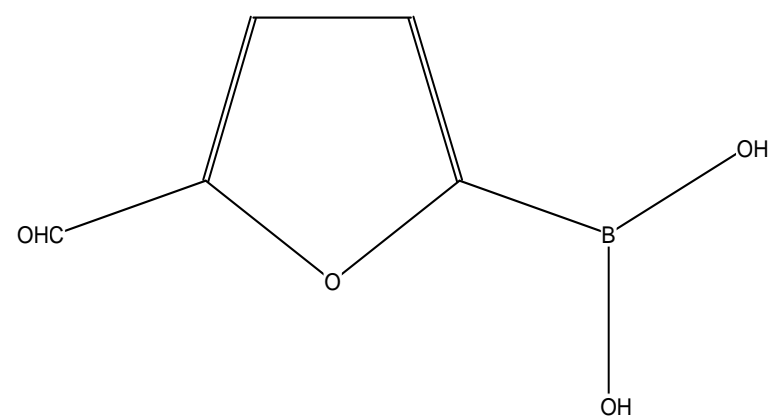

ITEQAZ

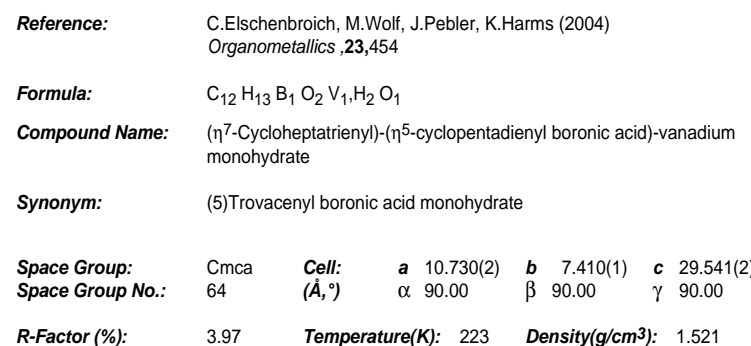

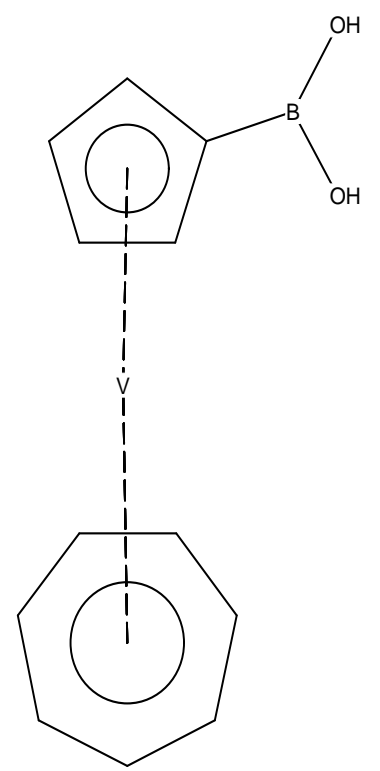




\section{Search: search2 (Thu Apr 05 09:21:46 2007): Hits 41-44}

ITIQIL

Reference:

V.R.Pedireddi, N.S.Lekshmi (2004) Tetrahedron Lett. ,45, 1903

Formula:

$\mathrm{C}_{6} \mathrm{H}_{7} \mathrm{~B}_{1} \mathrm{O}_{2}, 2\left(\mathrm{C}_{10} \mathrm{H}_{8} \mathrm{~N}_{2}\right)$

Compound Name: Phenylboronic acid bis(4,4'-bipyridine)

Space Group: $\quad$ Fdd2 $\quad$ Cell: $\quad \begin{array}{llllll}\text { a } & 26.519(23) & \boldsymbol{b} & 9.245(8) & \boldsymbol{c} & 17.612(15)\end{array}$

Space Group No: $\quad 43 \quad(\dot{A}, 0) \quad \alpha 90.00 \quad \beta 90.00 \quad \gamma 90.00$

R-Factor (\%): $\quad 5.22 \quad$ Temperature(K): $140 \quad$ Density $\left(\mathbf{g} / \mathrm{cm}^{3}\right): 1.336$
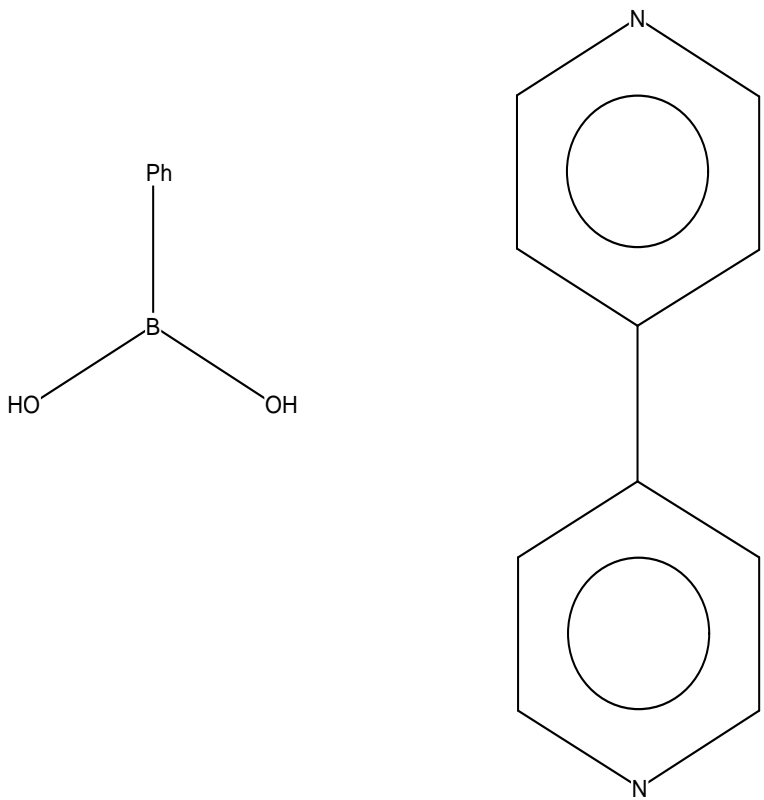

ITIQUX

Reference:

V.R.Pedireddi, N.S.Lekshmi (2004) Tetrahedron Lett. ,45,

Formula:

2 $\left(\mathrm{C}_{7} \mathrm{H}_{9} \mathrm{~B}_{1} \mathrm{O}_{3}\right), \mathrm{C}_{10} \mathrm{H}_{8} \mathrm{~N}_{2}$

Compound Name: $\quad$ bis(4-Methoxyphenylboronic acid) 4,4-bipyridine

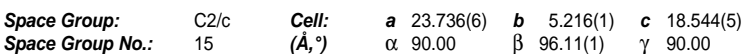

R-Factor (\%): $\quad 4.63 \quad$ Temperature(K): $140 \quad$ Density $\left(\mathrm{g} / \mathrm{cm}^{3}\right): 1.339$
ITIQOR

Reference: V.R.Pedireddi, N.S.Lekshmi (2004) Tetrahedron Lett. ,45, 1903

Formula:

$\mathrm{C}_{6} \mathrm{H}_{7} \mathrm{~B}_{1} \mathrm{O}_{2}, \mathrm{C}_{12} \mathrm{H}_{10} \mathrm{~N}_{2}, \mathrm{H}_{2} \mathrm{O}_{1}$

Compound Name: Phenylboronic acid 1,2-bis(4-pyridyl)ethene monohydrate

Space Group: $\quad$ P21/c Cell: $\quad$ a $6.860(2) \quad b \quad 19.092(5) \quad c \quad 12.829(3)$

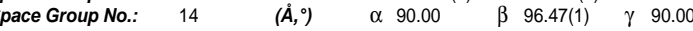

R-Factor (\%): $\quad 3.97 \quad$ Temperature(K): $140 \quad$ Density(g/cm 3 ): 1.282
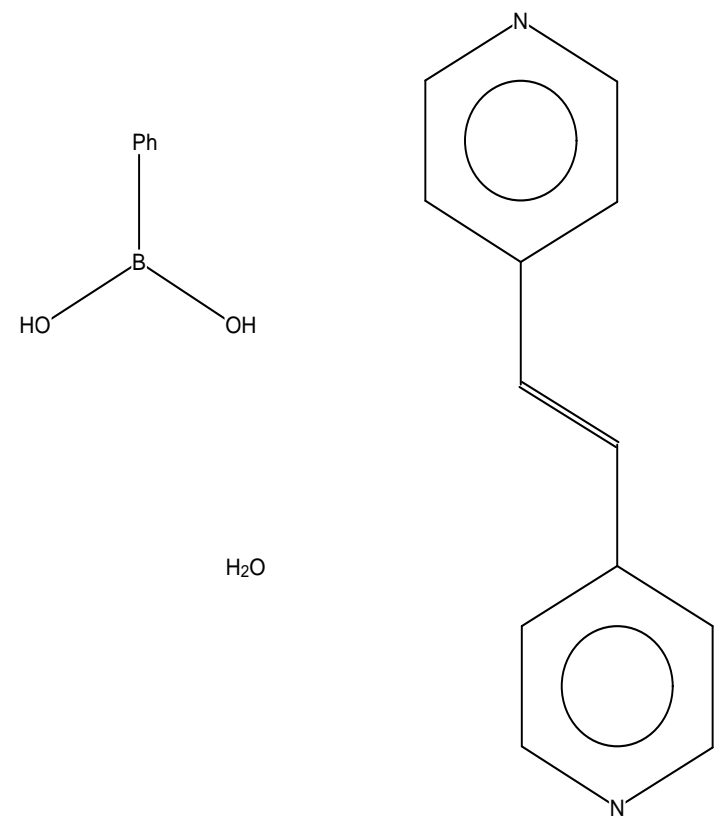

ITIRAE

Reference: $\quad$ V.R.Pedireddi, N.S.Lekshmi (2004) Tetrahedron Lett. 45, 1903

Formula: $\quad \mathrm{C}_{7} \mathrm{H}_{9} \mathrm{~B}_{1} \mathrm{O}_{3}$

Compound Name: 4-Methoxyphenylboronic acid

Space Group: $\quad$ P21/n $\quad$ Cell: $\quad$ a $11.259(3) \quad b \quad 5.064(1) \quad$ c $13.878(3)$ Space Group No.: $\quad 14 \quad(\dot{A}, \circ) \quad \alpha \quad 90.00 \quad \beta 111.04(1) \quad \gamma \quad 90.00$ R-Factor (\%): $\quad 3.41 \quad$ Temperature(K): $140 \quad$ Density $\left(\mathrm{g} / \mathrm{cm}^{3}\right): 1.367$
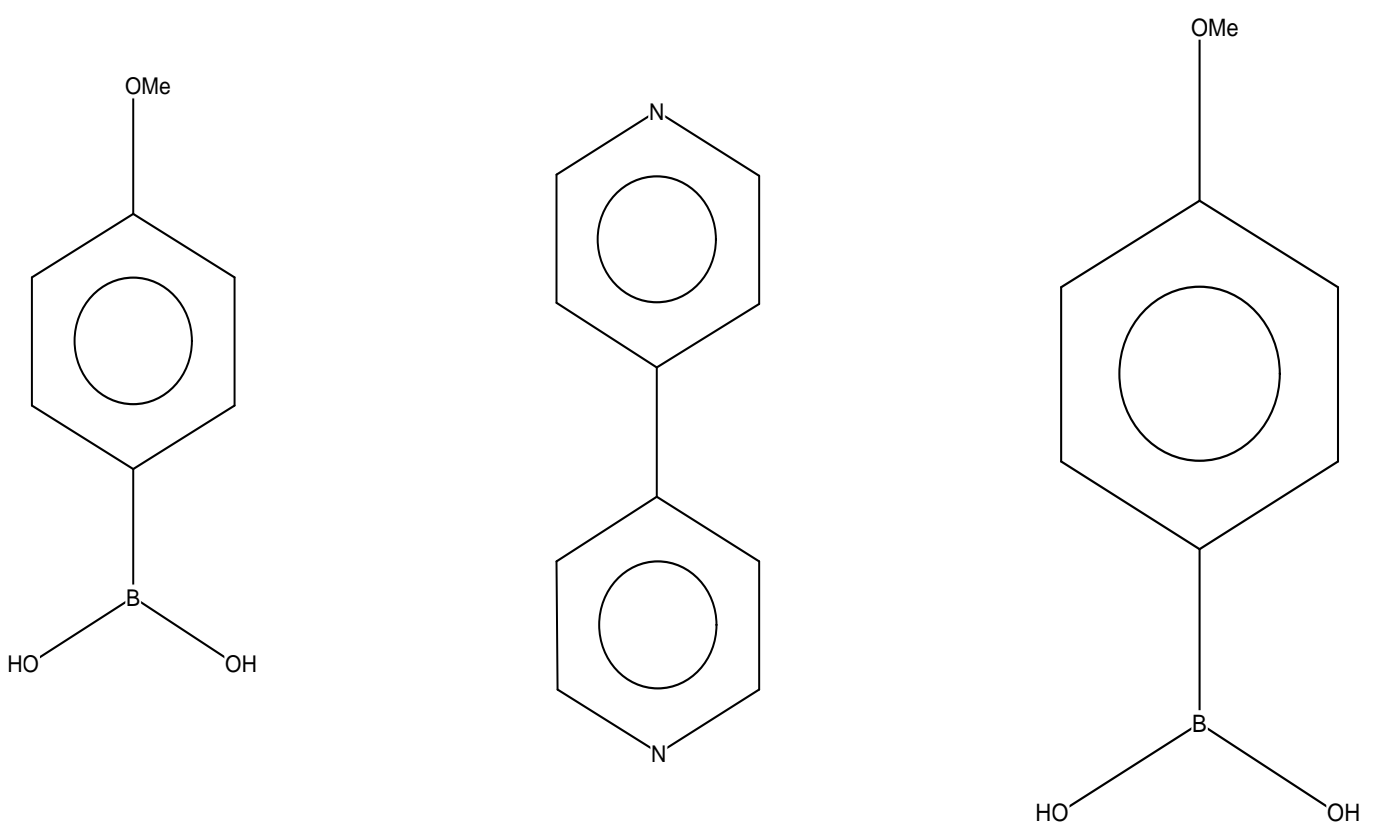


\section{Search: search2 (Thu Apr 05 09:21:46 2007): Hits 45-48}

IYAXAH

Reference:

P.Rodriguez-Cuamatzi, G.Vargas-Diaz, T.Maris,

J.D.Wuest, H.Hopfl (2004) Acta Crystallogr.,Sect.E:Struct.Rep.Online, 60,01316

Formula:

$\mathrm{C}_{6} \mathrm{H}_{8} \mathrm{~B}_{2} \mathrm{O}_{4}$

Compound Name:

1,4-Phenylenediboronic acid

$\begin{array}{ll}\text { Space Group: } & \text { P } \\ \text { Space Group No.: } & 2\end{array}$

R-Factor (\%): $\quad 5.00$

\begin{tabular}{|c|c|c|c|}
\hline $\begin{array}{l}\text { Cell: } \\
(\dot{A}, \circ)\end{array}$ & $\begin{array}{l}a \quad 4.989(3) \\
\alpha 104.43(1)\end{array}$ & $\begin{array}{lr}\boldsymbol{b} & 5.305(3) \\
\beta & 97.89(0)\end{array}$ & $\begin{array}{cc}c & 7.368(4) \\
\gamma & 93.80(1)\end{array}$ \\
\hline & K) & ensity, & 1.4 \\
\hline
\end{tabular}

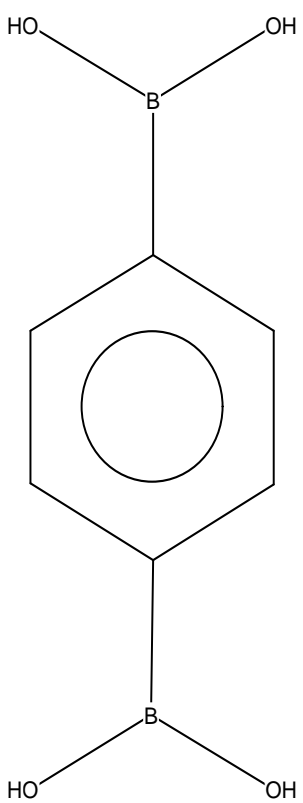

KECJIM

Reference:

P.Rogowska, M.K.Cyranski, A.Sporzynski, A.Ciesielsk (2006) Tetrahedron Lett. 47,1389

Formula:

$\mathrm{C}_{8} \mathrm{H}_{11} \mathrm{~B}_{1} \mathrm{O}_{3}, \mathrm{C}_{5} \mathrm{H}_{9} \mathrm{~N}_{1} \mathrm{O}_{2}$

Compound Name: L-Proline 4-ethoxyphenylboronic acid

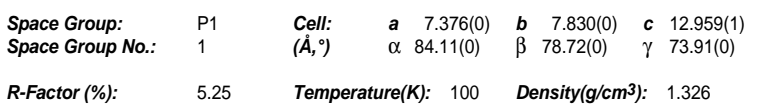

R-Factor (\%): $\quad 5.25 \quad$ Temperature(K): $100 \quad$ Density $\left(\mathrm{g} / \mathrm{cm}^{3}\right)$ : 1.326

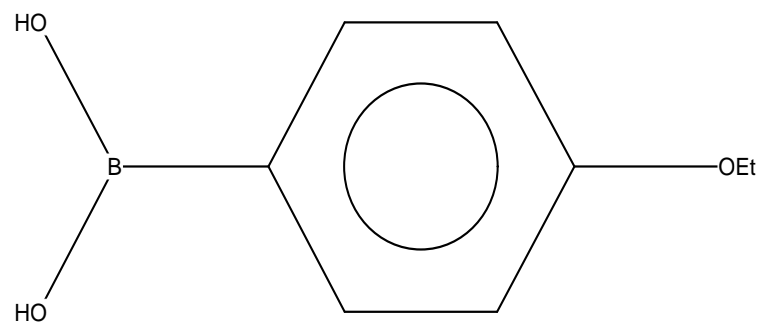

KAJPIU

Reference:

S.S.Al-Juaid, C.Eaborn, M.N.A.El-Kheli, P.B.Hitchcock, P.D.Lickiss, M.E.Molla, J.D.Smith, J.A.Zora (1989) J.Chem Soc Dalton Trans. 447

Formula:

$\mathrm{C}_{10} \mathrm{H}_{29} \mathrm{~B}_{1} \mathrm{O}_{2} \mathrm{Si}_{3}$

Compound Name:

Dihydroxy-(tris(trimethylsilyl)methyl)borane

Space Group: $\quad$ Pna21 Cell: $\quad$ a 15.675(2) $\quad$ b 16.121(2) $\quad$ c 14.662(2) $\begin{array}{lllllll}\text { Space Group No.: } 33 & \left(\dot{A},{ }^{\circ}\right) & \alpha & 90.00 & \beta & 90.00 & \gamma 90.00\end{array}$

R-Factor (\%): $\quad 16.30 \quad$ Temperature(K): $295 \quad$ Density $\left(\mathrm{g} / \mathrm{cm}^{3}\right): 0.991$

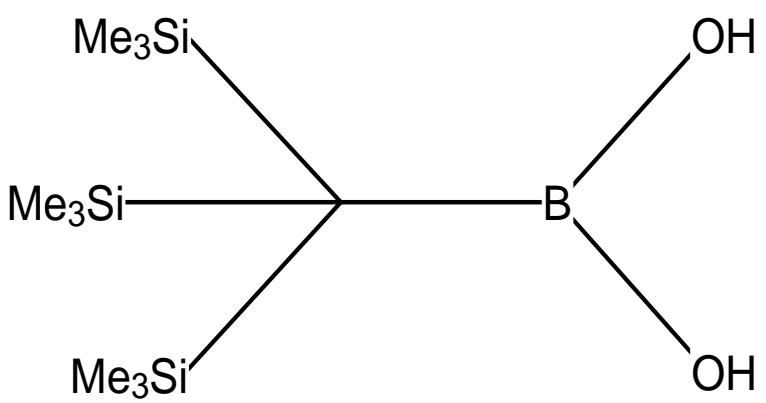

KECJOS

Reference: P.Rogowska, M.K.Cyranski, A.Sporzynski, A.Ciesielski

Formula: $\quad \mathrm{C}_{8} \mathrm{H}_{11} \mathrm{~B}_{1} \mathrm{O}_{3}, \mathrm{C}_{5} \mathrm{H}_{11} \mathrm{~N}_{1} \mathrm{O}_{2}$

Compound Name: Betaine 4-ethoxyphenylboronic acid

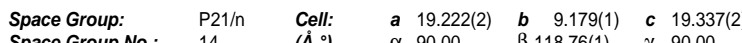
Space Group No.: $\quad 14 \quad(\dot{A}, \circ) \quad \alpha \quad 90.00 \quad \beta 118.76(1) \quad \gamma \quad 90.00$

R-Factor (\%): $\quad 3.86 \quad$ Temperature(K): $100 \quad$ Density $\left(\mathrm{g} / \mathrm{cm}^{3}\right): \quad 1.258$
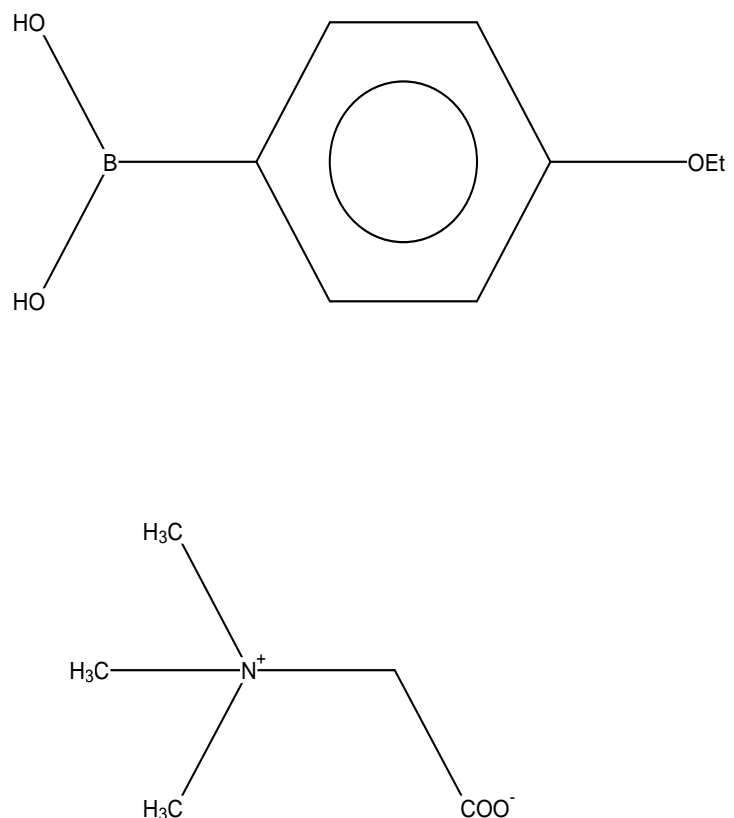


\section{Search: search2 (Thu Apr 05 09:21:46 2007): Hits 49-52}

LABCUM

Reference:

S.Soundararajan, EN. Duesler, J.H.Hageman (1993) Acta Crystallogr.,Sect.C.Cryst.Struct.Commun. ,49,690

Formula: $\mathrm{C}_{7} \mathrm{H}_{6} \mathrm{~B}_{1} \mathrm{~N}_{1} \mathrm{O}_{6}$

Compound Name:

4-Carboxy-2-nitrobenzeneboronic acid

Space Group: Space Group No.

P21/

$14 \quad(A, \%)$

cell: $\quad \begin{aligned} & a \\ & 10.542(2)\end{aligned}$

R-Factor (\%):

5.30 Temperature(K): 295 Density $\left(\mathrm{g} / \mathrm{cm}^{3}\right): 1.650$

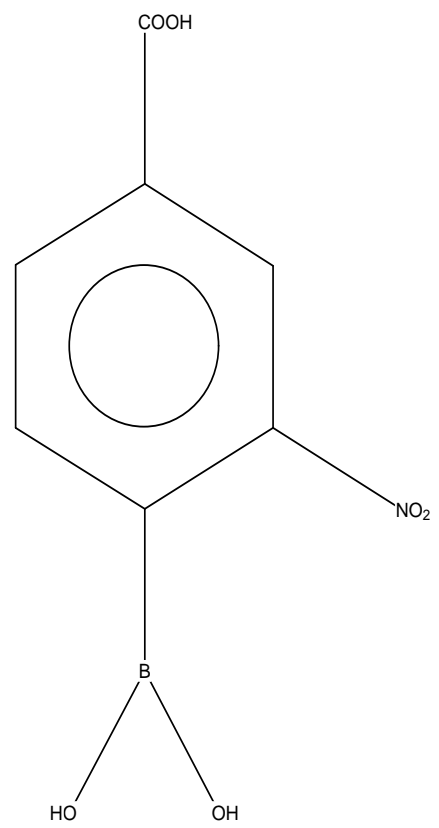

LEFYAX

Reference:

N.SeethaLekshmi, V.R.Pedireddi (2006) Inorg.Chem. ,45,

Formula:

$\mathrm{H}_{12} \mathrm{Mn}_{1} \mathrm{O}_{6}{ }^{2+}, 2\left(\mathrm{C}_{7} \mathrm{H}_{6} \mathrm{~B}_{1} \mathrm{O}_{4}{ }^{1-}\right), 4\left(\mathrm{H}_{2} \mathrm{O}_{1}\right)$

Compound Name: hexa-aqua-manganese(ii) bis(4-carboxylatophenylboronic acid) tetrahydrate

Space Group:

Space Group No.:

P-1 Cell: $\quad \begin{array}{llllll}a & 6.862(2) & b & 9.705(3) & c & 9.806(3)\end{array}$

R-Factor (\%):
C

3.40

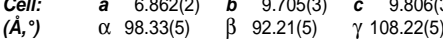

Temperature(K): $133 \quad$ Density $\left(\mathbf{g} / \mathrm{cm}^{3}\right): 1.535$

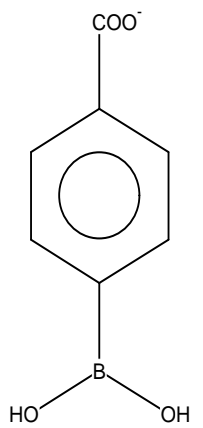

LEFXUQ

Reference: N.SeethaLekshmi, V.R.Pedireddi (2006) Inorg.Chem. ,45, 2400

Formula:

$\mathrm{H}_{12} \mathrm{Co}_{1} \mathrm{O}_{6}{ }^{2+}, 2\left(\mathrm{C}_{7} \mathrm{H}_{6} \mathrm{~B}_{1} \mathrm{O}_{4}{ }^{1-}\right), 4\left(\mathrm{H}_{2} \mathrm{O}_{1}\right)$

Compound Name: hexa-aqua-cobalt(ii) bis(4-carboxylatophenylboronic acid) tetrahydrate

$\begin{array}{lllllllll}\text { Space Group: } & \text { P-1 } & \text { Cell: } & \boldsymbol{a} & 6.776(3) & \boldsymbol{b} & 9.592(4) & \boldsymbol{c} & 9.786(5)\end{array}$ $\begin{array}{lllllll}\text { Space Group No.: } \quad 2 & \left(\dot{A},{ }^{\circ}\right) & \alpha & 98.19(7) & \beta & 91.66(8) & \gamma 108.35(7)\end{array}$

R-Factor (\%): $\quad 4.14 \quad$ Temperature(K): $133 \quad$ Density $\left(\mathbf{g} / \mathrm{cm}^{3}\right): 1.586$
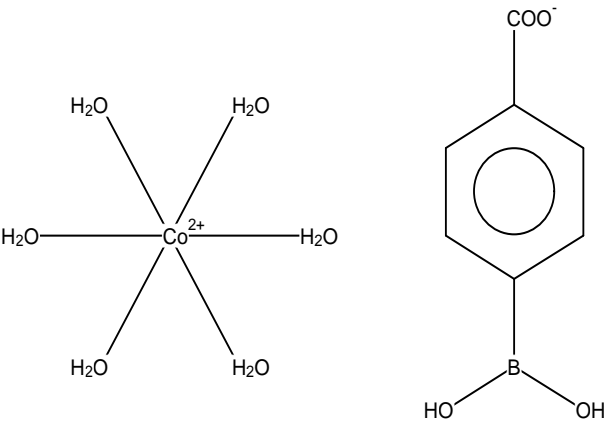

$\mathrm{H}_{2} \mathrm{O}$

\section{LEFYEB}

Reference: N.SeethaLekshmi, V.R.Pedireddi (2006) Inorg.Chem. ,45,

Formula:

$\mathrm{H}_{12} \mathrm{Ni}_{1} \mathrm{O}_{6}{ }^{2+}, 2\left(\mathrm{C}_{7} \mathrm{H}_{6} \mathrm{~B}_{1} \mathrm{O}_{4}{ }^{1-}\right), 4\left(\mathrm{H}_{2} \mathrm{O}_{1}\right)$

Compound Name: hexa-aqua-nickel(ii) bis(4-carboxylatophenylboronic acid) tetrahydrate

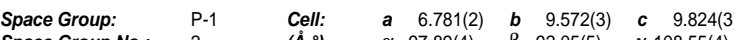

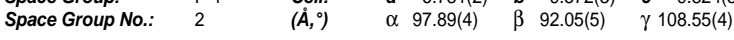

R-Factor (\%): $\quad 4.12 \quad$ Temperature(K): $133 \quad$ Density $\left(\mathrm{g} / \mathrm{cm}^{3}\right): \quad 1.583$

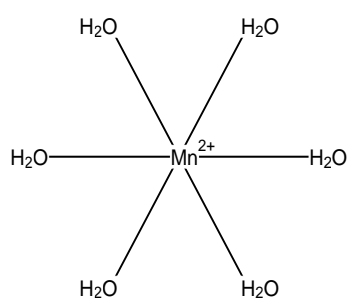

$\mathrm{HO}$

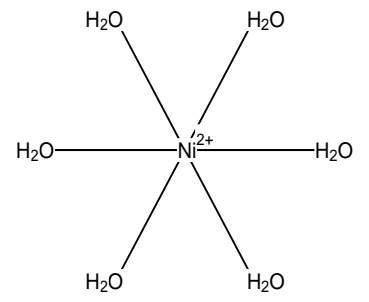<smiles>O=C(O)c1ccc(B(O)O)cc1</smiles> 


\section{Search: search2 (Thu Apr 05 09:21:46 2007): Hits 53-56}

LEFYIF

Reference:

N.SeethaLekshmi, V.R.Pedireddi (2006) Inorg.Chem. ,45, 2400

Formula:

$\left(\mathrm{C}_{48} \mathrm{H}_{56} \mathrm{Co}_{2} \mathrm{~N}_{8} \mathrm{O}_{4}{ }^{4+}\right) n, 4 n\left(\mathrm{C}_{7} \mathrm{H}_{6} \mathrm{~B}_{1} \mathrm{O}_{4}{ }^{1-}\right)$

Compound Name: catena-(tetrakis( $\mu_{2}-1,2-$-bis(4-pyridyl)ethane-N,N')-tetra-aqua-di-cobalt(ii) catena-(tetrakis $\left(\mu_{2}-1,2\right.$-bis(4-pyridyl)ethan $)$,

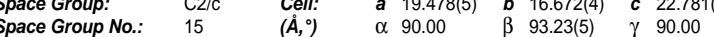

$\begin{array}{llll}\text { R-Factor (\%): } & 9.09 & \text { Temperature(K): } 133 \quad \text { Density }\left(\mathrm{g} / \mathrm{cm}^{3}\right): & 1.427\end{array}$
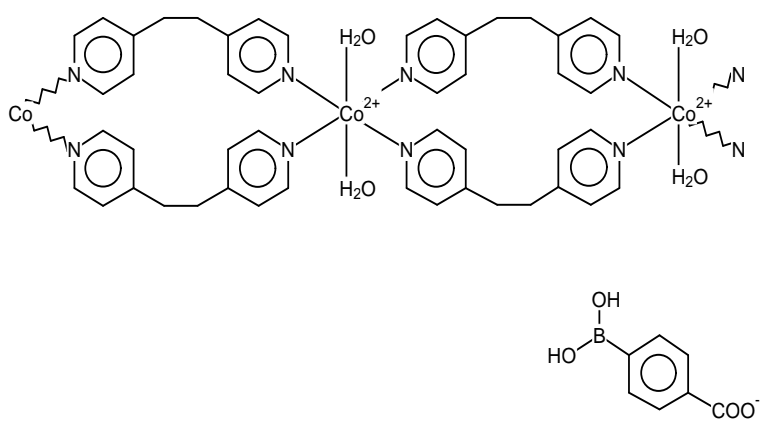

OCAJUY

\begin{tabular}{|c|c|c|c|c|c|c|}
\hline Reference: & \multicolumn{4}{|c|}{$\begin{array}{l}\text { Jem-Mau Lo, Shyh-Ming Chen, Mei-Hsun Chen, } \\
\text { Yu-Jen Chen, Fen-Ling Liao, Tian-Huey Lu (2004) } \\
\text { Acta Crystallogr.,Sect.E.Struct.Rep.Online }, 60,01851\end{array}$} & & \\
\hline Formula: & \multicolumn{6}{|c|}{$\mathrm{C}_{10} \mathrm{H}_{11} \mathrm{~B}_{1} \mathrm{O}_{3}$} \\
\hline Compound Name: & \multicolumn{6}{|c|}{ 3-(4-Dihyroxyborylphenyl)cyclobutanone } \\
\hline $\begin{array}{l}\text { Space Group: } \\
\text { Space Group No.: }\end{array}$ & $\begin{array}{l}\mathrm{P} 21 / \mathrm{C} \\
14\end{array}$ & $\begin{array}{l}\text { Cell: } \\
(\hat{A}, \circ)\end{array}$ & $\begin{array}{ll}\text { a } & 11.465(1) \\
\alpha & 90.00\end{array}$ & $\begin{array}{lr}\boldsymbol{b} & 9.832(0) \\
\beta & 98.55(0)\end{array}$ & & $\begin{array}{l}8.367(0) \\
90.00\end{array}$ \\
\hline R-Factor (\%): & 3.41 & Temp & ure(K): 294 & Density $(\mathrm{g} / \mathrm{cm}$ & 3): & 1.353 \\
\hline
\end{tabular}

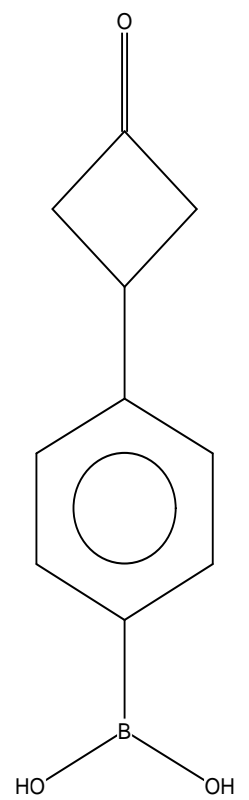

NITFOL

Reference:

R.Baggio, D.Elbaum, Z.F.Kanyo, P.J.Carroll, R.C.Cavalli, D.E.Ash, D.W.Christianson (1997) J.Am.Chem.Soc. 119,8107

Formula: $\mathrm{C}_{6} \mathrm{H}_{15} \mathrm{~B}_{1} \mathrm{~N}_{1} \mathrm{O}_{4}{ }^{1+}, \mathrm{Cl}_{1}{ }^{1}$

Compound Name:

2(S)-Amino-6-boronohexanoic acid hydrochloride

Space Group: Space Group No.:

P212121 Cell: a $\quad$ 9.914(2) b 20.213(2) c c $5.180(0)$

R-Factor (\%):

7.68 Temperature(K): 295 Density(g/cm3): 1.353

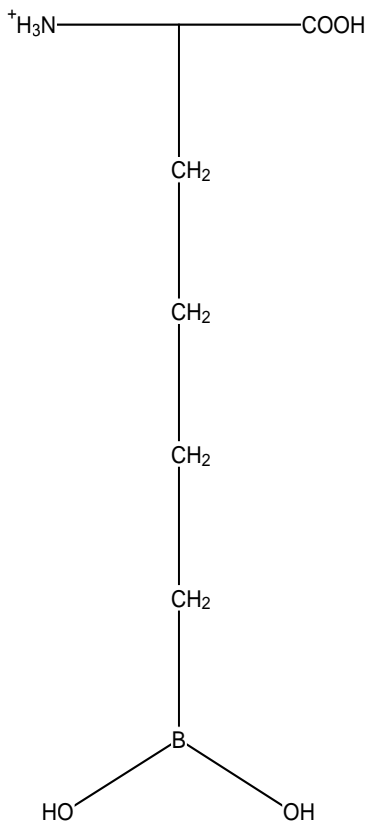

OLIDOC

Reference:

S.Das, V.L.Alexeev, A.C.Sharma, S.J.Geib, S.A.Asher (2003) Tetrahedron Lett. 44,7719

Formula:

$\mathrm{C}_{6} \mathrm{H}_{7} \mathrm{~B}_{1} \mathrm{~F}_{1} \mathrm{~N}_{1} \mathrm{O}_{2}$

Compound Name: 4-Amino-3-fluorophenylboronic acid

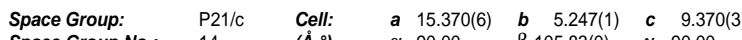
$\begin{array}{lllllll}\text { Space Group No.: } \quad 14 & \left(\dot{\boldsymbol{A}},{ }^{\circ}\right) & \alpha & 90.00 & \beta 105.83(0) & \gamma & 90.00\end{array}$

R-Factor (\%): $\quad 4.94 \quad$ Temperature(K): $150 \quad$ Density $\left(\mathrm{g} / \mathrm{cm}^{3}\right): 1.416$

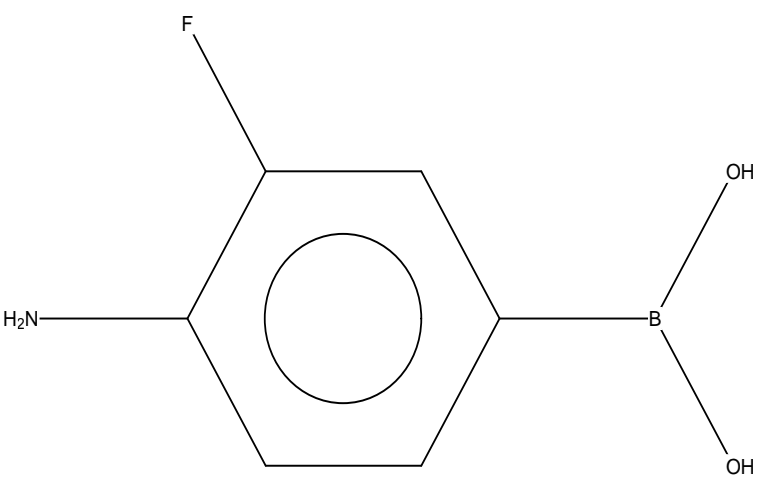




\section{Search: search2 (Thu Apr 05 09:21:46 2007): Hits 57-60}

PAXSUD

Reference:

C.B.Aakeroy, J.Desper, B.Levin, D.J.Salmon (2004) Trans.Am.Crystallogr.Assoc. ,39,123

Formula: $\mathrm{C}_{7} \mathrm{H}_{9} \mathrm{~B}_{1} \mathrm{O}_{2}$

Compound Name: 3-Methylbenzeneboronic acid

\begin{tabular}{|c|c|c|c|c|c|}
\hline oup: & $\begin{array}{l}\mathrm{P} 21 / \mathrm{c} \\
14\end{array}$ & $\begin{array}{l}\text { Cell: } \\
(\dot{A}, \circ)\end{array}$ & $\begin{array}{ll}\text { a } & 15.063(4) \\
\alpha & 90.00\end{array}$ & $\begin{array}{lr}\boldsymbol{b} & 5.671(1) \\
\beta & 94.85(0)\end{array}$ & $\begin{array}{ll}c & 9.101(3) \\
\gamma & 90.00\end{array}$ \\
\hline acto & 3.87 & Temp & ): 203 & $n s i t y\left(g / \mathrm{cm}^{3}\right.$ & 166 \\
\hline
\end{tabular}

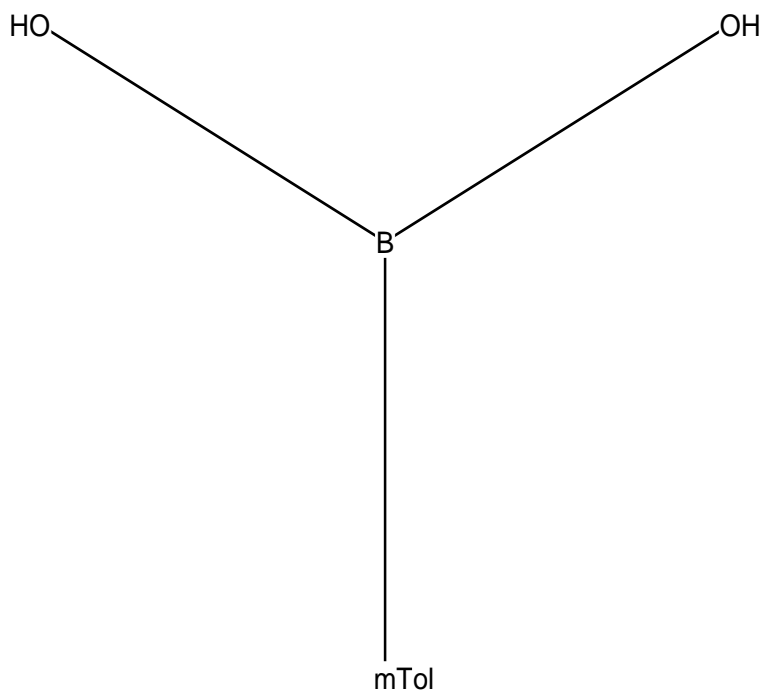

PAXTEO

$\begin{array}{ll}\text { Reference: } & \text { C.B.Aakeroy, J.Desper, B.Levin, D.J.Salmon (2004) } \\ & \text { Trans.Am.Crystallogr.Assoc. 39,123 } \\ \text { Formula: } & \mathrm{C}_{7} \mathrm{H}_{9} \mathrm{~B}_{1} \mathrm{O}_{2}, \mathrm{C}_{5} \mathrm{H}_{7} \mathrm{~N}_{3}\end{array}$

Compound Name: 2-Amino-4-methylpyrimidine 4-methylbenzeneboronic acid $\begin{array}{lllllllll}\text { Space Group: } & \text { P21/c } & \text { Cell: } & \boldsymbol{a} & 9.508(1) & \boldsymbol{b} & 11.939(1) & \boldsymbol{c} & 11.266(1) \\ \text { Space Group No.: } & 14 & \text { (A், }) & \alpha & 90.00 & \beta & 102.72(0) & \gamma & 90.00\end{array}$

R-Factor (\%): $\quad 4.74 \quad$ Temperature(K): $203 \quad$ Density $\left(\mathrm{g} / \mathrm{cm}^{3}\right): 1.305$
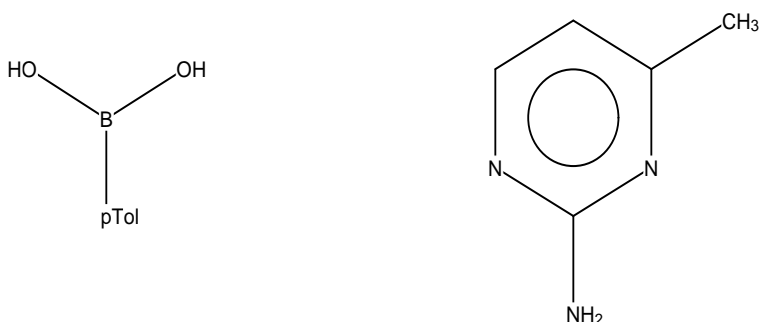

PAXTAK

Reference: $\quad$ C.B.Aakeroy, J.Desper, B.Levin, D.J.Salmon (2004) Trans.Am.Crystallogr.Assoc. ,39,123

Formula

$\mathrm{C}_{7} \mathrm{H}_{9} \mathrm{~B}_{1} \mathrm{O}_{2}, 1.5\left(\mathrm{C}_{10} \mathrm{H}_{8} \mathrm{~N}_{2}\right)$

Compound Name: $\quad$ 3-Methylbenzeneboronic acid sesquikis(4,4'-bipyridine)

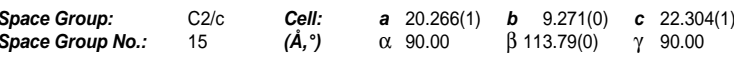

$\begin{array}{lllll}R \text {-Factor (\%): } \quad 5.14 \quad \text { Temperature(K): } & 163 \quad \text { Density }\left(\mathrm{g} / \mathrm{cm}^{3}\right): & 1.283\end{array}$
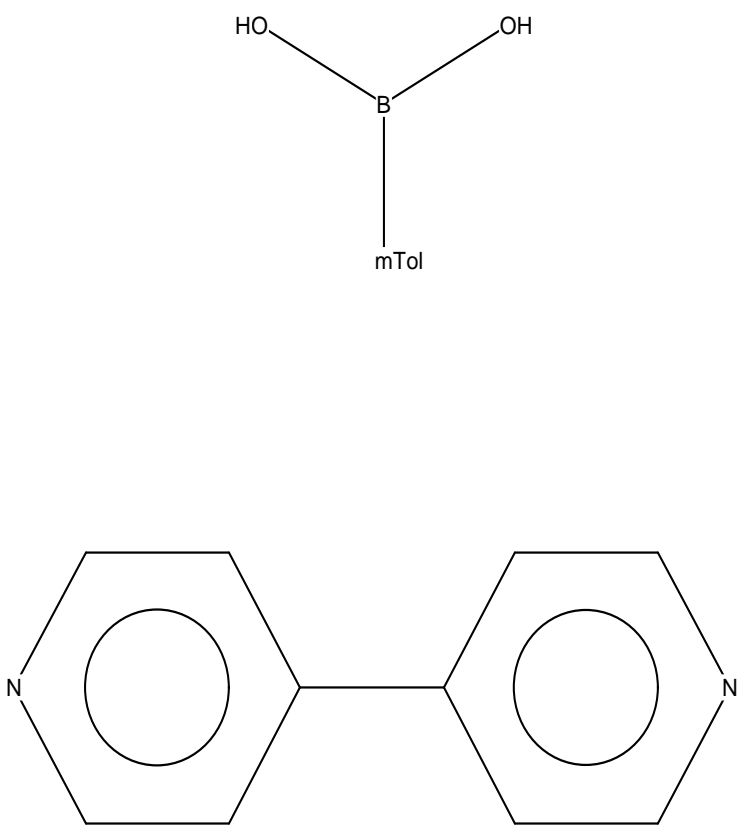

PAXTIS

$\begin{array}{ll}\text { Reference: } & \text { C.B.Aakeroy, J.Desper, B.Levin, D.J.Salmon (2004) } \\ & \text { Trans.Am.Crystallogr.Assoc. ,39,123 } \\ \text { Formula: } & \mathrm{C}_{7} \mathrm{H}_{7} \mathrm{~B}_{1} \mathrm{O}_{4}, \mathrm{C}_{10} \mathrm{H}_{8} \mathrm{~N}_{2} \\ \text { Compound Name: } & \text { 4-Carboxybenzeneboronic acid 4,4'-bipyridine }\end{array}$

Compound Name: 4-Carboxybenzeneboronic acid 4,4'-bipyridine

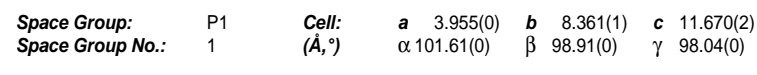

R-Factor (\%): $\quad 4.46 \quad$ Temperature(K): $293 \quad$ Density $\left(\mathrm{g} / \mathrm{cm}^{3}\right): 1.455$
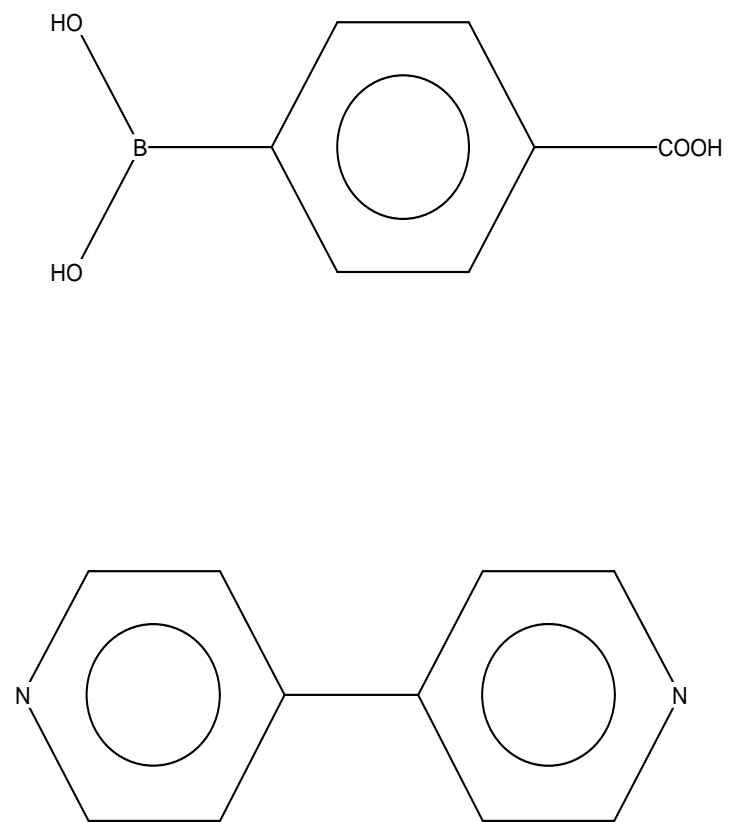


\section{Search: search2 (Thu Apr 05 09:21:46 2007): Hits 61-64}

PAYYAP

Reference:

Hong-Feng Li, Xiang-Yun Wang, Qing-Chuan Yang,

Yuan-Fang Liu (1995)

Gaodeng Xuexia Huaxue Xuebao(Chin)(Chem J Chin Univ.(Chinese Edition)) Formula: 16,1841

Formula: $\mathrm{C}_{6} \mathrm{H}_{9} \mathrm{~B}_{1} \mathrm{~N}_{1} \mathrm{O}_{2}{ }^{1+}, \mathrm{Cl}_{1}{ }^{1}$

Compound Name: 3-(Dihydroxyboryl)phenylammonium chloride

Space Group: $\quad$ P21/c Cell: $\quad$ a $\quad 5.193(3) \quad b \quad 15.802(14)$ c $10.307(8)$

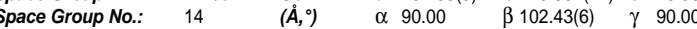

R-Factor (\%): $\quad 3.33 \quad$ Temperature(K): $295 \quad$ Density $\left(\mathbf{g} / \mathrm{cm}^{3}\right): 1.394$

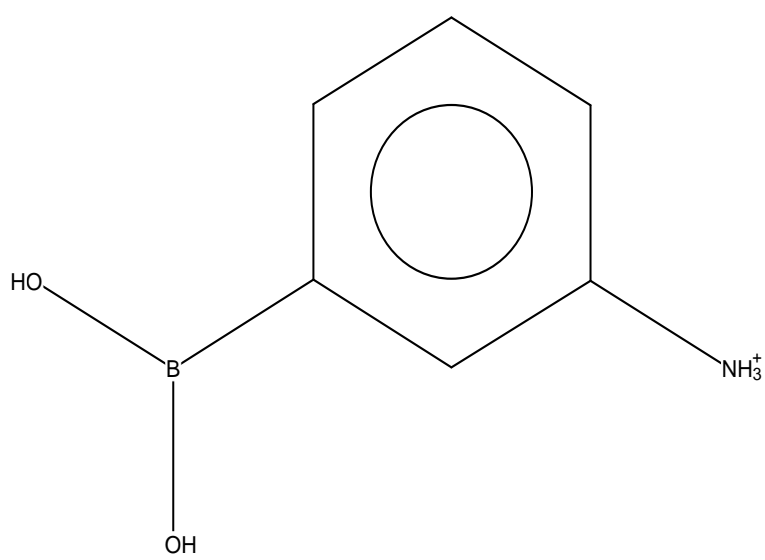

$\mathrm{Cl}$

QADKIQ

$\begin{array}{ll}\text { Reference: } & \text { R.Dreos, G.Nardin, L.Randaccio, P.Siega, G.Tauzher } \\ \text { (2003) Inorg.Chem. ,42,612 }\end{array}$

Formula: $\mathrm{C}_{15} \mathrm{H}_{25} \mathrm{~B}_{2} \mathrm{CO}_{1} \mathrm{~N}_{4} \mathrm{O}_{8}, 3\left(\mathrm{H}_{2} \mathrm{O}_{1}\right)$

Compound Name: (O,O'-(Hydroxy(4-(dihydroxyboryl)phenyl)boron)-bis(dimethylglyoximato) -aqua-methyl-cobalt trihydrate

Synonym: $\quad$ O,O'-(Hydroxy(4-(dihydroxyboryl)phenyl)boron)-aqua-methyl-cobaloxime trihydrate

Space Group: $\quad$ P-1 $\quad$ Cell: $\quad \begin{array}{llllll}\text { a } & 8.853(3) & \boldsymbol{b} & 11.865(4) & \boldsymbol{c} & 12.866(4)\end{array}$ Space Group No.: $2 \quad\left(\dot{A},{ }^{\circ}\right) \quad \alpha 106.24(2) \quad \beta 111.20(1) \quad \gamma \quad 97.83(1)$

R-Factor (\%): $\quad 4.63 \quad$ Temperature(K): $150 \quad$ Density $\left(\mathbf{g} / \mathrm{cm}^{3}\right): 1.492$

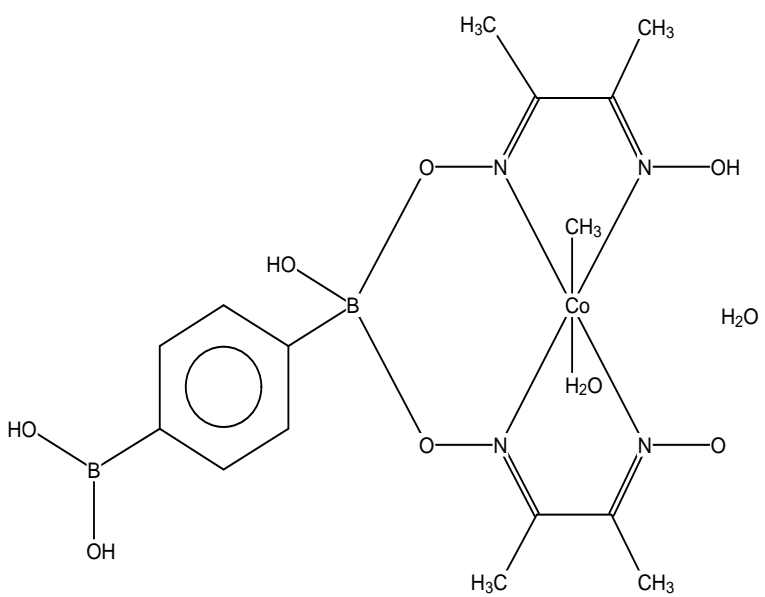

PHBORA

Reference: $\quad$ S.J.Rettig, J.Trotter (1977) Can.J.Chem. 55,3071

$\mathrm{C}_{6} \mathrm{H}_{7} \mathrm{~B}_{1} \mathrm{O}_{2}$

Compound Name: Phenylboronic acid

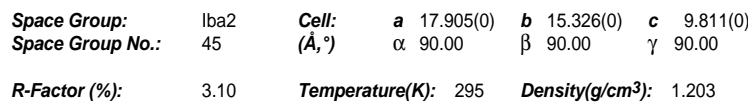

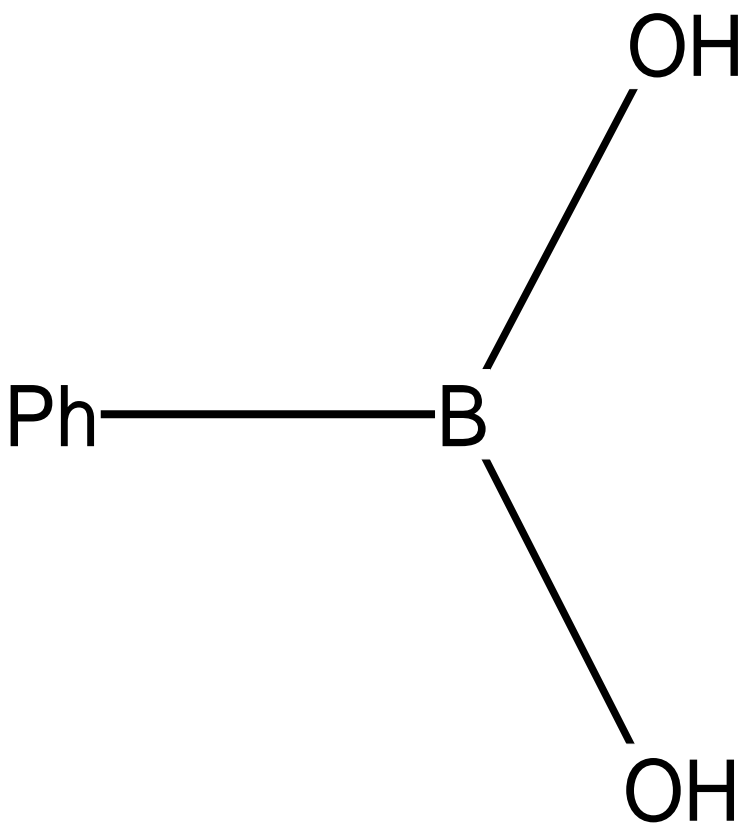

QIXTIA

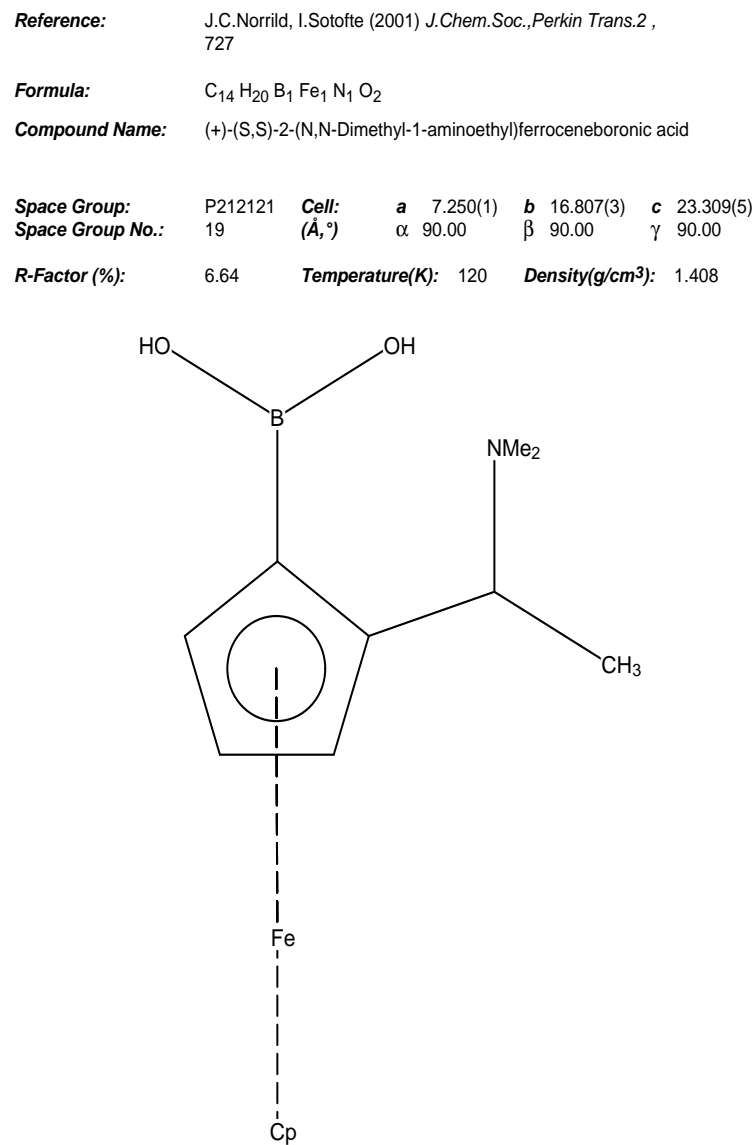




\section{Search: search2 (Thu Apr 05 09:21:46 2007): Hits 65-68}

QIXVAU

Reference:

J.C.Norrild, I.Sotofte (2001) J.Chem.Soc.,Perkin Trans.2,

Formula:

$\mathrm{C}_{13} \mathrm{H}_{18} \mathrm{~B}_{1} \mathrm{Fe}_{1} \mathrm{~N}_{1} \mathrm{O}_{2}$

Compound Name: rac-2-(N,N-Dimethylaminomethyl)ferroceneboronic acid

\begin{tabular}{|c|c|c|c|c|c|}
\hline up: & $\begin{array}{l}\text { Pca21 } \\
29\end{array}$ & $\begin{array}{l}\text { Cell: } \\
\left(\dot{A},{ }^{\circ}\right)\end{array}$ & $\begin{array}{ll}a & 21.431(4) \\
\alpha & 90.00\end{array}$ & $\begin{array}{ll}\boldsymbol{b} & 6.196(1) \\
\beta & 90.00\end{array}$ & $\begin{array}{ll}c & 20.414(4) \\
\gamma & 90.00\end{array}$ \\
\hline ractor & 7.88 & emp & ): 120 & sity $(\mathrm{g} / \mathrm{cm}$ & 1.406 \\
\hline
\end{tabular}

$\mathrm{HO}$

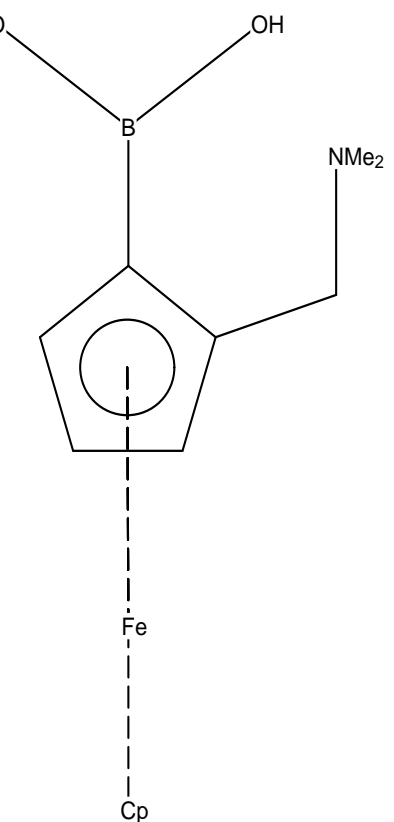

REHDOY

Reference:

J.Serwatowski, T.Klis, K.Kacprzak (2006) Acta Crystallogr..Sect.E:Struct.Rep.Online ,62,01308

Formula: $\mathrm{C}_{13} \mathrm{H}_{11} \mathrm{~B}_{1} \mathrm{Br}_{1} \mathrm{~F}_{1} \mathrm{O}_{3}$

Compound Name:

$\begin{array}{llllllll}\text { Space Group: } & \text { P-1 } & \text { Cell: } & \boldsymbol{a} 4.023(0) & \boldsymbol{b} & 15.278(2) & \boldsymbol{c} & 21.685(3) \\ \text { Space Group No.: } & 2 & (\dot{\boldsymbol{A}}, \circ) & \alpha 105.08(1) & \beta & 90.03(1) & \gamma & 92.09(1)\end{array}$

R-Factor (\%): $\quad 4.86 \quad$ Temperature(K): $100 \quad$ Density $\left(\mathrm{g} / \mathrm{cm}^{3}\right): 1.678$

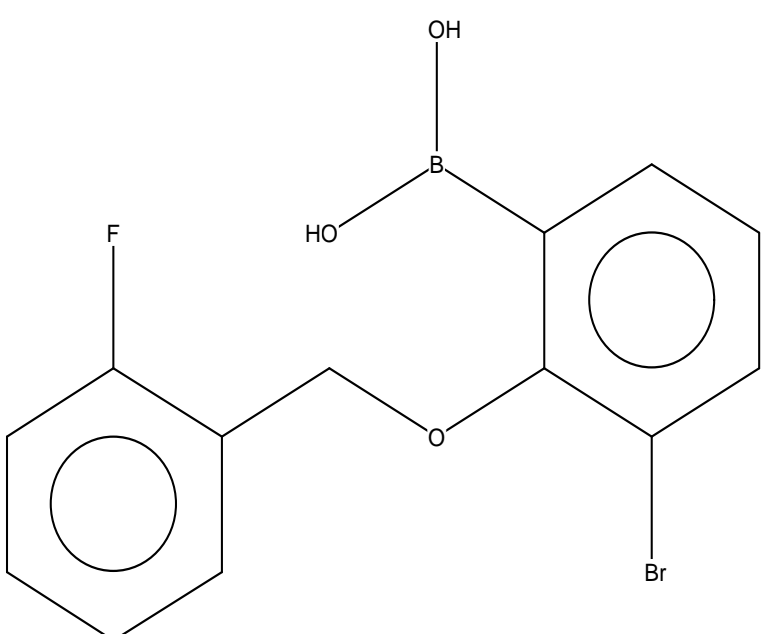

QIXVAU01

J.C.Norrild, I.Sotofte (2001) J.Chem.Soc.,Perkin Trans.2,

Formula:

$\mathrm{C}_{13} \mathrm{H}_{18} \mathrm{~B}_{1} \mathrm{Fe}_{1} \mathrm{~N}_{1} \mathrm{O}_{2}$

Compound Name: $\quad$ rac-2-(N,N-Dimethylaminomethyl)ferroceneboronic acid

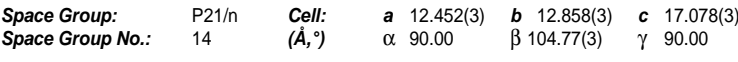

R-Factor (\%): $\quad 2.31 \quad$ Temperature(K): $120 \quad$ Density $\left(\mathrm{g} / \mathrm{cm}^{3}\right): 1.442$

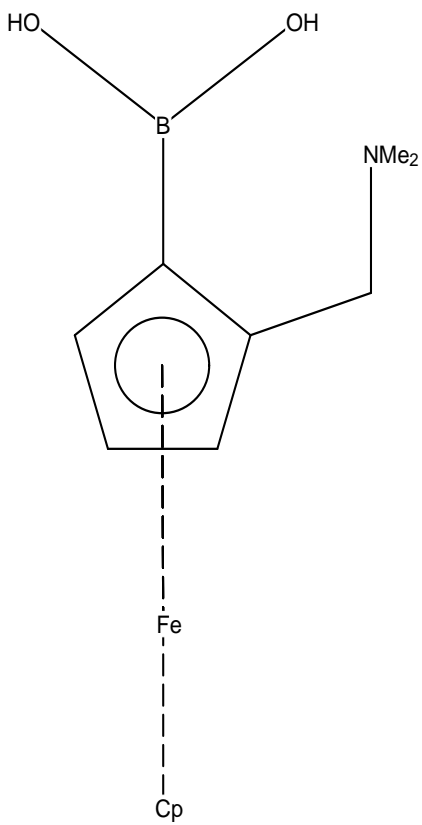

ROGMEF

Reference:

B.Schilling, V.Kaiser, D.E.Kaufmann (1997) Chem.Ber. 130,923

Formula:

$\mathrm{C}_{20} \mathrm{H}_{16} \mathrm{~B}_{2} \mathrm{O}_{4}, 2\left(\mathrm{C}_{4} \mathrm{H}_{10} \mathrm{O}_{1}\right)$

Compound Name:

1,1'-Binaphthyl-2,2'-diboronic acid diethyl ether solvate

Space Group: $\quad$ P21/c Cell: $\quad$ a $16.395(2) \quad b \quad 9.200(3) \quad$ c $19.300(4)$

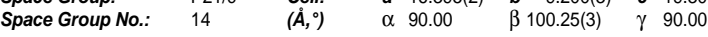

R-Factor (\%): $\quad 8.07 \quad$ Temperature(K): $210 \quad$ Density $\left(\mathrm{g} / \mathrm{cm}^{3}\right): 1.137$

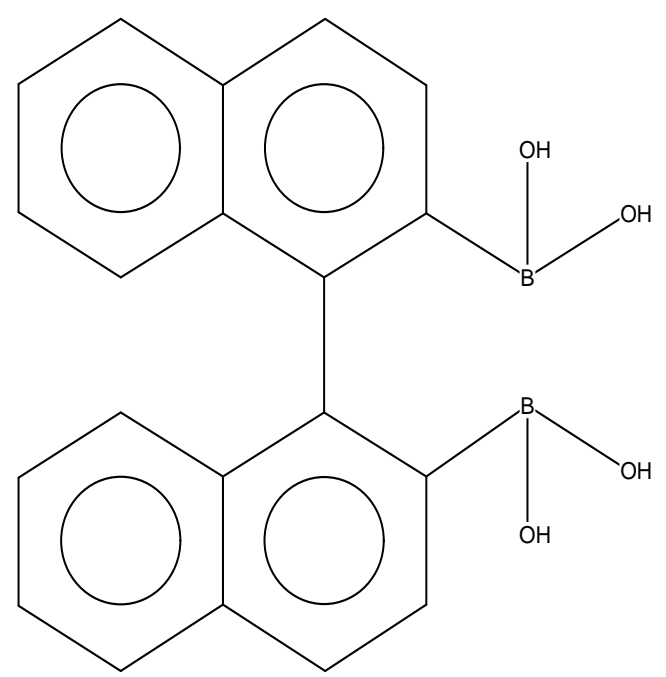




\section{Search: search2 (Thu Apr 05 09:21:46 2007): Hits 69-72}

RONLIP

Reference:

T.Akita, K.Kobayashi (1997) Adv.Mater. ,9,346

Formula:

$\mathrm{C}_{13} \mathrm{H}_{18} \mathrm{~B}_{1} \mathrm{~N}_{2} \mathrm{O}_{4}$

Compound Name: $\quad$ 2-(4'-Dihydroxyborylphenyl)-4,4,5,5-tetramethylimidazoline-3-oxide 1oxyl redical

Space Group: $\quad$ P21/n $\quad$ Cell: $\quad$ a $10.503(3) \quad$ b $20.882(4) \quad$ c $\quad 6.434(2)$

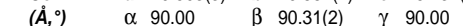

R-Factor (\%): $\quad 4.80 \quad$ Temperature(K): $295 \quad$ Density $\left(\mathrm{g} / \mathrm{cm}^{3}\right): 1.304$

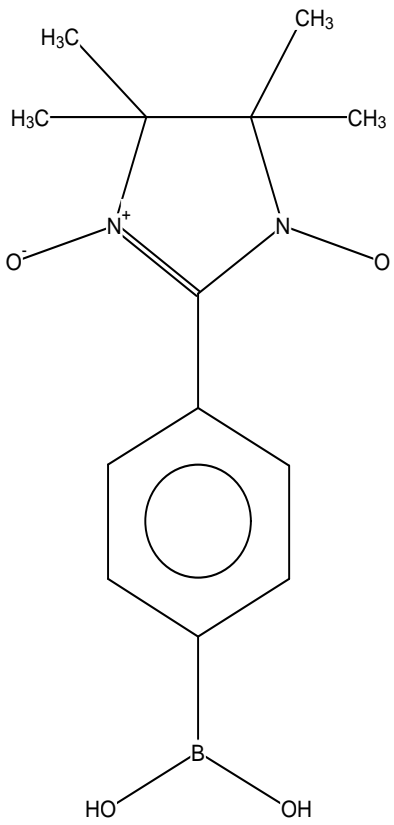

TUNGAK

Reference:

D.C.Bradley, I.S.Harding, A.D.Keefe, M.Motevall, Dao Hong Zheng (1996) J.Chem Soc Dalton Trans. ,3931

Formula: $\mathrm{C}_{6} \mathrm{H}_{5} \mathrm{~B}_{1} \mathrm{~F}_{2} \mathrm{O}_{2}$

Compound Name:

(2,6-Difluorophenyl)dihydroxyborane

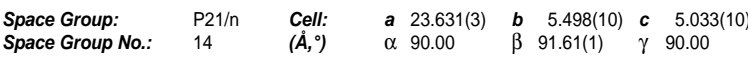

R-Factor (\%): $\quad 4.28 \quad$ Temperature(K): $295 \quad$ Density $\left(\mathbf{g} / \mathrm{cm}^{3}\right): 1.605$

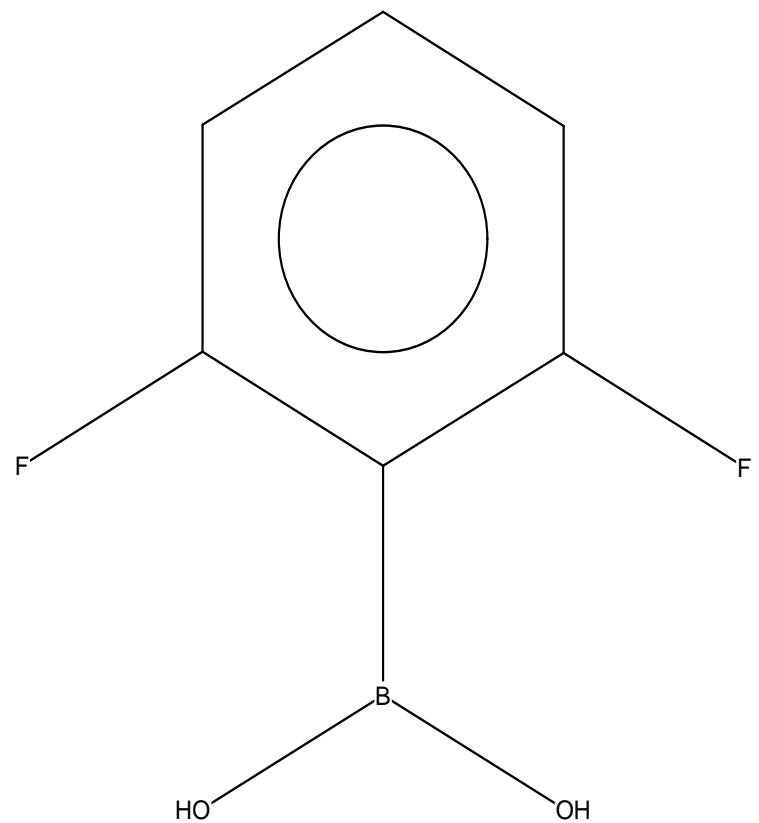

TASCEW

Reference:

Youjun Yang, J.O.Escobedo, A.Wong, C.M.Schowalter, M.C.Touchy, Lijuan Jiao, W.E.Crowe, F.R.Fronczek, R.M.Strongin (2005) J.Org.Chem. ,70,6907

Formula:

$\mathrm{C}_{8} \mathrm{H}_{11} \mathrm{~B}_{1} \mathrm{O}_{4}$

Compound Name: 2,4-Dimethoxyphenylboronic acid

$\begin{array}{lllllllll}\text { Space Group: } & \text { P-1 } & \text { Cell: } & \text { a } & 6.992(2) & \boldsymbol{b} & 7.916(2) & \boldsymbol{c} & 7.998(2) \\ \text { Space Group No.: } & 2 & (\hat{A}, \circ) & \alpha & 94.75(1) & \beta & 94.53(1) & \gamma & 96.54(1)\end{array}$

R-Factor (\%): $\quad 3.60 \quad$ Temperature(K): $105 \quad$ Density(g/cm3): 1.384

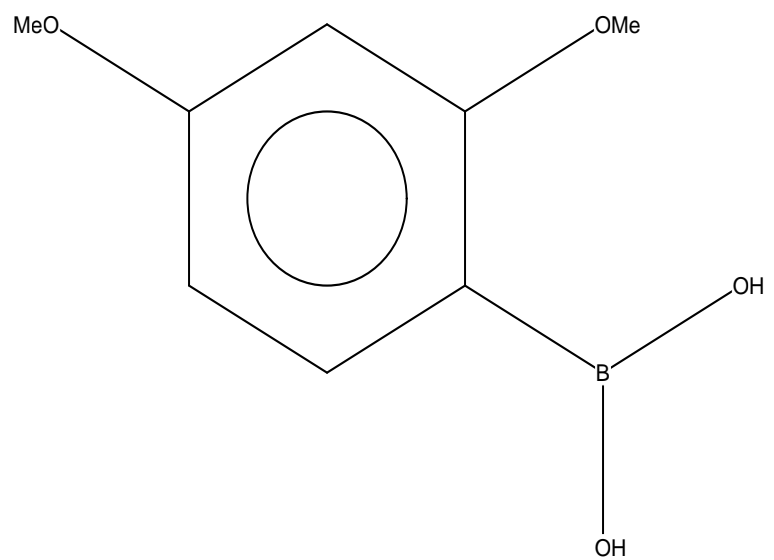

UCETUS

Reference: $\quad$ V.V.Izmer, A.Y.Lebedev, M.V.Nikulin, A.N.Ryabov,

A.F.Asachenko, A.V.Lygin, D.A.Sorokin, A.Z Voskoboynikov (2006) Organometallics , 25,1217

Formula: $\quad \mathrm{C}_{11} \mathrm{H}_{15} \mathrm{~B}_{1} \mathrm{O}_{3}$

Compound Name: trans-1-Methoxy-2-methyl-2,3-dihydroinden-4-yl boronic acid

Space Group: $\quad$ P-1 $\quad$ Cell: $\quad \begin{array}{llllll}\text { a } & 7.777(1) & \boldsymbol{b} & 8.536(1) & \text { c } & 8.748(1)\end{array}$

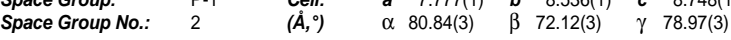

R-Factor (\%): $\quad 4.31 \quad$ Temperature(K): $293 \quad$ Density $\left(\mathrm{g} / \mathrm{cm}^{3}\right): 1.269$

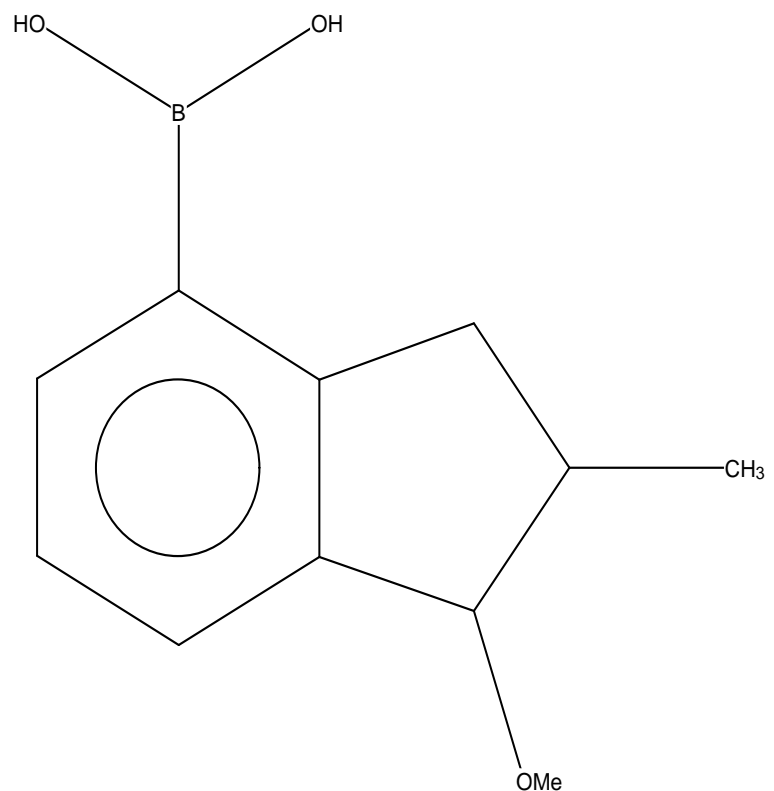




\section{Search: search2 (Thu Apr 05 09:21:46 2007): Hits 73-76}

UMUHOZ

\begin{tabular}{|c|c|c|c|c|c|c|}
\hline Reference: & \multicolumn{6}{|c|}{$\begin{array}{l}\text { S.M.Cornet, K.B.Dillon, C.D.Entwistle, M.A.Fox, } \\
\text { A.E.Goeta, H.P.Goodwin, T.B.Marder, A.L.Thompson (2003) } \\
\text { Dalton Trans. , } 4395\end{array}$} \\
\hline Formula: & \multicolumn{6}{|c|}{$\mathrm{C}_{8} \mathrm{H}_{5} \mathrm{~B}_{1} \mathrm{~F}_{6} \mathrm{O}_{2}$} \\
\hline Compound Name: & \multicolumn{6}{|c|}{ (2,6-bis(Trifluoromethyl)phenyl)-dihydroxy-borane } \\
\hline Synonym: & \multicolumn{6}{|c|}{ (2,6-bis(Trifluoromethyl)phenyl)boronic acid } \\
\hline $\begin{array}{l}\text { Space Group: } \\
\text { Space Group No.: }\end{array}$ & $\begin{array}{l}\text { P21212 } \\
18\end{array}$ & $\begin{array}{l}\text { Cell: } \\
(\dot{A}, \circ)\end{array}$ & $\begin{array}{ll}\text { a } & 14.086(1) \\
\alpha & 90.00\end{array}$ & $\begin{array}{ll}\boldsymbol{b} & 14.462(1) \\
\beta & 90.00\end{array}$ & $\begin{array}{l}c \\
\gamma\end{array}$ & $\begin{array}{l}5.003(0) \\
90.00\end{array}$ \\
\hline R-Factor (\%): & 3.05 & Temp & ure(K): 100 & Density $(\mathrm{g} / \mathrm{cm}$ & & 1.681 \\
\hline
\end{tabular}

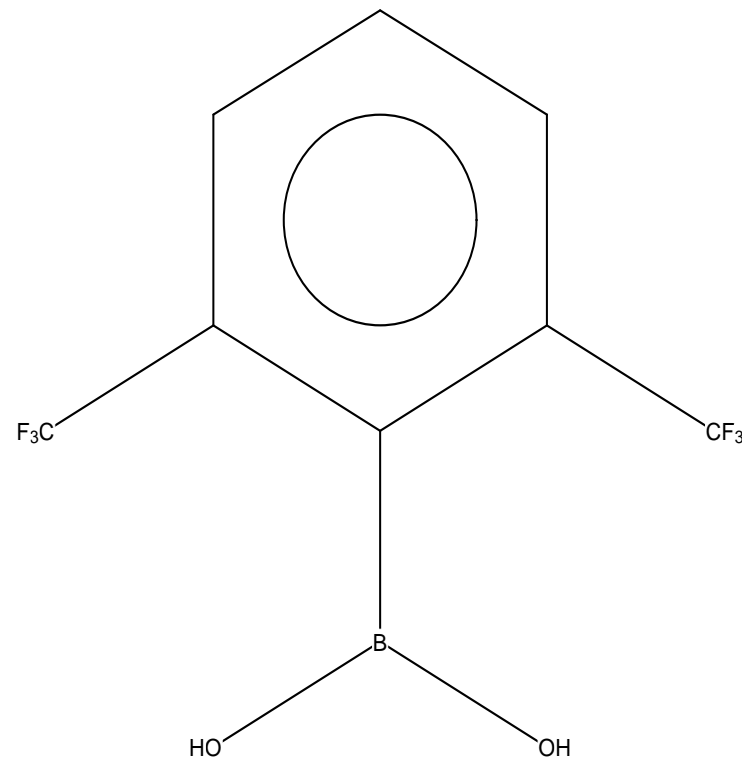

VEFCOZ

$\begin{array}{ll}\text { Reference: } & \text { K.E.Maly, T.Maris, J.D.Wuest (2006) CrystEngComm ,8,33 } \\ \text { Formula: } & \mathrm{C}_{14} \mathrm{H}_{12} \mathrm{~B}_{2} \mathrm{O}_{4}, 3\left(\mathrm{C}_{4} \mathrm{H}_{8} \mathrm{O}_{2}\right)\end{array}$

Compound Name: 1,2-Ethynediylbis(4,1-phenylene)diboronic acid 1,4-dioxane solvate

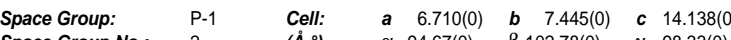

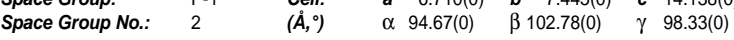

R-Factor (\%): $\quad 7.25 \quad$ Temperature(K): $100 \quad$ Density $\left(\mathbf{g} / \mathrm{cm}^{3}\right)$ : 1.301
VEFCIT

Reference: $\quad$ K.E.Maly, T.Maris, J.D.Wuest (2006) CrystEngComm ,8,33

Formula: $\mathrm{C}_{14} \mathrm{H}_{12} \mathrm{~B}_{2} \mathrm{O}_{4}, 3\left(\mathrm{C}_{4} \mathrm{H}_{8} \mathrm{O}_{1}\right)$

Compound Name: $\quad$ 1,2-Ethynediylbis(4,1-phenylene)diboronic acid tetrahydrofuran solvate

$\begin{array}{lllllllll}\text { Space Group: } & \text { P-1 } & \text { Cell: } & \boldsymbol{a} & 6.541(0) & \boldsymbol{b} & 9.420(0) & \boldsymbol{c} & 10.812(1)\end{array}$

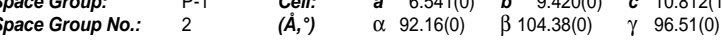

R-Factor (\%): $\quad 7.19 \quad$ Temperature(K): $100 \quad$ Density(g/cm $): 1.252$
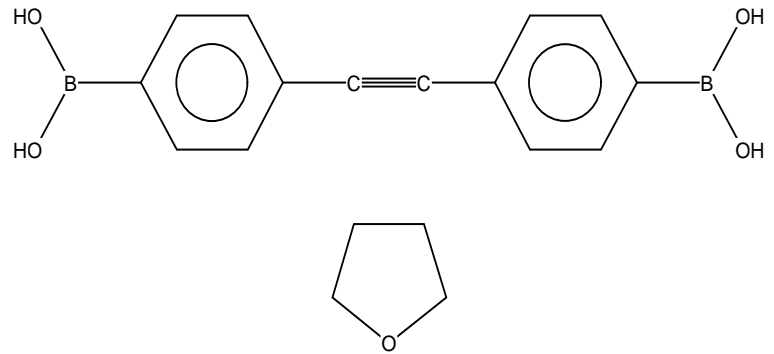

VEFCUF

Reference: $\quad$ K.E.Maly, T.Maris, J.D.Wuest (2006) CrystEngComm ,8,33

Formula: $\quad \mathrm{C}_{14} \mathrm{H}_{12} \mathrm{~B}_{2} \mathrm{O}_{4}$

Compound Name: 1,2-Ethynediylbis(4,1-phenylene)diboronic acid

Space Group: $\quad \mathrm{P} 21 / \mathrm{n} \quad$ Cell: $\quad$ a $11.343(0) \quad \boldsymbol{b} \quad 5.069(0) \quad$ c $11.581(0)$ Space Group No.: $\quad 14 \quad\left(\dot{A},{ }^{\circ}\right) \quad \alpha \quad 90.00 \quad \beta 103.74(0) \quad \gamma \quad 90.00$

R-Factor (\%): $\quad 3.53 \quad$ Temperature(K): $200 \quad$ Density $\left(\mathrm{g} / \mathrm{cm}^{3}\right): 1.365$

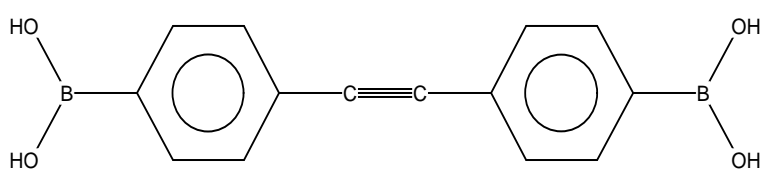<smiles>C1COCCO1</smiles>

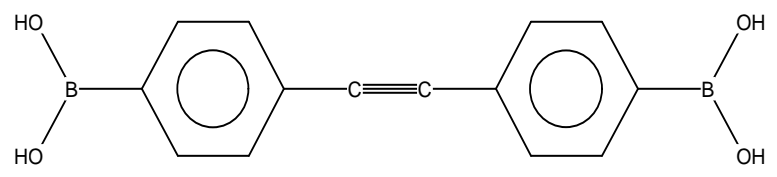




\section{Search: search2 (Thu Apr 05 09:21:46 2007): Hits 77-80}

VEXFUZ

Reference:

H.Feulner, G.Linti, H.Noth (1990) Chem.Ber. 123,1841

Formula:

$\mathrm{C}_{7} \mathrm{H}_{7} \mathrm{~B}_{1} \mathrm{O}_{3}$

Compound Name: p-Formylbenzeneboronic acid

\begin{tabular}{|c|c|c|c|c|c|}
\hline $\begin{array}{l}\text { pace Group: } \\
\text { pace Group No.: }\end{array}$ & $\begin{array}{l}P-1 \\
2\end{array}$ & $\begin{array}{l}\text { Cell: } \\
\left(\dot{A},{ }^{\circ}\right)\end{array}$ & $\begin{array}{ll}a & 7.323(2) \\
\alpha & 82.89\end{array}$ & $\begin{array}{ll}\boldsymbol{b} & 7.459(2) \\
\beta & 68.68\end{array}$ & $\begin{array}{ll}c & 7.464(2) \\
\gamma & 68.55\end{array}$ \\
\hline $\mathrm{ac}$ & 9.72 & remp & 295 & ensity $(\mathrm{g} / \mathrm{cm}$ & 1.409 \\
\hline
\end{tabular}

(\%): $\quad 9.72$

Temperature(K): 295 Density(g/cm3): 1.409

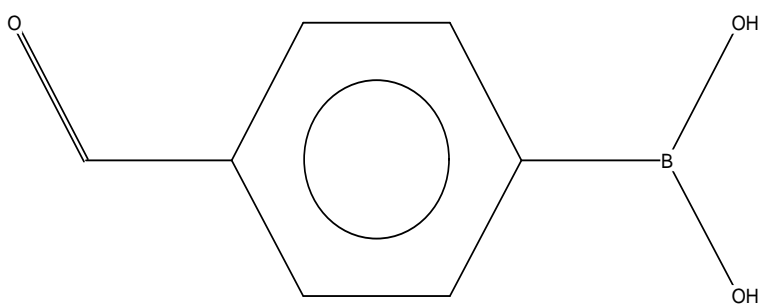

VEXFUZ02

Reference:

F.R.Fronczek, N.N.St.Luce, R.M.Strongin (2001) Acta Crystallogr..Sect.C:Cryst.Struct Commun. ,57,1423

Formula:

$\mathrm{C}_{7} \mathrm{H}_{7} \mathrm{~B}_{1} \mathrm{O}_{3}$

Compound Name: 4-Formylphenylboronic acid $\begin{array}{lllllllll}\text { Space Group: } & \text { Cc } & \text { Cell: } & \boldsymbol{a} & 11.124(0) & \boldsymbol{b} & 9.872(0) & \boldsymbol{c} & 7.199(0) \\ \text { Space Group No.: } & 9 & (\tilde{A}, 0) & \alpha & 90.00 & \beta 119.07(0) & \gamma & 90.00\end{array}$

R-Factor (\%): $\quad 3.80 \quad$ Temperature(K): $120 \quad$ Density $\left(\mathbf{g} / \mathrm{cm}^{3}\right): 1.441$
VEXFUZ01

Reference: H.Feulner, G.Linti, H.Noth (1990) Chem.Ber. ,123,1841

Formula:

$\mathrm{C}_{7} \mathrm{H}_{7} \mathrm{~B}_{1} \mathrm{O}_{3}$

Compound Name: p-Formylbenzeneboronic acid $\begin{array}{lllllll}\text { Space Group No.: } \quad 15 & \left(\hat{A},{ }^{\circ}\right) & \alpha & 90.00 & \beta 119.37(3) & \gamma & 90.00\end{array}$

R-Factor (\%): $\quad 14.52 \quad$ Temperature(K): $295 \quad$ Density(g/cm3): 1.410

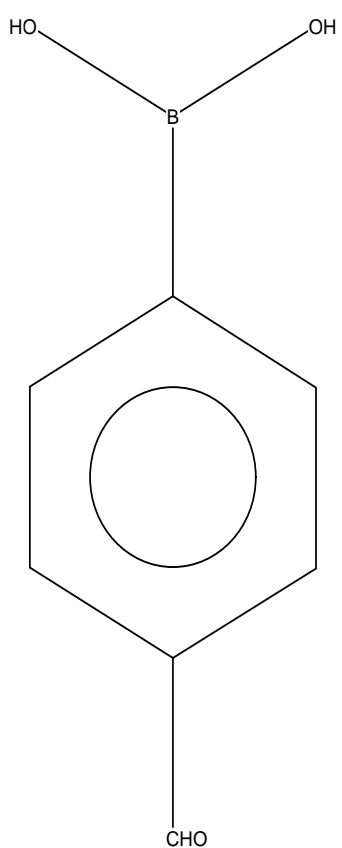

WADQIC

Reference:

A.Ganguly, C.Y.Meyers, P.D.Robinson (2003) Acta Crystallogr.,Sect.E:Struct.Rep.Online ,59,0759

Formula

$\mathrm{C}_{8} \mathrm{H}_{9} \mathrm{~B}_{1} \mathrm{O}_{3}, \mathrm{H}_{2} \mathrm{O}_{1}$

Compound Name:

2-Acetylphenylboronic acid monohydrate

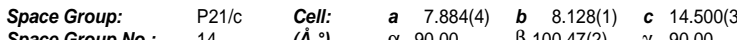
Space Group No.: $\quad 14 \quad\left(\dot{A},{ }^{\circ}\right) \quad \alpha \quad 90.00 \quad \beta 100.47(2) \quad \gamma \quad 90.00$

R-Factor (\%): $\quad 3.40 \quad$ Temperature(K): $296 \quad$ Density $\left(\mathrm{g} / \mathrm{cm}^{3}\right): 1.323$
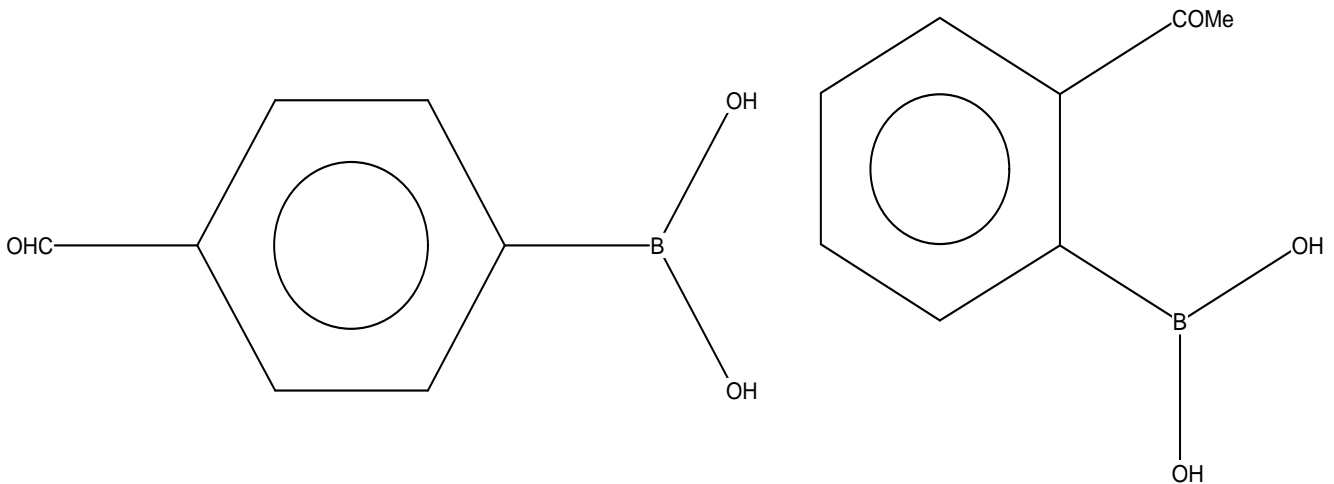


\section{Search: search2 (Thu Apr 05 09:21:46 2007): Hits 81-84}

WAJXEL

Reference:

P.N.Horton, M.B.Hursthouse, M.A.Beckett

M.P.Rugen-Hankey (2004) Acta Crystallogr..Sect.E:Struct.Rep.Online, 60,02204

Formula:

$\mathrm{C}_{6} \mathrm{H}_{2} \mathrm{~B}_{1} \mathrm{~F}_{5} \mathrm{O}_{2}$

Compound Name: Pentafluorophenylboronic acid

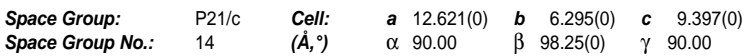

R-Factor (\%): $\quad 4.40 \quad$ Temperature(K): $120 \quad$ Density $\left(\mathrm{g} / \mathrm{cm}^{3}\right): \quad 1.905$

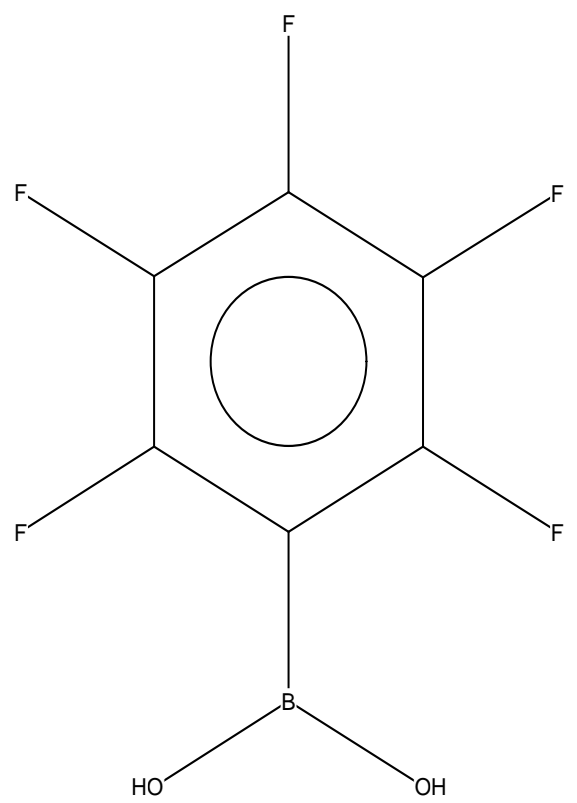

WEJCIY

$\begin{array}{ll}\text { Reference: } & \begin{array}{l}\text { S.Lulinski, J.Serwatowski (2006) } \\ \text { Acta Crystallogr.,Sect.C:Cryst.Struct.Commun. ,62,0301 }\end{array} \\ \text { Formula: } & \mathrm{C}_{8} \mathrm{H}_{9} \mathrm{~B}_{1} \mathrm{O}_{4} \\ \text { Compound Name: } & \text { 2-(Methoxycarbonyl)phenylboronic acid }\end{array}$

Compound Name: 2-(Methoxycarbonyl)phenylboronic acid

$\begin{array}{lllllllll}\text { Space Group: } & \text { P21/m } & \text { Cell: } & \boldsymbol{a} & 8.276(0) & \boldsymbol{b} & 19.712(0) & \boldsymbol{c} & 8.732(0) \\ \text { Space Group No.: } & 11 & \left(\boldsymbol{A},{ }^{\circ}\right) & \alpha & 90.00 & \beta & 115.01(0) & \gamma & 90.00\end{array}$

R-Factor (\%): $\quad 3.25 \quad$ Temperature(K): $100 \quad$ Density(g/cm 3 ): 1.389

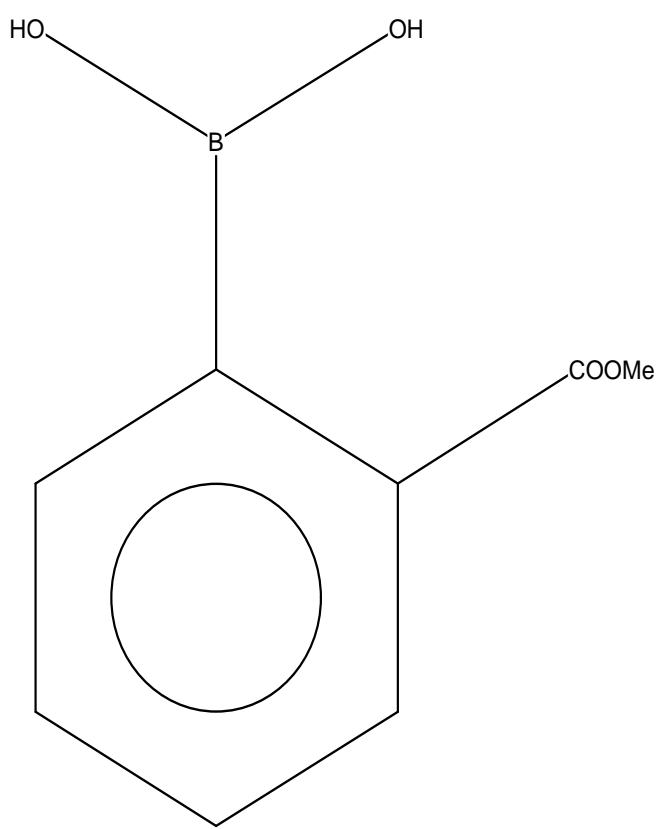

WAPDIB

Reference:

A.E.Thompson, A.S.Batsanov, M.R.Bryce, N.Saygill, P.R.Parry, B.Tarbit (2005) Tetrahedron ,61,5131

Formula:

$\mathrm{C}_{7} \mathrm{H}_{10} \mathrm{~B}_{1} \mathrm{~N}_{1} \mathrm{O}_{3}$

Compound Name: 2-Ethoxy-3-pyridylboronic acid

$\begin{array}{lllllllll}\text { Space Group: } & \text { P21/n } & \text { Cell: } & \text { a } & 3.940(1) & \boldsymbol{b} & 14.335(2) & \boldsymbol{c} & 14.226(2) \\ \text { Space Group No.: } & 14 & (\boldsymbol{A}, \circ) & \alpha & 90.00 & \beta & 94.60(1) & \gamma & 90.00\end{array}$

R-Factor (\%): $\quad 3.99 \quad$ Temperature(K): $120 \quad$ Density $\left(\mathrm{g} / \mathrm{cm}^{3}\right): \quad 1.385$

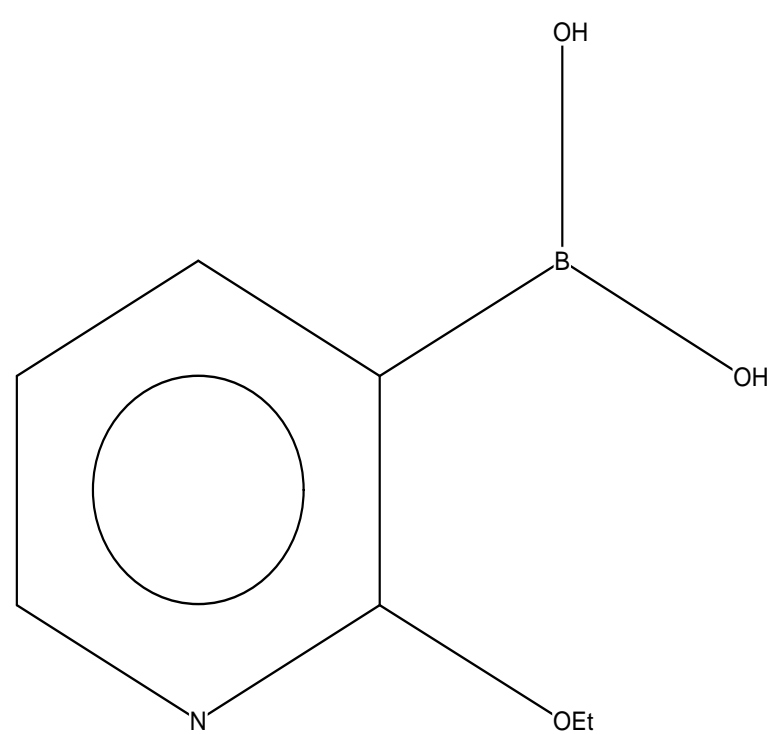

XARNAG

$\begin{array}{ll}\text { Reference: } & \text { N.S.P.Bhuvanesh, J.H.Reibenspies, Yuegang Zhang, } \\ & \text { P.L.Lee (2005) J.Appl.Crystallogr. ,38,632 } \\ \text { Formula: } & \mathrm{C}_{6} \mathrm{H}_{6} \mathrm{~B}_{1} \mathrm{Br}_{1} \mathrm{O}_{2} \\ \text { Compound Name: } & \text { 3-Bromophenylboronic acid }\end{array}$
$\begin{array}{llllllll}\text { Space Group No.: } \quad 14 & \left(\dot{A},{ }^{\circ}\right) & \alpha & 90.00 & \beta & 93.36(0) & \gamma & 90.00\end{array}$ R-Factor (\%): $\quad 6.35 \quad$ Temperature(K): $295 \quad$ Density $\left(\mathrm{g} / \mathrm{cm}^{3}\right): 1.701$

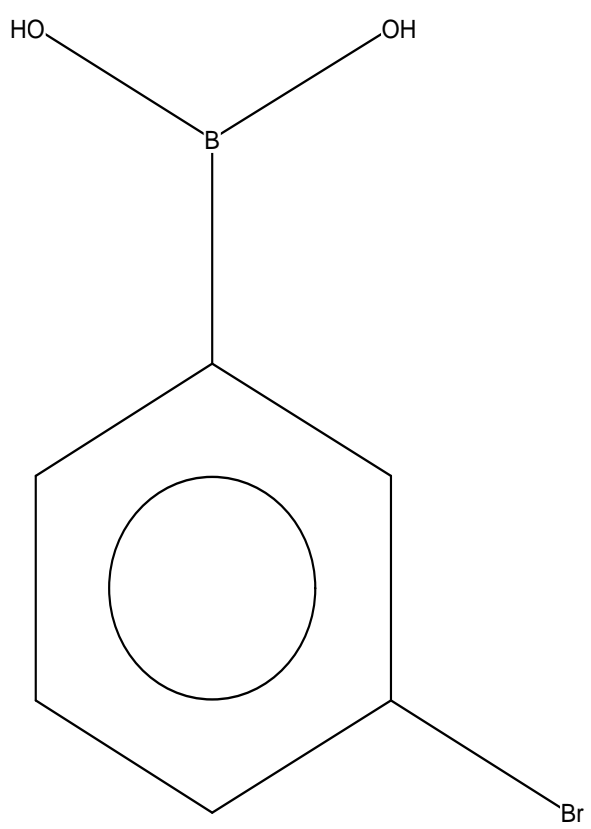




\section{Search: search2 (Thu Apr 05 09:21:46 2007): Hits 85-88}

XECHOD

\begin{tabular}{|c|c|c|c|c|c|c|}
\hline Reference: & \multicolumn{6}{|c|}{$\begin{array}{l}\text { J.M.Blacquiere, O.Sicora, C.M.Vogels, M.Cuperlovic-Culf, } \\
\text { A.Decken, R.J.Quellette, S.A.Westcott (2005) Can.J.Chem. , } 83,2052\end{array}$} \\
\hline Formula: & \multicolumn{6}{|c|}{$\mathrm{C}_{12} \mathrm{H}_{15} \mathrm{~B}_{1} \mathrm{~N}_{2} \mathrm{O}_{5} \mathrm{~S}_{1}$} \\
\hline Compound Name: & \multicolumn{6}{|c|}{$\begin{array}{l}\text { 2-(5-Ethoxycarb } \\
\text { 3-boronic acid }\end{array}$} \\
\hline $\begin{array}{l}\text { Space Group: } \\
\text { Space Group No.: }\end{array}$ & $\begin{array}{l}\mathrm{P} 21 / \mathrm{n} \\
14\end{array}$ & $\begin{array}{l}\text { Cell: } \\
(\dot{A}, \circ)\end{array}$ & $\begin{array}{ll}a & 10.991(0) \\
\alpha & 90.00\end{array}$ & $\begin{array}{l}b \quad 12.027(0) \\
\beta 108.79(0)\end{array}$ & & $\begin{array}{l}11.696(0) \\
90.00\end{array}$ \\
\hline R-Factor (\%): & 3.75 & Tempe & $\operatorname{re}(K): 198$ & Density $(\mathrm{g} / \mathrm{cm}$ & 3): 1 & 1.407 \\
\hline
\end{tabular}

R-Factor (\%): $\quad 3.75 \quad$ Temperature(K): $198 \quad$ Density $\left(\mathrm{g} / \mathrm{cm}^{3}\right): 1.407$

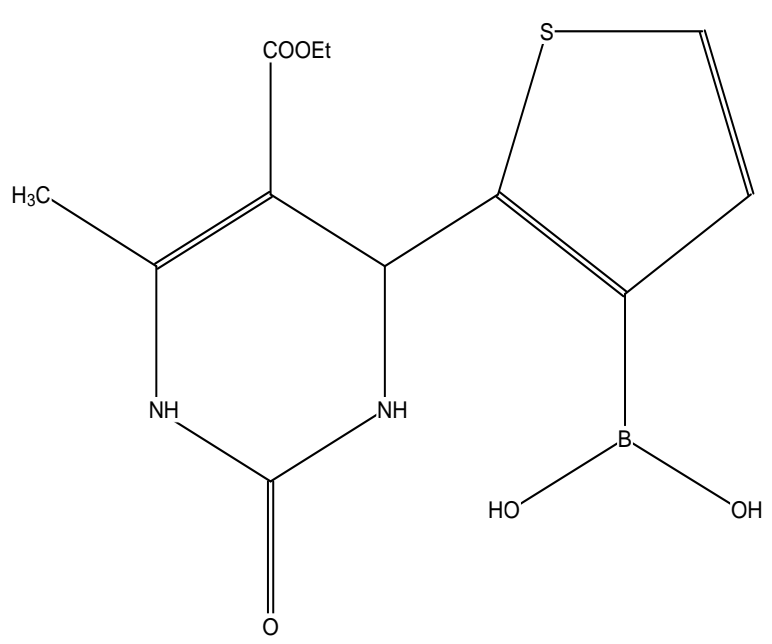

XUVBAR

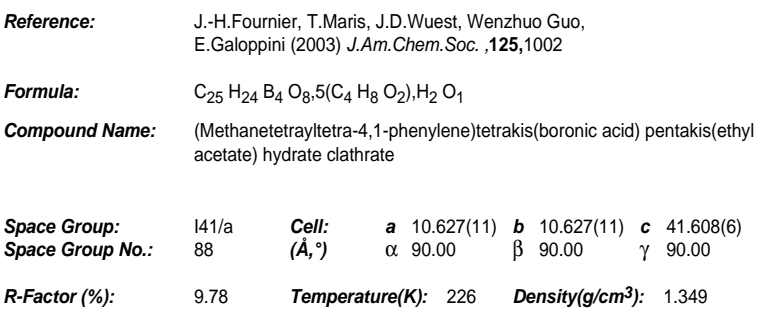

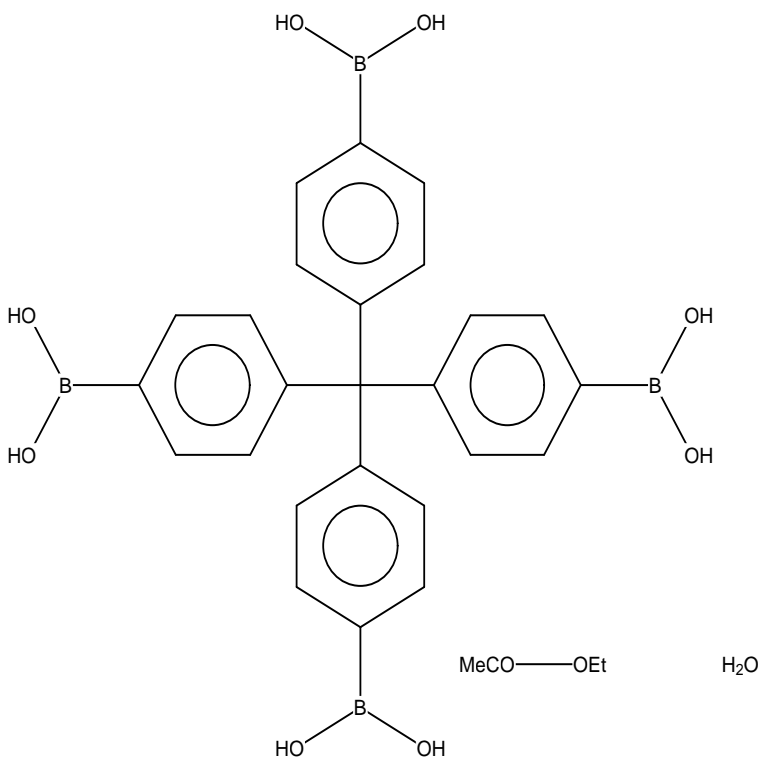

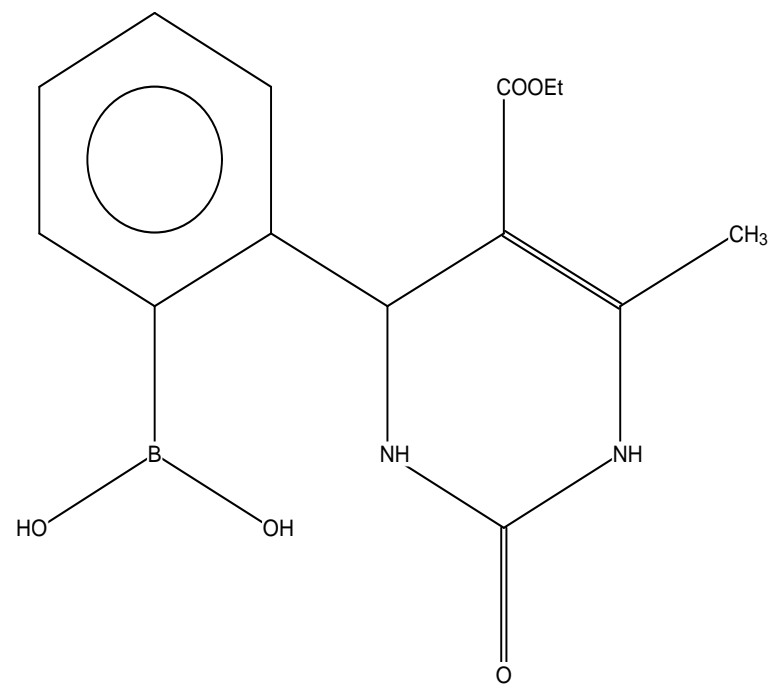

XECHUJ

Reference: $\quad J . M$ Blacquiere, O.Sicora, C.M.Vogels, M.Cuperlovic-Culf, A.Decken, R.J.Quellette, S.A.Westcott (2005) Can.J.Chem. ,83,2052

Formula: $\mathrm{C}_{14} \mathrm{H}_{17} \mathrm{~B}_{1} \mathrm{~N}_{2} \mathrm{O}_{5}$

Compound Name: 2-(5-Ethoxycarbonyl-4-methyl-2-oxo-3,6-dihydro-1H-pyrimidin-6-yl) phenylboronic acid

Space Group: $\quad$ P21/n Cell: $\quad \begin{array}{llllll}\text { a } & 11.528(0) & \text { b } & 11.969(0) & \text { c } & 11.618(0)\end{array}$

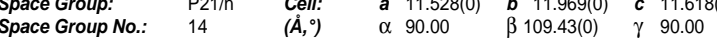

R-Factor (\%): $\quad 4.37 \quad$ Temperature(K): $198 \quad$ Density(g/ $\left./ \mathrm{cm}^{3}\right): 1.336$

XUVBEV

\begin{tabular}{|c|c|c|c|c|c|c|}
\hline Reference: & \multicolumn{6}{|c|}{$\begin{array}{l}\text { J.-H.Fournier, T.Maris, J.D.Wuest, Wenzhuo Guo, } \\
\text { E.Galoppini (2003) J.Am.Chem.Soc. , 125,1002 }\end{array}$} \\
\hline Formula: & \multicolumn{6}{|c|}{$\mathrm{C}_{24} \mathrm{H}_{24} \mathrm{~B}_{4} \mathrm{O}_{8} \mathrm{Si}_{1}, 5\left(\mathrm{C}_{4} \mathrm{H}_{8} \mathrm{O}_{2}\right), \mathrm{H}_{2} \mathrm{O}_{1}$} \\
\hline Compound Name: & \multicolumn{6}{|c|}{$\begin{array}{l}\text { (Silanetetrayltetra-4,1-phenylene)tetrakis(boronic acid) pentakis(ethyl } \\
\text { acetate) hydrate clathrate }\end{array}$} \\
\hline $\begin{array}{l}\text { Space Group: } \\
\text { Space Group No.: }\end{array}$ & $\begin{array}{l}141 / \mathrm{a} \\
88\end{array}$ & $\begin{array}{l}\text { Cell: } \\
(\dot{A}, \circ)\end{array}$ & $\begin{array}{ll}a & 10.837(1) \\
\alpha & 90.00\end{array}$ & $\begin{array}{ll}\boldsymbol{b} & 10.837(1) \\
\beta & 90.00\end{array}$ & & $\begin{array}{l}45.603(9) \\
90.00\end{array}$ \\
\hline R-Factor (\%): & 7.58 & Temp & ure(K): 210 & Density $(\mathrm{g} / \mathrm{cm}$ & 3): & 1.203 \\
\hline
\end{tabular}

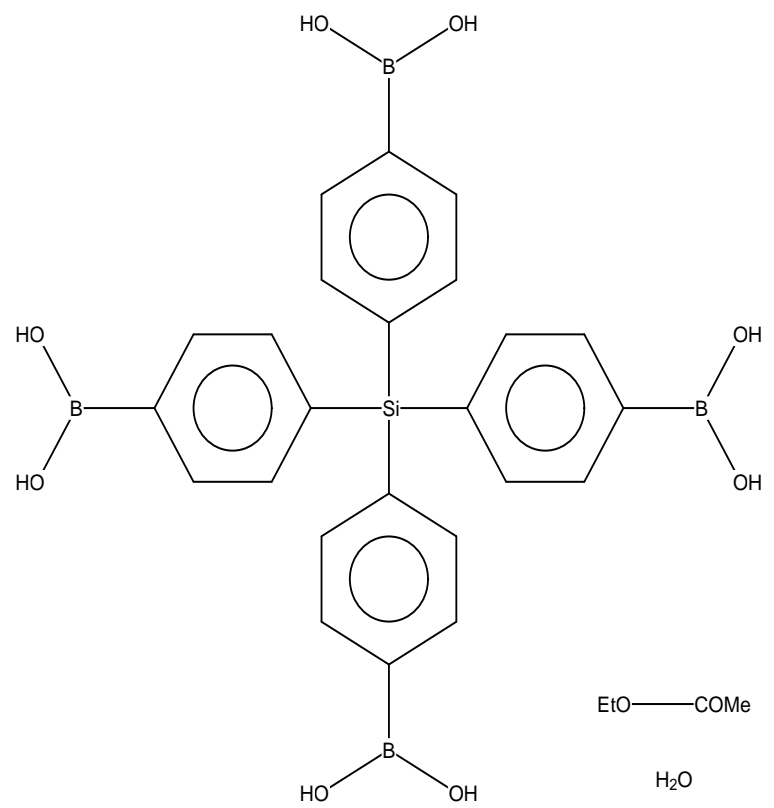




\section{Search: search2 (Thu Apr 05 09:21:46 2007): Hits 89-92}

XUVBIZ

\begin{tabular}{|c|c|c|c|c|c|c|}
\hline Reference: & \multicolumn{6}{|c|}{$\begin{array}{l}\text { J.-H.Fournier, T.Maris, J.D.Wuest, Wenzhuo Guo, } \\
\text { E.Galoppini (2003) J.Am.Chem.Soc. } 125,1002\end{array}$} \\
\hline Formula: & \multicolumn{6}{|c|}{$\mathrm{C}_{25} \mathrm{H}_{24} \mathrm{~B}_{4} \mathrm{O}_{8}, 5\left(\mathrm{C}_{4} \mathrm{H}_{8} \mathrm{O}_{1}\right), \mathrm{H}_{2} \mathrm{O}_{1}$} \\
\hline Compound Name: & \multicolumn{6}{|c|}{$\begin{array}{l}\text { (Methanetetrayltetra-4,1-phenylene)tetrakis(boronic acid) } \\
\text { pentakis(tetrahydrofuran) hydrate clathrate }\end{array}$} \\
\hline $\begin{array}{l}\text { Space Group: } \\
\text { Space Group No.: }\end{array}$ & $\begin{array}{l}141 / \mathrm{a} \\
88\end{array}$ & $\begin{array}{l}\text { Cell: } \\
(\AA, \%)\end{array}$ & $\begin{array}{ll}a & 10.794(17) \\
\alpha & 90.00\end{array}$ & $\begin{array}{ll}\text { b } & 10.794(17) \\
\beta & 90.00\end{array}$ & $\begin{array}{l}c \\
\gamma\end{array}$ & $\begin{array}{l}42.080(70) \\
90.00\end{array}$ \\
\hline R-Factor (\%): & 0.00 & Temp & $r e(K): 226$ & Density $\left(\mathrm{g} / \mathrm{cm}^{3}\right)$ & & 1.184 \\
\hline
\end{tabular}

$\quad 0.00 \quad$ Temperature(K): 226 Density $\left(\mathbf{g} / \mathrm{cm}^{3}\right): 1.184$

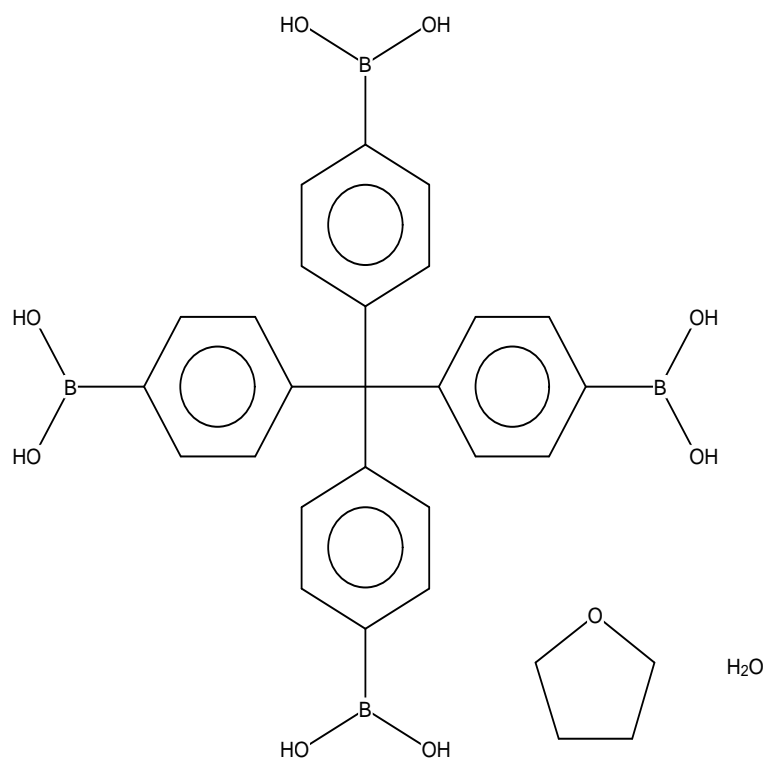

$\mathrm{YICHOH}$

\begin{tabular}{|c|c|c|c|c|c|c|}
\hline Reference: & \multicolumn{6}{|c|}{$\begin{array}{l}\text { W.H.Scouten, X.-C.Liu, N.Khangin, D.F.Mullica, } \\
\text { E.L.Sappenfield (1994) J.Chem.Cryst. ,24,621 }\end{array}$} \\
\hline Formula: & \multicolumn{6}{|c|}{$\mathrm{C}_{8} \mathrm{H}_{10} \mathrm{~B}_{1} \mathrm{~N}_{1} \mathrm{O}_{3}$} \\
\hline Compound Name: & \multicolumn{6}{|c|}{ o-Methoxyiminomethylbenzeneboronic acid } \\
\hline Synonym: & \multicolumn{6}{|c|}{ o-Boronobenzalmethoxyamine } \\
\hline $\begin{array}{l}\text { Space Group: } \\
\text { Space Group No.: }\end{array}$ & $\begin{array}{l}\text { Pccn } \\
56\end{array}$ & $\begin{array}{l}\text { Cell: } \\
\left(\dot{A},{ }^{\circ}\right)\end{array}$ & $\begin{array}{ll}\text { a } & 14.158 \\
\alpha & 90.00\end{array}$ & $\begin{array}{ll}\boldsymbol{b} & 17.156 \\
\beta & 90.00\end{array}$ & & $\begin{array}{l}7.734 \\
90.00\end{array}$ \\
\hline 3-Factor (\%): & 5.80 & Temp & $\operatorname{re}(\boldsymbol{K}): 295$ & Density $(g /$ & 3): & 1.266 \\
\hline
\end{tabular}

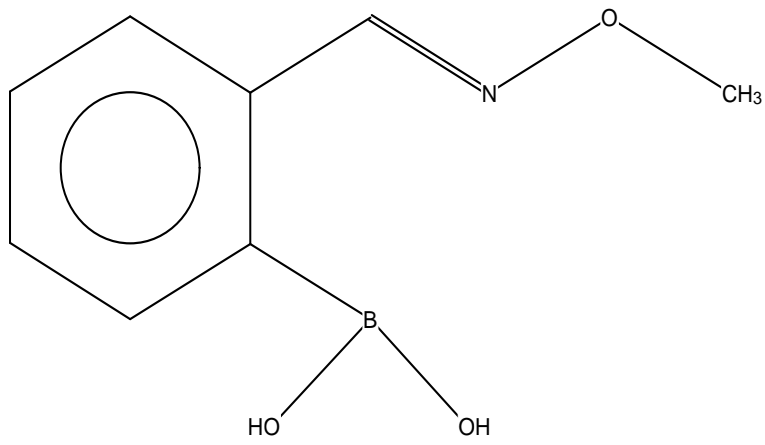

YICHIB

$\begin{array}{ll}\text { Reference: } & \text { W.H.Scouten, X.-C.Liu, N.Khangin, D.F.Mullica, } \\ \text { E.L.Sappenfield (1994) J.Chem.Cryst. ,24,621 }\end{array}$

Formula: $\quad \mathrm{C}_{7} \mathrm{H}_{7} \mathrm{~B}_{1} \mathrm{O}_{3}$

Compound Name: o-Formylbenzeneboronic acid

$\begin{array}{lllllllll}\text { Space Group: } & \text { P21/n } & \text { Cell: } & \boldsymbol{a} & 3.883 & \boldsymbol{b} & 13.225 & \boldsymbol{c} & 14.029 \\ \text { Space Group No.: } & 14 & \left(\hat{A},{ }^{\circ}\right) & \alpha & 90.00 & \beta & 92.16 & \gamma & 90.00\end{array}$

R-Factor (\%): $\quad 3.70 \quad$ Temperature(K): $295 \quad$ Density $\left(\mathbf{g} / \mathrm{cm}^{3}\right): 1.383$

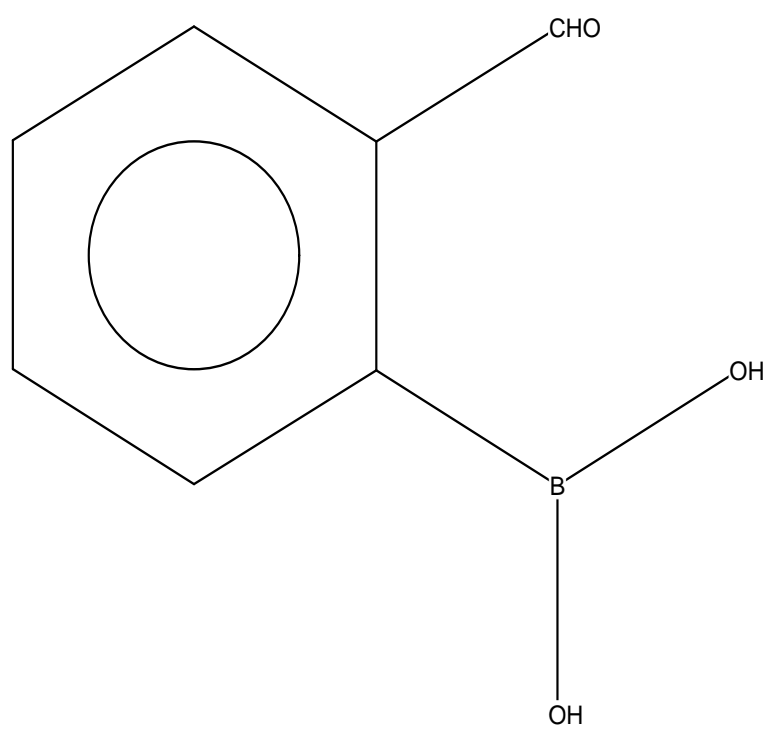

YIWKOE

$\begin{array}{ll}\text { Reference: } & \text { M.T.Reetz, J.Huff, J.Rudolph, K.Tollner, A.Deege, } \\ & \text { R.Goddard (1994) J.Am.Chem.Soc. 116,11588 }\end{array}$

Formula: $\quad \mathrm{C}_{9} \mathrm{H}_{11} \mathrm{~N}_{1} \mathrm{O}_{2}, \mathrm{C}_{8} \mathrm{H}_{5} \mathrm{~B}_{1} \mathrm{~F}_{6} \mathrm{O}_{2}, \mathrm{C}_{12} \mathrm{H}_{24} \mathrm{O}_{6}$

Compound Name: Phenylalanine 3,5-bis(trifluoromethyl)phenylboronic acid 18-crown-6

\begin{tabular}{lllllllll} 
Space Group: & P1 & Cell: & $\boldsymbol{a}$ & 8.853 & $\boldsymbol{b}$ & 9.261 & \multicolumn{1}{c}{$c$} & 12.141 \\
Space Group No.: & 1 & $\left(\boldsymbol{A},{ }^{\circ}\right)$ & $\alpha$ & 85.39 & $\beta$ & 89.00 & $\gamma$ & 61.38
\end{tabular}

R-Factor (\%): $\quad 9.30 \quad$ Temperature(K): $295 \quad$ Density $\left(\mathrm{g} / \mathrm{cm}^{3}\right): 1.311$

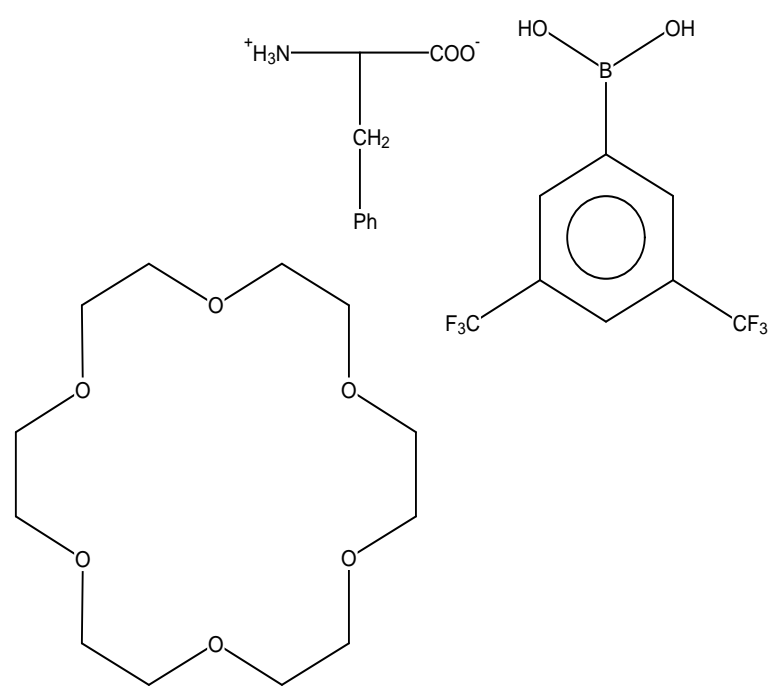




\section{Search: search2 (Thu Apr 05 09:21:46 2007): Hits 93-96}

ZAPDAV

Reference:

M.Pilkington, J.D.Wallis, S.Larsen (1995) Chem.Commun. 1499

Formula:

$\mathrm{C}_{14} \mathrm{H}_{12} \mathrm{~B}_{2} \mathrm{O}_{4}$

Compound Name: 2,2'-Ethynylenedibenzeneboronic acid

\begin{tabular}{|c|c|c|c|c|c|}
\hline $\begin{array}{l}\text { ace Group: } \\
\text { lace Group No.: }\end{array}$ & $\begin{array}{l}\mathrm{P} 21 / \mathrm{n} \\
14\end{array}$ & $\begin{array}{l}\text { Cell: } \\
\left(\dot{A},{ }^{\circ}\right)\end{array}$ & $\begin{array}{ll}a & 7.794(2) \\
\alpha & 90.00\end{array}$ & $\begin{array}{l}b \quad 5.079(1) \\
\beta 103.39(2)\end{array}$ & $\begin{array}{ll}c & 16.458(4) \\
\gamma & 90.00\end{array}$ \\
\hline Factor $(9$ & 4.13 & Temp & 122 & Density $\left(\mathrm{g} / \mathrm{cm}^{3}\right.$ & 1.393 \\
\hline
\end{tabular}

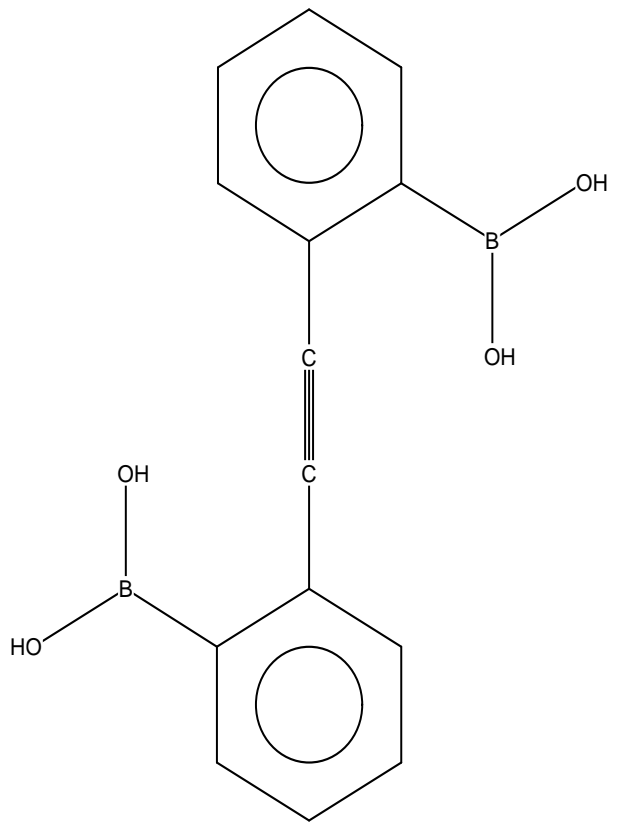

ZIGPAG01

Reference:

Y.Pontillon, T.Akita, A.Grand, K.Kobayashi, E.Lelievre-Berna, J.Pecaut, E.Ressouche, J.Schweizer (1999) J.Am.Chem.Soc. 121,10126

Formula: $\mathrm{C}_{6} \mathrm{H}_{7} \mathrm{~B}_{1} \mathrm{O}_{2}, \mathrm{C}_{13} \mathrm{H}_{17} \mathrm{~N}_{2} \mathrm{O}_{2}$

Compound Name: Phenyl nitronyl nitroxide radical phenylboronic acid

Space Group: $\quad$ P-1 $\quad$ Cell: $\quad$ a $\quad 9.360(0)$ b $13.640(0) \quad$ c $14.532(0)$

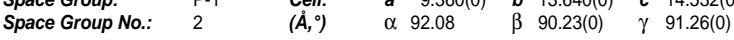

R-Factor (\%): $\quad 7.11 \quad$ Temperature(K): $143 \quad$ Density $\left(\mathrm{g} / \mathrm{cm}^{3}\right): \quad 1.273$
ZIGPAG

Reference: $\quad$ T.Akita, Y.Mazaki, K.Kobayashi (1995) Chem.Commun., 1861

Formula: $\quad \mathrm{C}_{6} \mathrm{H}_{7} \mathrm{~B}_{1} \mathrm{O}_{2}, \mathrm{C}_{13} \mathrm{H}_{17} \mathrm{~N}_{2} \mathrm{O}_{2}$

Compound Name: Phenyl nitronyl nitroxide radical phenylboronic acid

Space Group: $\quad$ P21/n $\quad$ Cell: $\quad$ a $14.764(3) \quad b \quad 9.482(3) \quad c \quad 13.686(2)$ $\begin{array}{llllllll}\text { Space Group No.: } \quad 14 & \left(\dot{A},{ }^{\circ}\right) & \alpha & 90.00 & \beta & 90.20(3) & \gamma & 90.00\end{array}$

R-Factor (\%): $\quad 3.89 \quad$ Temperature(K): $295 \quad$ Density(g/cm 3 ): 1.231

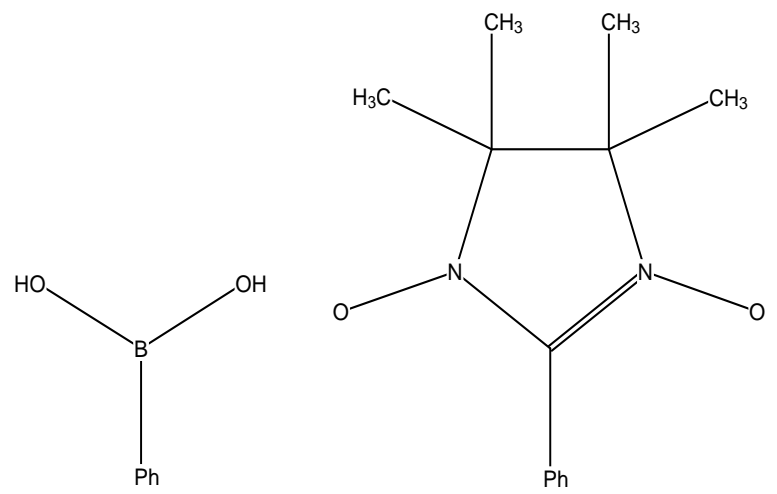

ZIGPAG02

Reference:

Pontillon, T.Akita, A.Grand, K.Kobayashi,

E.Lelievre-Berna, J.Pecaut, E.Ressouche, J.Schweizer (1999) J.Am.Chem.Soc. 121,10126

Formula:

$\mathrm{C}_{6} \mathrm{H}_{7} \mathrm{~B}_{1} \mathrm{O}_{2}, \mathrm{C}_{13} \mathrm{H}_{17} \mathrm{~N}_{2} \mathrm{O}_{2}$

Compound Name:

Phenyl nitronyl nitroxide radical phenylboronic acid

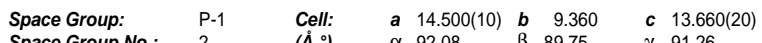
$\begin{array}{llllllll}\text { Space Group No.: } \quad 2 & (\dot{A}, \circ) & \alpha & 92.08 & \beta & 89.75 & \gamma & 91.26\end{array}$

R-Factor (\%): $\quad 4.90 \quad$ Temperature(K): $5 \quad$ Density $\left(\mathrm{g} / \mathrm{cm}^{3}\right): \quad 1.274$
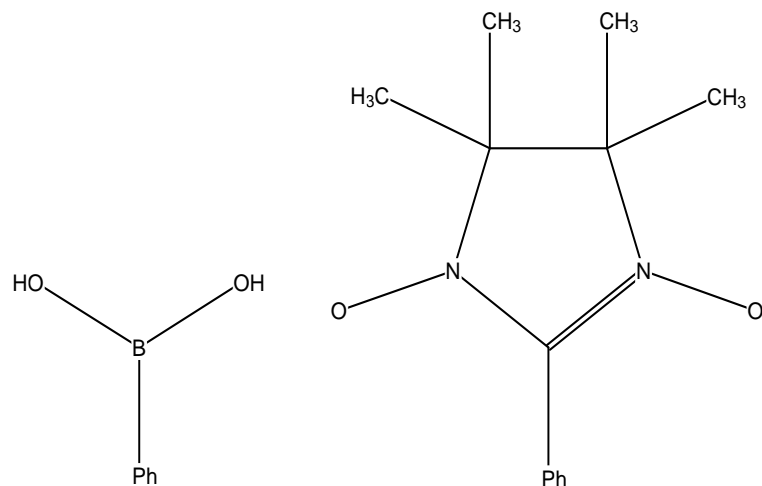
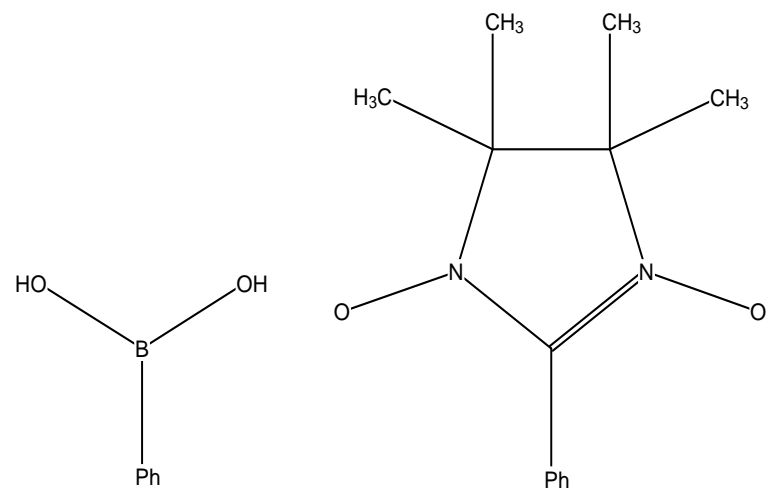


\section{Search: search2 (Thu Apr 05 09:21:46 2007): Hits 97-100}

ZILBEB

G.J.Gainsford, R.H.Meinhold, A.D.Woolhouse (1995) Acta Crystallogr, Sect.C:Cryst.Struct.Commun., 51,2694

Formula: $\mathrm{C}_{8} \mathrm{H}_{9} \mathrm{~B}_{1} \mathrm{O}_{2}$

Compound Name: Styrylboronic acid

Space Group: Space Group

R-Factor (\%):

\begin{tabular}{|c|c|c|c|c|}
\hline $\begin{array}{l}\mathrm{P} 21 / \mathrm{c} \\
14\end{array}$ & $\begin{array}{l}\text { Cell: } \\
\left(\dot{A},{ }^{\circ}\right)\end{array}$ & $\begin{array}{ll}\text { a } & 19.362(16) \\
\alpha & 90.00\end{array}$ & $\begin{array}{lr}b & 5.128(6) \\
\beta & 100.11(6)\end{array}$ & $\begin{array}{ll}c & 8.159(6) \\
\gamma & 90.00\end{array}$ \\
\hline 5.50 & Tem & 193 & Density $(g /$ & 1.232 \\
\hline
\end{tabular}

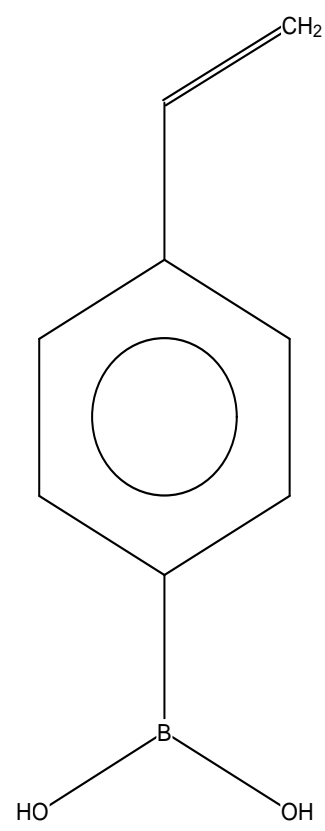

KEGNAM

Reference:

S.Gamsey, N.A.Baxter, Z.Sharrett, D.B.Cordes, M.M.OImstead, R.A.Wessling, B.Singaram (2006) Tetrahedron ,62, 6321

Formula:

$\mathrm{C}_{24} \mathrm{H}_{24} \mathrm{~B}_{2} \mathrm{~N}_{2} \mathrm{O}_{4}{ }^{2+}, 2\left(\mathrm{Br}_{1}{ }^{1-}\right)$

Compound Name:

1,1'-bis(2-(Dihydroxyboryl)benzyl)-4,4'-bipyridinium dibromide

Space Group: $\quad$ P21/c Cell: $\quad \begin{array}{llllll}\text { a } & 9.054(0) & \text { b } & 9.682(0) & \text { c } & 14.391(1)\end{array}$

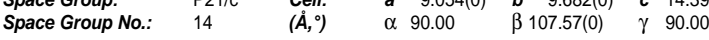

R-Factor (\%): $\quad 3.06 \quad$ Temperature(K): $166 \quad$ Density $\left(\mathrm{g} / \mathrm{cm}^{3}\right): 1.618$
GENTOJ

Reference:

B.Shivachev, R.Petrova, ENaydenova (2006) Acta Crystallogr.,Sect.E:Struct.Rep.Online ,62,03887

Formula: $\mathrm{C}_{8} \mathrm{H}_{13} \mathrm{~N}_{3} \mathrm{O}_{2}, \mathrm{C}_{6} \mathrm{H}_{7} \mathrm{~B}_{1} \mathrm{O}_{2}$

Compound Name: 3-Amino-1,3-diazaspiro(4.5)decane-2,4-dione phenylboronic acid

Synonym:

3'-Aminocyclohexanespiro-5'-hydantoin phenylboronic acid

Space Group: $\quad$ P-1 $\quad$ Cell: $\quad$ a $6.043(1) \quad$ b $12.094(1) \quad c \quad 12.301(1)$

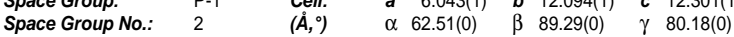

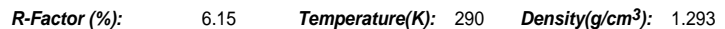
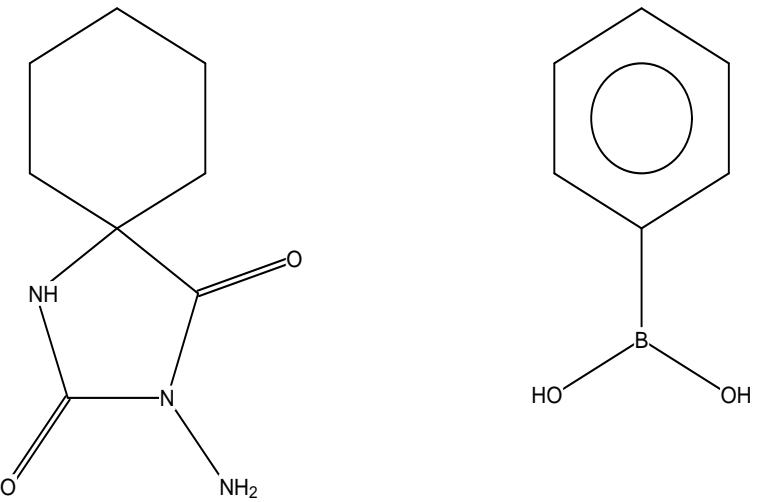

KEGNEQ

Reference:

S.Gamsey, N.A.Baxter, Z.Sharrett, D.B.Cordes, M.M.OImstead, R.A.Wessling, B.Singaram (2006) Tetrahedron ,62, 6321

Formula:

$\mathrm{C}_{24} \mathrm{H}_{24} \mathrm{~B}_{2} \mathrm{~N}_{2} \mathrm{O}_{4}{ }^{2+}, 2\left(\mathrm{Br}_{1}{ }^{1-}\right), 5\left(\mathrm{H}_{2} \mathrm{O}_{1}\right)$

Compound Name: 1,1'-bis(4-(Dihydroxyboryl)benzyl)-4,4'-bipyridinium dibromide pentahydrate

Space Group: $\quad$ P21/c $\quad$ Cell: $\quad$ a $16.932(5) \quad$ b 28.674(8) $\quad$ c $12.118(3)$ $\begin{array}{lllllll}\text { Space Group No.: } \quad 14 & \left(\dot{A},{ }^{\circ}\right) & \alpha & 90.00 & \beta 103.96(0) & \gamma & 90.00\end{array}$ R-Factor (\%): $\quad 8.27 \quad$ Temperature(K): $90 \quad$ Density(g/cm $): 1.573$

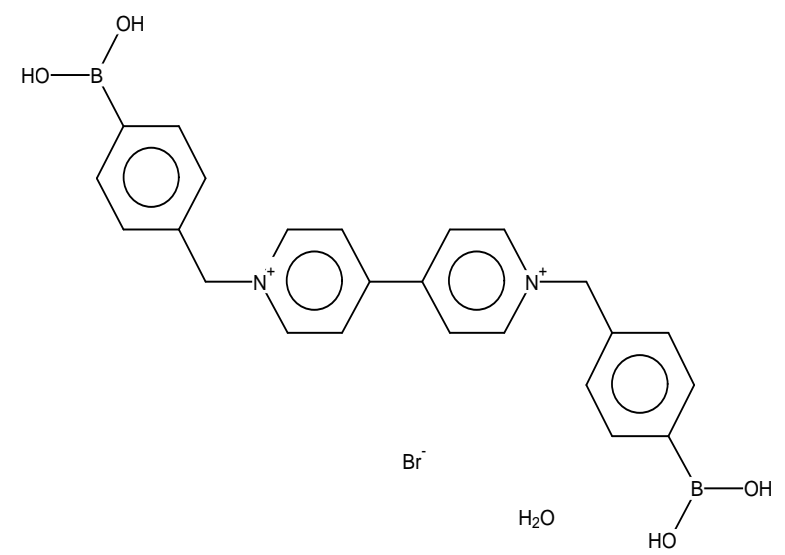




\section{Search: search2 (Thu Apr 05 09:21:46 2007): Hits 101-104}

KEGNIU

\begin{tabular}{|c|c|c|c|c|c|c|}
\hline Reference: & \multicolumn{6}{|c|}{$\begin{array}{l}\text { S.Gamsey, N.A.Baxter, Z.Sharrett, D.B.Cordes, } \\
\text { M.M.Olmstead, R.A.Wessling, B.Singaram (2006) Tetrahedron ,62, } \\
6321\end{array}$} \\
\hline Formula: & \multicolumn{6}{|c|}{$\mathrm{C}_{24} \mathrm{H}_{24} \mathrm{~B}_{2} \mathrm{~N}_{2} \mathrm{O}_{4}{ }^{2+}, 2\left(\mathrm{Br}_{1}{ }^{1-}\right), \mathrm{H}_{2} \mathrm{O}_{1}$} \\
\hline Compound Name: & \multicolumn{6}{|c|}{$\begin{array}{l}\text { 1,1'-bis(3-(Dihydroxyboryl)benzyl)-4,4'-bipyridinium dibromide } \\
\text { monohydrate }\end{array}$} \\
\hline $\begin{array}{l}\text { Space Group: } \\
\text { Space Group No.: }\end{array}$ & $\begin{array}{l}\mathrm{P} 21 / \mathrm{c} \\
14\end{array}$ & $\begin{array}{l}\text { Cell: } \\
(\dot{A}, \%)\end{array}$ & $\begin{array}{ll}\text { a } & 14.395(1) \\
\alpha & 90.00\end{array}$ & $\begin{array}{l}\text { b } 14.037(0) \\
\beta 104.30(0)\end{array}$ & & $\begin{array}{l}12.759(0) \\
90.00\end{array}$ \\
\hline -Factor (\%): & 2.93 & Temp & ure(K): 90 & Density $(\mathrm{g} / \mathrm{cm}$ & 3): & 1.606 \\
\hline
\end{tabular}

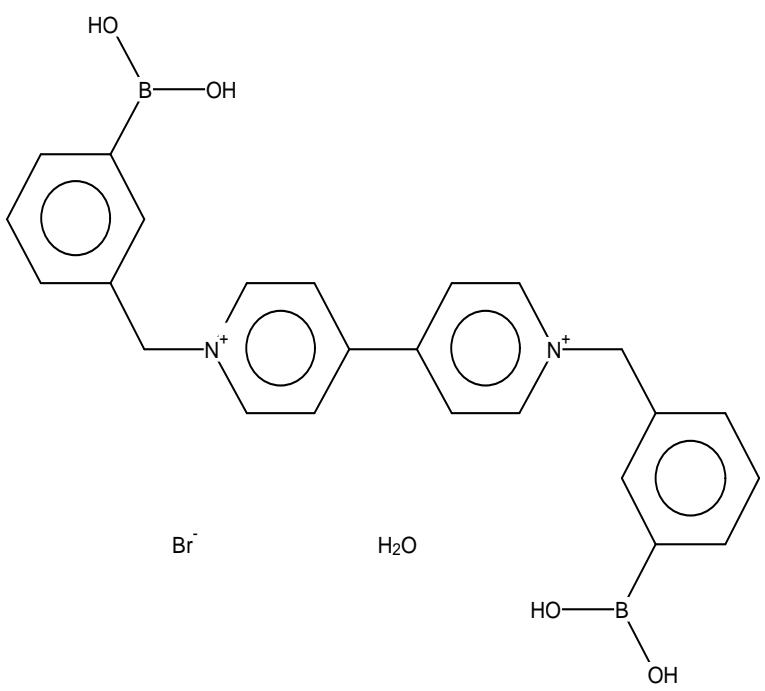

PEQLED

$\begin{array}{ll}\text { Reference: } & \text { H.Kara, C.J.Adams, A.G.Orpen, T.J.Podesta (2006) } \\ & \text { New J.Chem.(Nouv.J.Chim.) ,30,1461 }\end{array}$

Formula: $2\left(\mathrm{C}_{5} \mathrm{H}_{7} \mathrm{~B}_{1} \mathrm{~N}_{1} \mathrm{O}_{2}{ }^{1+}\right), \mathrm{C}_{4} \mathrm{Ni}_{1} \mathrm{O}_{4} \mathrm{~S}_{4}{ }^{2-}, 2\left(\mathrm{H}_{2} \mathrm{O}_{1}\right)$

Compound Name: $\quad$ bis((4-Pyridinio)boronic acid) bis(dithiooxalato-S, $\left.\mathrm{S}^{\prime}\right)$-nickel dihydrate $\begin{array}{lllllllll}\text { Space Group: } & \text { P-1 } & \text { Cell: } & \text { a } & 7.252(0) & \boldsymbol{b} & 7.469(0) & \boldsymbol{c} & 20.571(2) \\ \text { Space Group No.: } & 2 & (\dot{\boldsymbol{A}}, \circ) & \alpha & 94.37(0) & \beta & 94.19(0) & \gamma & 92.64(0)\end{array}$ R-Factor (\%): $\quad 2.66 \quad$ Temperature(K): $173 \quad$ Density $\left(\mathrm{g} / \mathrm{cm}^{3}\right): 1.750$
PEPNUU

Reference:

A.N.Cammidge, V.H.M.Goddard, H.Gopee, N.L.Harrison, D.L.Hughes, C.J.Schubert, B.M.Sutton, G.L.Watts, A.J.Whitehead (2006) Organic Letters ,8,4071

Formula:

$\left(\mathrm{H}_{10} \mathrm{Na}_{1} \mathrm{O}_{5}{ }^{1+}\right) n, n\left(\mathrm{C}_{7} \mathrm{H}_{10} \mathrm{~B}_{1} \mathrm{O}_{4}{ }^{1-}\right)$

Compound Name:

catena-(( $\mu_{2}$-aqua)-tetraaqua-sodium (4-methoxyphenyl)boronate)

Space Group: Space Group No.:

212121 Cell: $\quad$ a $6.126(2) \quad b \quad 7.352(1) \quad c \quad 29.508(5)$

R-Factor (\%):

3.51

Temperature(K): 293

Density $\left(\mathrm{g} / \mathrm{cm}^{3}\right): 1.409$
$\mathrm{MeO}$

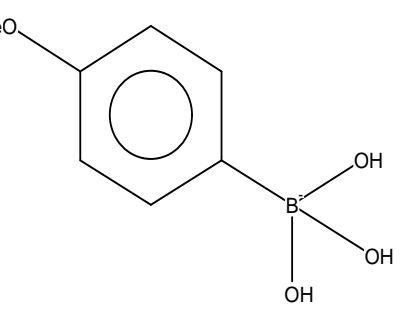

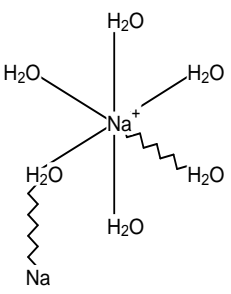

PEQLIH

Reference: $\quad$ H.Kara, C.J.Adams, A.G.Orpen, T.J.Podesta (2006) New J.Chem.(Nouv.J.Chim.) 30,1461

Formula: $2\left(\mathrm{C}_{5} \mathrm{H}_{7} \mathrm{~B}_{1} \mathrm{~N}_{1} \mathrm{O}_{2}{ }^{1+}\right), \mathrm{C}_{4} \mathrm{O}_{4} \mathrm{Pd}_{1} \mathrm{~S}_{4}{ }^{2-}, 2\left(\mathrm{H}_{2} \mathrm{O}_{1}\right)$

Compound Name:

bis((4-Pyridinio)boronic acid) bis(dithiooxalato-S, $\left.\mathrm{S}^{\prime}\right)$-palladium dihydrate

\section{Space Group:} Space Group No.: $\quad 2$ P-1 Cell: $\quad$ a $7.482(1) \quad b \quad 7.495(1) \quad c \quad 20.573(4)$ R-Factor (\%): 4.13<smiles>OB(O)c1cc[nH+]cc1</smiles><smiles></smiles><smiles>OB(O)c1cc[nH+]cc1</smiles><smiles>O=C1S[Pb]2(S1)SC(=O)C(=O)S2</smiles>

$\mathrm{H}_{2} \mathrm{O}$ 


\section{Search: search2 (Thu Apr 05 09:21:46 2007): Hits 105-108}

PEQLON

Reference:

H.Kara, C.J.Adams, A.G.Orpen, T.J.Podesta (2006) New J.Chem.(Nouv.J.Chim.) , 30,1461

Formula:

$2\left(\mathrm{C}_{5} \mathrm{H}_{7} \mathrm{~B}_{1} \mathrm{~N}_{1} \mathrm{O}_{2}{ }^{1+}\right), \mathrm{C}_{4} \mathrm{O}_{4} \mathrm{Pt}_{1} \mathrm{~S}_{4}{ }^{2-, 2}\left(\mathrm{H}_{2} \mathrm{O}_{1}\right)$

Compound Name:

bis((4-Pyridinio)boronic acid) bis(dithiooxalato-S, $\left.S^{\prime}\right)$-platinum dihydrate

$\begin{array}{ll}\text { Space Group: } & \text { P-1 } \\ \text { Space Group No: } & 2\end{array}$

R-Factor (\%): $\quad 3.63$

$\begin{array}{lllllll}\text { Cell: } & \boldsymbol{a} & 7.420(0) & \boldsymbol{b} & 7.460(0) & \boldsymbol{c} & 20.396(2) \\ \left(\hat{A},{ }^{\circ}\right) & \alpha & 94.42(0) & \beta & 96.48(0) & \gamma & 92.59(0) \\ \text { Temperature(K): } & 173 & \text { Density }\left(\mathbf{g} / \mathrm{cm}^{3}\right): & 2.139\end{array}$<smiles>OB(O)c1cc[nH+]cc1</smiles><smiles>O=C1S[Pb]2(S1)SC(=O)S2</smiles>

$\mathrm{H}_{2} \mathrm{O}$

PEQMAA

Reference:

H.Kara, C.J.Adams, A.G.Orpen, T.J.Podesta (2006) New J.Chem.(Nouv.J.Chim.) , 30,1461

Formula:

$2\left(\mathrm{C}_{5} \mathrm{H}_{7} \mathrm{~B}_{1} \mathrm{~N}_{1} \mathrm{O}_{2}{ }^{1+}\right), \mathrm{C}_{4} \mathrm{Cu}_{1} \mathrm{O}_{4} \mathrm{~S}_{4}{ }^{2-}$

Compound Name:

bis((3-Pyridinio)boronic acid) bis(dithiooxalato-S, $\left.\mathrm{S}^{\prime}\right)$-copper

Space Group: $\quad$ P-1 $\quad$ Cell: $\quad$ a $3.896(0)$ b $10.119(2) \quad$ c $13.447(3)$ $\begin{array}{lllllll}\text { Space Group No.: } \quad 2 & \left(\dot{A},{ }^{\circ}\right) & \alpha 100.74(3) & \beta & 94.97(3) & \gamma & 97.65(3)\end{array}$

R-Factor (\%): 5.90

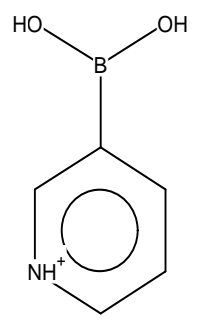<smiles>O=C1S[C]2SC(=O)S[C]2S1</smiles>

H.Kara, C.J.Adams, A.G.Orpen, T.J.Podesta (2006) New J.Chem.(Nouv.J.Chim.) , 30,1461

Reference: $2\left(\mathrm{C}_{5} \mathrm{H}_{7} \mathrm{~B}_{1} \mathrm{~N}_{1} \mathrm{O}_{2}{ }^{1+}\right), \mathrm{C}_{4} \mathrm{O}_{8} \mathrm{Pt}_{1}{ }^{2-}$

Formula:

bis((4-Pyridinio)boronic acid) bis(oxalato-O,O')-platinum

Space Group: Space Group No.: $\quad 2$

R-Factor (\%):

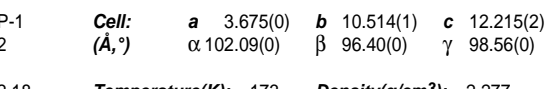

2.18 Temperature(K): $173 \quad$ Density $\left(\mathrm{g} / \mathrm{cm}^{3}\right)$ : 2.277

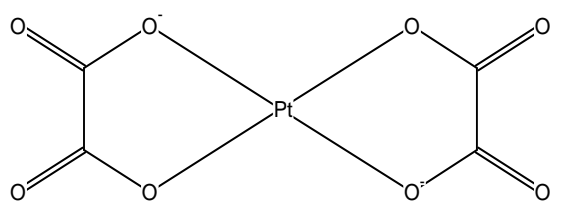

PEQMEE

Reference:

H.Kara, C.J.Adams, A.G.Orpen, T.J.Podesta (2006) New J.Chem.(Nouv.J.Chim.) , 30,1461

Formula: $2\left(\mathrm{C}_{5} \mathrm{H}_{7} \mathrm{~B}_{1} \mathrm{~N}_{1} \mathrm{O}_{2}{ }^{1+}\right), \mathrm{C}_{4} \mathrm{Ni}_{1} \mathrm{O}_{4} \mathrm{~S}_{4}{ }^{2}$

Compound Name:

bis((3-Pyridinio)boronic acid) bis(dithiooxalato-S, $\left.\mathrm{S}^{\prime}\right)$-nickel

Space Group: $\quad$ P-1 $\quad$ Cell: $\quad$ a $3.905(0) \quad$ b $10.220(2) \quad$ c $13.302(3)$

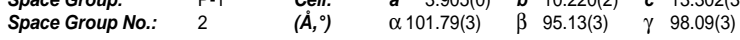

R-Factor (\%): $\quad 3.28$

Temperature(K): 298<smiles>OB(O)c1ccc[nH+]c1</smiles><smiles>O=C1SN2[SH](S1)[SH]1C(=O)S[SH]21</smiles> 


\section{Search: search2 (Thu Apr 05 09:21:46 2007): Hits 109-111}

PEQMII

Reference:

H.Kara, C.J.Adams, A.G.Orpen, T.J.Podesta (2006) New J.Chem.(Nouv.J.Chim.) ,30,1461

Formula:

$2\left(\mathrm{C}_{5} \mathrm{H}_{7} \mathrm{~B}_{1} \mathrm{~N}_{1} \mathrm{O}_{2}{ }^{1+}\right), \mathrm{C}_{4} \mathrm{O}_{4} \mathrm{Pd}_{1} \mathrm{~S}_{4}{ }^{2-}$

Compound Name: $\quad$ bis((3-Pyridinio)boronic acid) bis(dithiooxalato-S,S')-palladium

\begin{tabular}{|c|c|c|c|c|c|}
\hline $\begin{array}{l}\text { pace Group: } \\
\text { pace Group No.: }\end{array}$ & $\begin{array}{l}P-1 \\
2\end{array}$ & $\begin{array}{l}\text { Cell: } \\
\left(\dot{A},{ }^{\circ}\right)\end{array}$ & $\begin{array}{l}a \quad 3.942(0) \\
\alpha 100.46(3)\end{array}$ & $\begin{array}{ll}\boldsymbol{b} & 10.164(2) \\
\beta & 94.77(3)\end{array}$ & $\begin{array}{ll}c & 13.431(3) \\
\gamma & 98.41(3)\end{array}$ \\
\hline ctor (\%): & 2.78 & & K): 2 & $\operatorname{Density}\left(\mathrm{g} / \mathrm{cm}^{3}\right.$ & \\
\hline
\end{tabular}

R-Factor (\%): $\quad 2.78$

Temperature(K): $273 \quad$ Density $\left(\mathrm{g} / \mathrm{cm}^{3}\right): 1.898$<smiles>O=C1SC2(S1)SC(=O)C(=O)S2</smiles><smiles>OB(O)c1ccc[nH+]c1</smiles>

H.Kara, C.J.Adams, A.G.Orpen, T.J.Podesta (2006) New J.Chem.(Nouv.J.Chim.) , 30,1461

Reference: $2\left(\mathrm{C}_{5} \mathrm{H}_{7} \mathrm{~B}_{1} \mathrm{~N}_{1} \mathrm{O}_{2}{ }^{1+}\right), \mathrm{C}_{4} \mathrm{O}_{8} \mathrm{Pt}_{1}{ }^{2-}$

Formula:

bis((3-Pyridinio)boronic acid) bis(oxalato-O,O')-platinum $\begin{array}{ll}\text { Space Group: } & \text { P-1 } \\ \text { Space Group No.: } & 2\end{array}$

R-Factor (\%):

1.51

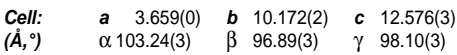

Temperature(K): $173 \quad$ Density $\left(\mathbf{g} / \mathrm{cm}^{3}\right): 2.308$<smiles>OB(O)c1ccc[nH+]c1</smiles><smiles>O=C1O[PH]2(O1)OC(=O)C(=O)O2</smiles>

WENZUL

Reference:

Ya-Ming Wu, Chang-Chuan Dong, Shan Liu,

Acta Crystallogr.,Sect.E:Struct.Rep.Online ,62,04236

Formula:

$\mathrm{C}_{6} \mathrm{H}_{6} \mathrm{~B}_{1} \mathrm{~F}_{1} \mathrm{O}_{2}$

Compound Name: 3-Fluorophenylboronic acid

Space Group: $\quad$ P21/c $\quad$ Cell: $\quad \begin{array}{lllllll}\text { a } & 5.756(1) & \boldsymbol{b} & 5.027(1) & \text { c } & 22.402(5)\end{array}$ Space Group No.: $\quad 14 \quad\left(\dot{A},{ }^{\circ}\right) \quad \alpha \quad 90.00 \quad \beta \quad 91.19(3) \quad \gamma \quad \gamma 90.00$

R-Factor (\%): $\quad 8.43 \quad$ Temperature(K): $294 \quad$ Density $\left(\mathbf{g} / \mathrm{cm}^{3}\right): 1.434$

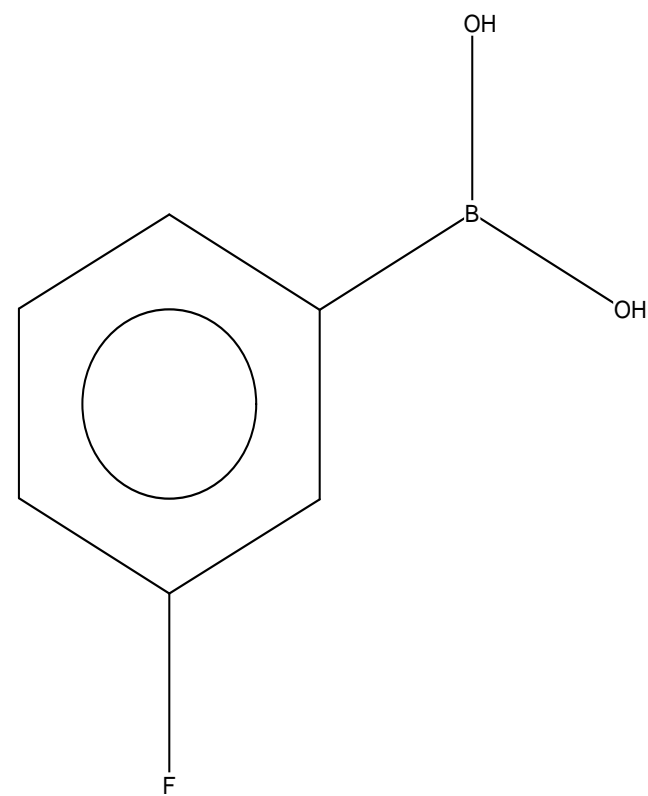

